$\stackrel{\text { samp }}{1}$

PACIFIC

\title{
Development of Site-Specific Water Quality Criteria for the Arpa Harbor Wastewater Treatment Plant in Tipalao Bay, Guam
}

\author{
P. J. Earley \\ G. H. Rosen \\ I. D. Rivera-Duarte \\ M. A. Colvin \\ SSC Pacific \\ R. Dolecal \\ SDSU Research Foundation
}

Approved for public release.

SSC Pacific

San Diego, CA 92152-5001 

TECHNICAL REPORT 2068

July 2016

\title{
Development of Site-Specific Water Quality Criteria for the Arpa Harbor Wastewater Treatment Plant in Tipalao Bay, Guam
}

\author{
P. J. Earley \\ G. H. Rosen \\ I. D. Rivera-Duarte \\ M. A. Colvin \\ SSC Pacific \\ R. Dolecal \\ SDSU Research Foundation
}

Approved for public release.
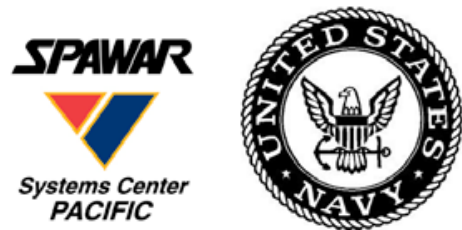

SSC Pacific

San Diego, CA 92152-5001 


\section{SSC Pacific \\ San Diego, California 92152-5001}

K. J. Rothenhaus, CAPT, USN Commanding Officer
C. A. Keeney

Executive Director

\section{ADMINISTRATIVE INFORMATION}

The work described in this report was performed by the Environmental Sciences Branch (Code 717500) and the Energy \& Environmental Sustainability Branch (Code 71760), Space and Naval Warfare Systems Center Pacific, San Diego, CA, to develop a new National Pollutant Discharge Elimination Systems (NPDES) Permit for the discharge of effluents from the Apra Harbor Wastewater Treatment Plant (WWTP) in Agat, Guam, into Tipalao Bay of the Philippine Sea.

Released by

P. J. Earley, Head

Environmental Sciences Branch
Under authority of

A. J. Ramirez, Head

Advanced Systems \& Applied

Sciences Division

This is a work of the United States Government and therefore is not copyrighted. This work may be copied and disseminated without restriction.

The citation of trade names and names of manufacturers in this publication is not to be construed as official government endorsement or approval of commercial products or services referenced herein.

CETIS $^{\text {TM }}$ is a trademark of Tidepool Scientific Software.

Nikon ${ }^{\circledR}$ and COOLPIX ${ }^{\circledR}$ are registered trademarks of Nikon, Whatman $^{\mathrm{TM}}$ is a trademarks of Whatman International Limted. 


\section{ACKNOWLEDGMENTS}

We sincerely express our appreciation to the following individuals for their contributions to this effort. Ken Richter and Brandon Swope from SPAWAR Systems Center Pacific (SSC Pacific) assisted in the sampling efforts. Personnel from the Naval Facilities Engineering Command, Marianas (NAVFAC MAR) provided invaluable support for field sampling operations, in particular Public Works, who provided professional, high-quality service and expertise during sampling events. Stacey Demaclid, Mari Babauta, and the personnel at the chemical laboratory facilities at the NAVFAC Apra Harbor Wastewater Treatment Plant (WWTP) provided support with reagents and laboratory equipment for sampling and preservation. The NAVFAC Dive Locker provided invaluable support during the deployment and retrieval of our equipment, which required special handling and precise placement-in particular, MDV Clouse, HMC Bartlett, ND1 Parizal, HM2 Dempsey, ND2 Amaro, ND3 Behnke, ND2 McCrackin, and ND3 Suszanski. We also thank the Guam Environmental Protection Agency (EPA) staff for advisory support and consultation regarding relevant sampling locations, as well as Dr. Laurie Raymundo and Catherine Brunson (University of Guam) for toxicity testing technical and facility support, Finally, the authors thank Jill Brandenberger and Carolyn Suslick at Pacific Northwest National Laboratory (PNNL) in Sequim, WA, for dissolved organic carbon measurements and Robert Santore (HDR | HydroQual) for assistance with BLM calculations.

Caitlin Harris from the Naval Research Enterprise Internship Program provided document review, copy editing and formatting.

Charles Delos, U.S. Environmental Protection Agency Office of Water, assisted with the experimental design for the Water-Effect Ratio study and the recalculation procedure.

Maria Lewis and Julie Shane of the Naval Facilities Engineering Command, Marianas provided project financial support, consultation, and program coordination. 



\section{EXECUTIVE SUMMARY}

\section{OBJECTIVE}

Space and Naval Warfare Systems Center Pacific (SSC Pacific) performed the studies described in this report to develop a new National Pollutant Discharge Elimination Systems (NPDES) Permit for the discharge of effluents from the Apra Harbor Wastewater Treatment Plant (WWTP) in Agat, Guam, into Tipalao Bay of the Philippine Sea. The technical approach adhered to proposed U.S. Environmental Protection Agency (USEPA) guidelines to develop and apply the following studies:

- Mixing zone analysis

- Recalculation Procedure

- Water Effect Ratio (WER)

- Chemical Translator (CT)

SSC Pacific conducted a mixing zone (MZ) analysis to simulate the discharge environment and evaluate the behavior of the plume from the industrial outfall in Tipalao Bay, Guam. The objective of the Recalculation Procedure (Recalc WQC) and WER studies are to develop site-specific criteria or Water Quality Criteria (WQC) that protect the environment and consider ambient regional conditions. The chemical translator converts ambient WQC, expressed as dissolved metal (DM), to a permit limit expressed as total recoverable metal (TRM). See Figure ES-1.

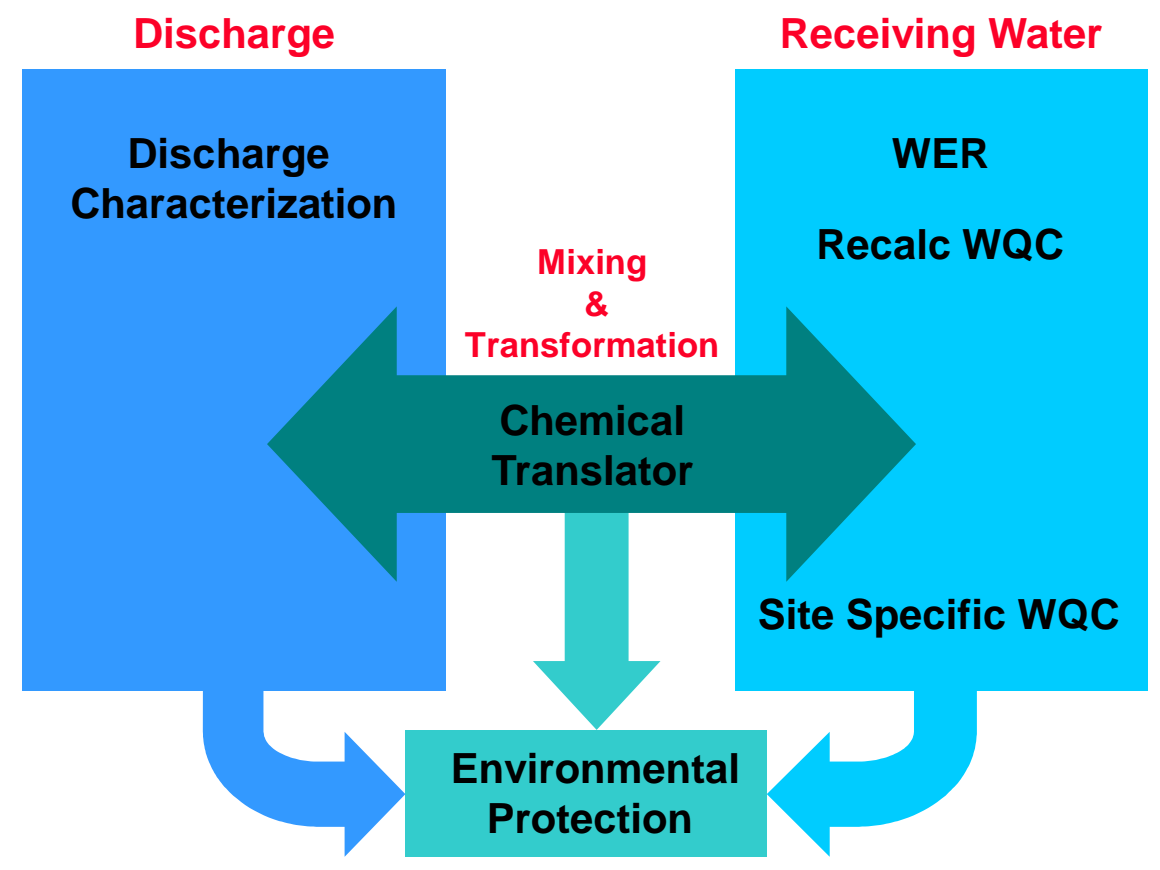

Figure ES-1. Technical approach for the development of a NPDES permit limit for effluents from the Apra Harbor WWTP. 
The combined results of this comprehensive study can be expressed in the following formula, which presents a new permit limit in TRM.

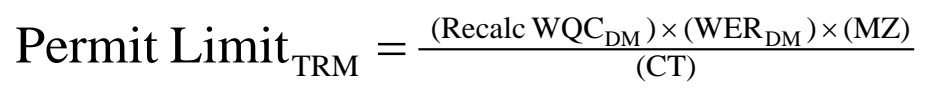

Equation ES-1. In this formula, the recalculation of water quality criteria expressed as dissolved metals (DM) and multiplied by the WER, also expressed as DM, which is multiplied by a mixing zone; the product of these three values then are divided by the chemical translator, resulting in a final permit limit expressed as total recoverable metal.

\section{RESULTS}

\section{Mixing Zone}

The SSC Pacific team selected the mixing zone model CORMIX (v7.0GT, Mixzone, 2011) as its evaluation tool. The CORMIX modeling framework uses the existing data on the discharge geometry, effluents, ambient conditions, and discharge characteristics to simulate theoretical steadystate discharges from the WWTP to estimate the mixing zone dimensions needed to meet water quality standards. We supplemented this modeling by deploying an acoustic Doppler current profiler (ADCP) for an extended time to quantify ambient currents in the discharge area and verify model results. Following the Guam Water Quality Standards, the team established a mixing zone area of 120 feet away in any direction from the point of discharge. Considering all scenarios, the acute 10th percentile current $(3.5 \mathrm{~cm} / \mathrm{sec})$ combined with the maximum wet weather peak flow (13.3 MGD) resulted in the least amount of mixing at the edge of the 120-foot mixing zone with a dilution factor of 39.2. This mixing zone adheres to USEPA Guidance (USEPA, 1985) and establishes an appropriate level of protection and regulatory control over the NPDES discharge.

\section{Copper and Nickel Recalculation}

The Recalculation Procedure (USEPA, 1994a) is a step-wise method that involves corrections, additions, and deletions to the national toxicity data set, rendering it more representative of species occurring at a specific site. The team applied this procedure to derive new copper and nickel permit limits for the Apra Harbor WWTP discharge. We used the current national criteria of 4.8- and 3.1- $\mu \mathrm{g}$

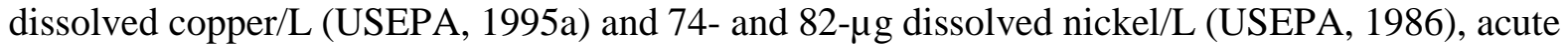
and chronic, respectively, to derive the NPDES permit limits for discharges into Tipalao Bay (Guam EPA, 2009). For the Marianas Region, the Recalculation Procedure resulted in a more comprehensive updated and site-specific toxicity data set. The criteria for recalculated acute and chronic dissolved copper were 8.2 and $4.1 \mu \mathrm{g} / \mathrm{L}$, respectively, and criteria for acute and chronic dissolved nickel were 67.4 and $22.6 \mu \mathrm{g} / \mathrm{L}$, respectively. These criteria provide the level of protection intended by USEPA (1985) for those facilities that discharge into the environment. We used these results to determine the permit limit in accordance with Equation ES-1.

\section{Reconsideration of Aluminum Criteria Established in the Apra Harbor NPDES Permit}

This report presents a brief discussion along with appropriate lines of evidence recommending that the Guam Marine Water Quality Standard for Aluminum be removed from current and future NPDES permit limits until one is established following current USEPA procedures. This recommendation is being made on the bases that there is no current scientific evidence to indicate clear adverse linkages between aluminum and adverse effects to marine organisms. In addition, USEPA has established new scientific guidelines for acceptable toxicity data used for determining permit limits and Aluminum does not have a current data set demonstrating any toxicity in the marine environment. 


\section{Chemical Translator}

The chemical translator is a conversion factor used to express the permit limit as total recoverable metal. It is empirically derived from the dilution of effluent with ambient water, and used to express the total recoverable metal concentration in the effluent that will be present as dissolved metal in ambient waters.

A suite of environmental properties can influence the ratio of total to dissolved metal. For this study, we examined the effects of water temperature, $\mathrm{pH}$, and salinity on the partitioning of copper and nickel. These parameters remained within relatively small ranges at each of the effluent and the ambient waters. Correlation of the translator to these variables was insignificant.

The team calculated the translator as the arithmetic mean of the measured values for the 2.6:1 mixture of effluent and ambient waters. The mean dissolved to total ratio (i.e., the translator) was $57 \%$ for copper, indicating that a portion of the total copper in the discharge (43\%) entering Tipalao Bay is not in the dissolved fraction. Similarly, for nickel, the mean dissolved to total ratio (i.e., the translator) was $77 \%$, indicating a portion of the total nickel in the discharge (23\%) entering Tipalao Bay is not in the dissolved fraction. These results demonstrate that $57 \%$ of the copper and $77 \%$ of the nickel in the effluent is bioavailable and considered by experts as a toxic fraction of these metals in the discharge. We applied these results to the permit calculation process to convert the permit limit into total recoverable copper and total recoverable nickel in accordance with Equation ES-1.

\section{Copper Bioavailability and Toxicity Studies towards Improved Regulatory Discharge Limits}

The toxicological effects and bioavailability of copper from 16 near-shore locations around Guam was assessed to understand the potential for surface waters from Guam to buffer against copperassociated toxicity. The team sampled locations near and adjacent to Tipalao Bay and Apra Harbor and conducted two types of toxicity tests, both of which included 48-hour embryo-larval development tests using mussels (USEPA, 1995b). The rationale for deriving site-specific WQC is to provide flexibility in establishing discharge limits under the NPDES while still providing the same level of protection intended in the USEPA's WQC derivation guidelines (USEPA, 1985). We developed a final dissolved copper WER of 1.40 from these tests that we used in Equation ES-1 for developing a chronic site-specific criterion of $5.74 \mu \mathrm{g} / \mathrm{L}$, when combined with the recalculation-generated value) for the entire island of Guam.

In addition, the team used the marine Biotic Ligand Model (BLM) for copper to predict the copper concentration that results in toxicity to bivalve embryos as an alternative to the WER procedure for developing a site-specific criterion for Guam. We used both the BLM and empirical toxicity data to estimate dissolved copper concentrations (at each of the sampling locations and the island as a whole) that would protect mussel embryos (Mytilus galloprovincialis). A final dissolved copper BLM resulted in a site-specific criterion of $5.23 \mu \mathrm{g} / \mathrm{L}$ for the entire island of Guam., This result was similar to the one derived using the empirical approach that integrated the Recalculation Procedure with the WER study.

\section{RECOMMENDATIONS}

NAVFAC Marianas recognized the requirements and conditions within the National Pollutant Discharge Elimination System Permit No. GU0110019 and initiated a study to develop site-specific discharge limitations using appropriate methods and guidance documents from the USEPA. This study incorporates the results from multiple lines of evidence to examine copper, nickel, and aluminum criteria applied in the permit. The objective is to establish new regulatory discharge limits based on the current state of the science, including the use and application of a mixing zone analysis, 
a recalculation procedure, a chemical translator study, a WER procedure, and the Biotic Ligand Model.

Based on the data generated from these studies (Table ES-1), we recommend new NPDES discharge limits for copper and nickel as outlined below, while a separate rationale exists to justify the removal of aluminum from further regulatory limits.

Table ES-1. NPDES permit limit calculations for copper and nickel $(\mu \mathrm{g} / \mathrm{L})$.

\begin{tabular}{|l|c|c|c|c|c|}
\hline & $\begin{array}{c}\text { Copper } \\
\text { (acute) }\end{array}$ & $\begin{array}{c}\text { Copper } \\
\text { (chronic) }\end{array}$ & $\begin{array}{c}\text { Copper } \\
\text { BLM (acute } \\
\text { and chronic) }\end{array}$ & $\begin{array}{c}\text { Nickel } \\
\text { (acute) }\end{array}$ & $\begin{array}{c}\text { Nickel } \\
\text { (chronic) }\end{array}$ \\
\hline Recalc WQC $_{\mathrm{DM}}$ & 8.2 & 4.1 & 5.2 & 68.1 & 22.8 \\
\hline WER $_{\mathrm{DM}}$ & 1.40 & 1.40 & $\mathrm{~N} / \mathrm{A}$ & $\mathrm{N} / \mathrm{A}$ & $\mathrm{N} / \mathrm{A}$ \\
\hline $\mathrm{MZ}$ & 39.2 & 39.2 & 39.2 & 39.2 & 39.2 \\
\hline $\mathrm{CT}$ & 0.57 & 0.57 & 0.57 & 0.77 & 0.77 \\
\hline Final Permit Limit & 790 & 395 & 358 & 3467 & 1161 \\
\hline
\end{tabular}

The copper limit is calculated as follows for the Apra Harbor WWTP:

$(8.2 \mu \mathrm{g} / \mathrm{L}) \times(1.40) \times(39.2) /(0.57)=790 \mu \mathrm{g} / \mathrm{L}$ total recoverable copper (acute)

$(4.1 \mu \mathrm{g} / \mathrm{L}) \times(1.40) \times(39.2) /(0.57)=395 \mu \mathrm{g} / \mathrm{L}$ total recoverable copper (chronic)

The BLM copper limit is calculated as follows for the Apra Harbor WWTP:

$(5.2 \mu \mathrm{g} / \mathrm{L}) \times 39.2) /(0.57)=358 \mu \mathrm{g} / \mathrm{L}$ total recoverable copper (acute and chronic)

The nickel limit is calculated as follows for the Apra Harbor WWTP:

$(68.1 \mu \mathrm{g} / \mathrm{L}) \times(39.2) /(0.77)=3467 \mu \mathrm{g} / \mathrm{L}$ total recoverable nickel (acute)

$(22.8 \mu \mathrm{g} / \mathrm{L}) \times(39.2) /(0.77)=1161 \mu \mathrm{g} / \mathrm{L}$ total recoverable nickel (chronic)

If aluminum were considered critical to maintain within the current permit, the new proposed limit would be calculated with a consideration given for a mixing zone as follows:

$(200 \mu \mathrm{g} / \mathrm{L}) \times(39.2)=7840 \mu \mathrm{g} / \mathrm{L}$ total recoverable aluminum (acute and chronic)

These new site-specific limits will enable the Navy to continue business and industrial operations in Guam while providing environmental protection and maintaining water quality in Tipalao Bay and the surrounding waters. 


\section{CONTENTS}

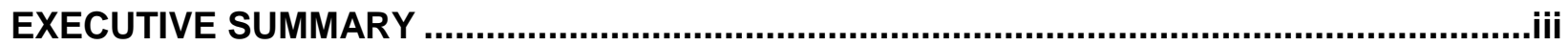

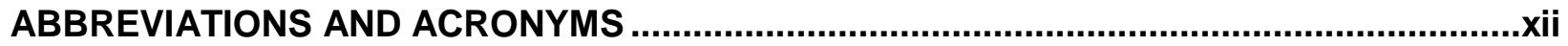

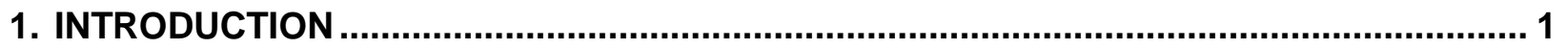

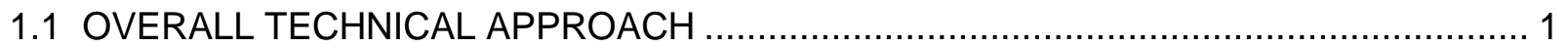

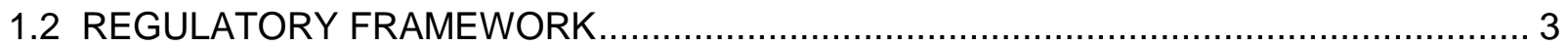

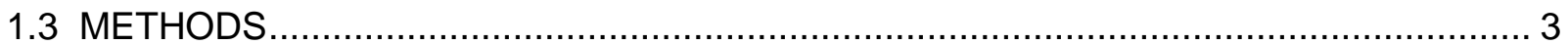

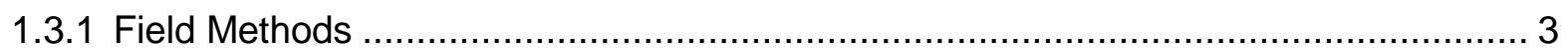

2. A MIXING ZONE ANALYSIS FOR DISCHARGES FROM THE APRA HARBOR

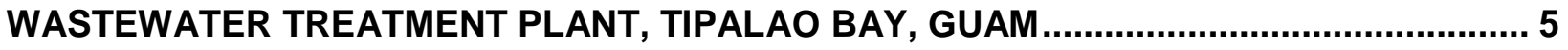

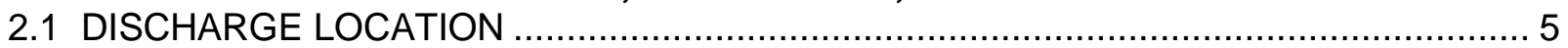

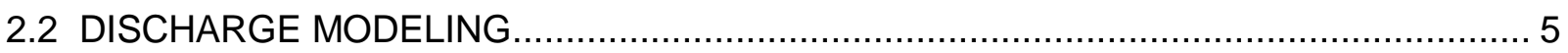

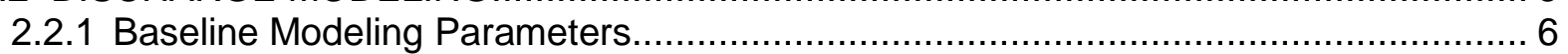

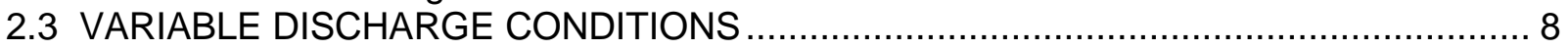

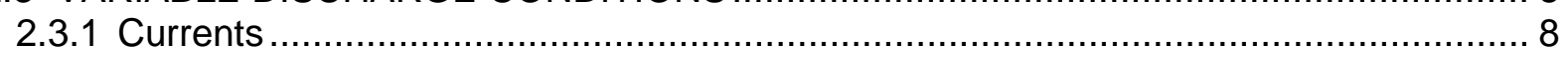

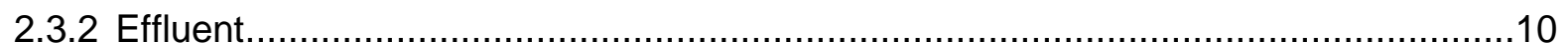

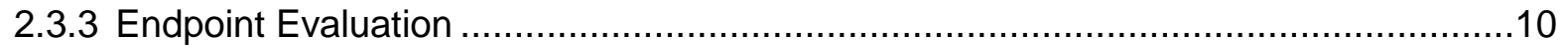

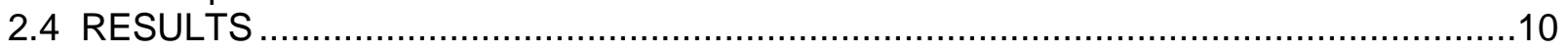

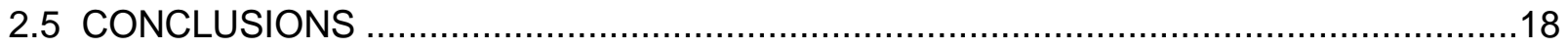

3. RECALCULATION OF A SITE-SPECIFIC COPPER WATER QUALITY STANDARD

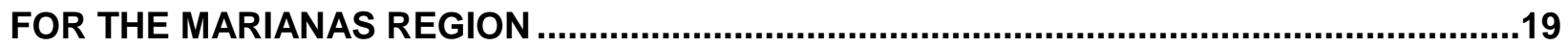

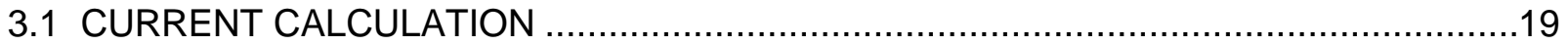

3.22011 UPDATED DATA SET AND DRAFT BLM-NORMALIZED CALCULATION ............19

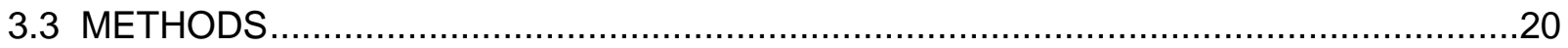

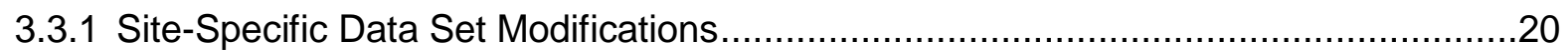

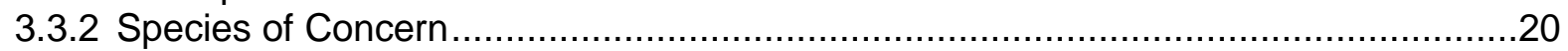

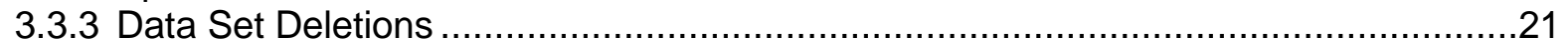

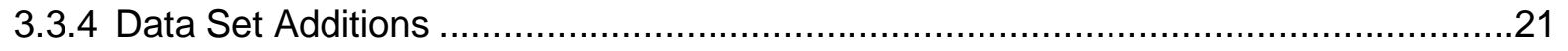

3.3.5 Recalculation Additions Considered, But Not Included ........................................23

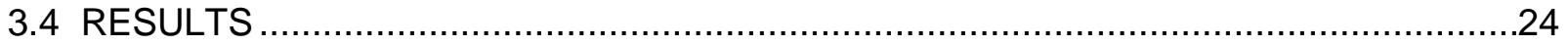

4. RECALCULATION OF A SITE-SPECIFIC NICKEL WATER QUALITY STANDARD

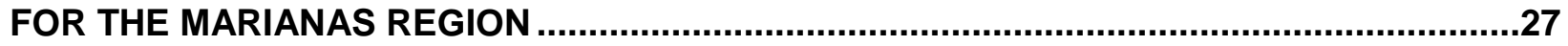

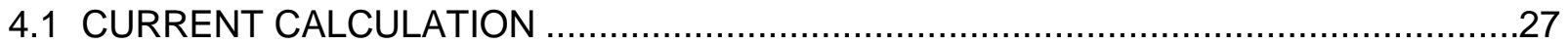

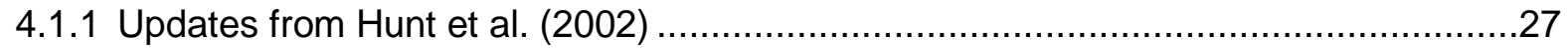

4.1.2 Chronic Toxicity Data Updates (Deforest and Shlekat, 2013) ...............................28

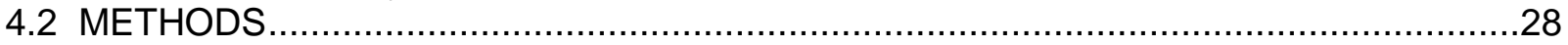

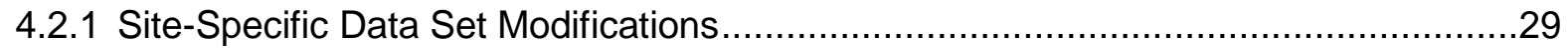

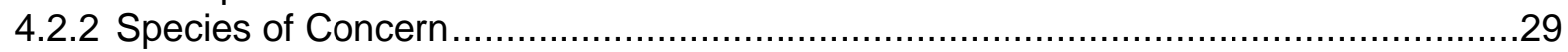

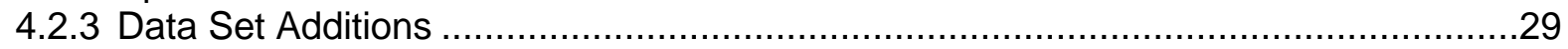

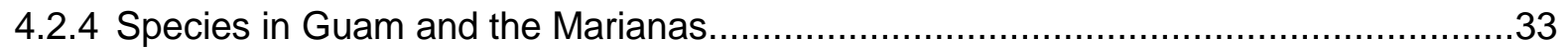

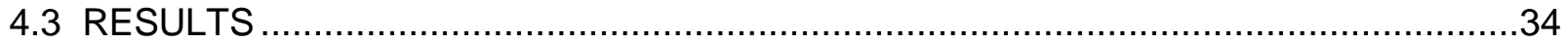

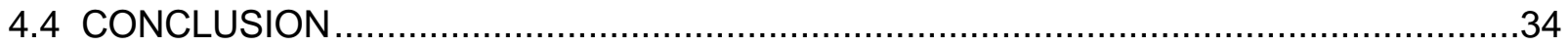

5. NICKEL AND COPPER TOXICITY TO EMBRYOS OF THE LONG-SPINED SEA

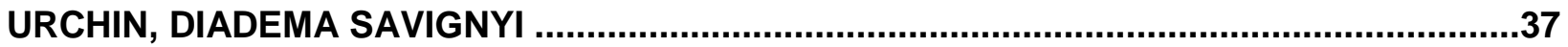

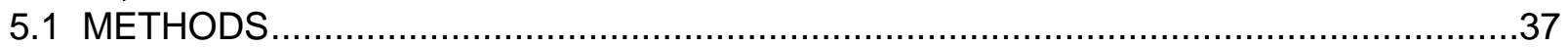

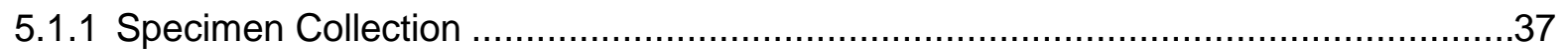

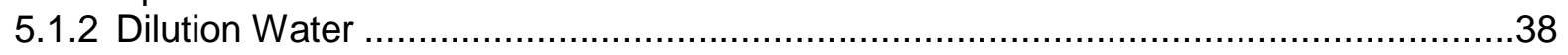

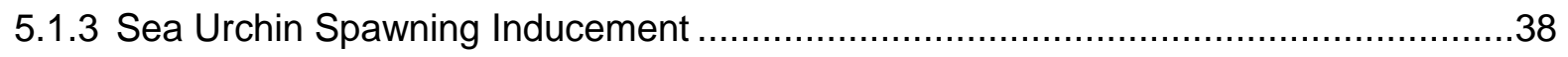

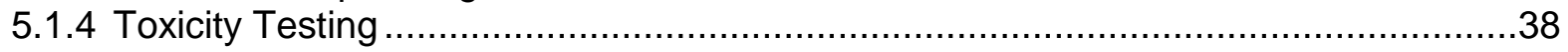

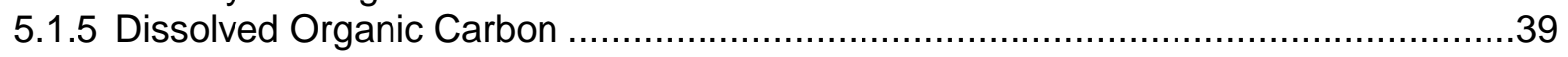




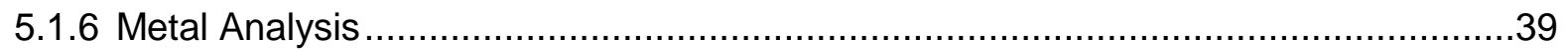

5.2 RESULTS

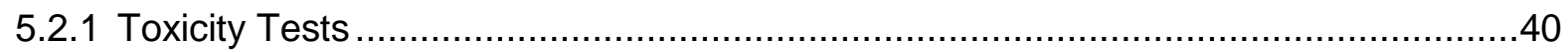

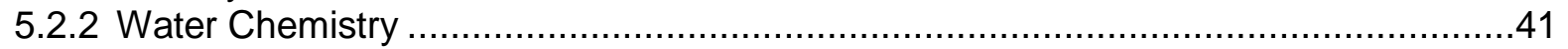

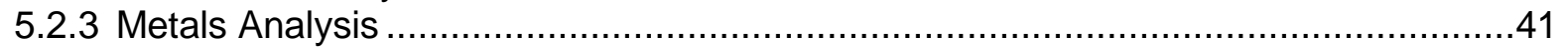

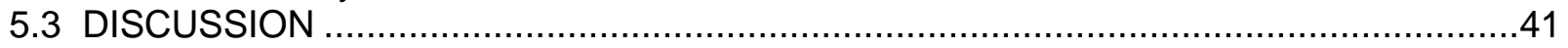

5.3.1 Relevance of Nickel Sensitivity to Regulation of Permitted Discharges ....................42

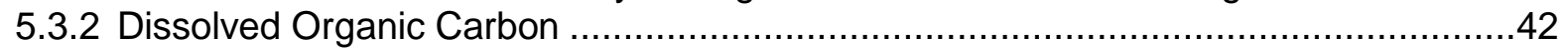

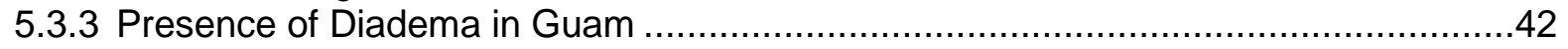

6. REMOVAL OF ALUMINUM FROM THE APRA HARBOR NPDES PERMIT ....................43

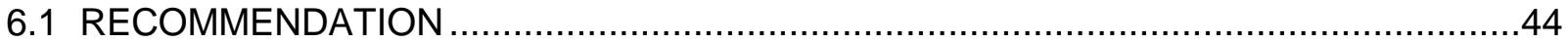

7. CHEMICAL TRANSLATOR FOR APRA HARBOR WASTEWATER TREATMENT PLANT DISCHARGE IN TIPALAO BAY, GUAM

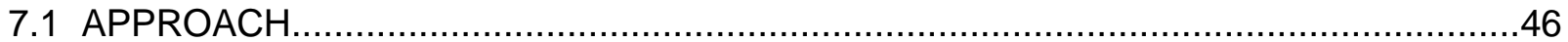

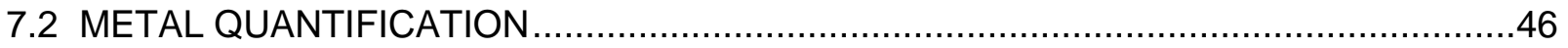

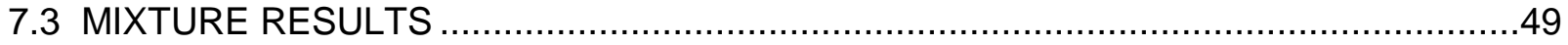

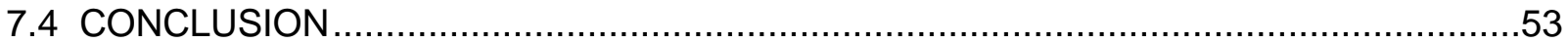

8. COPPER BIOAVAILABILITY AND TOXICITY STUDIES TOWARDS IMPROVED

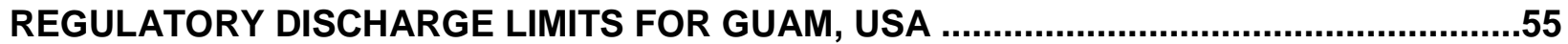

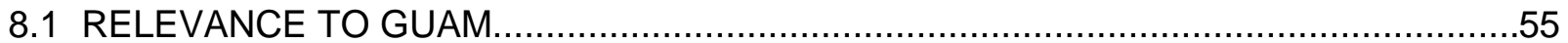

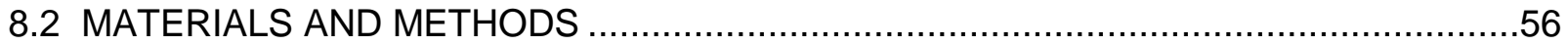

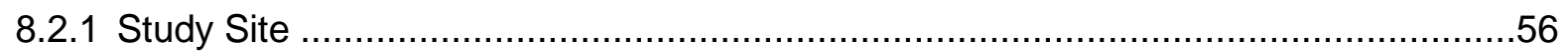

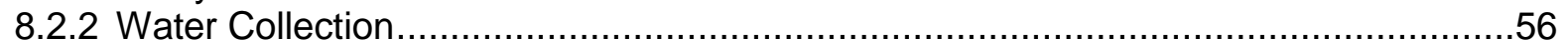

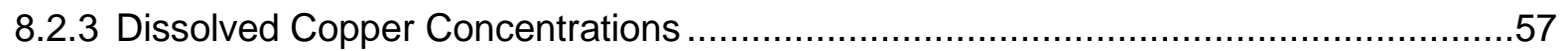

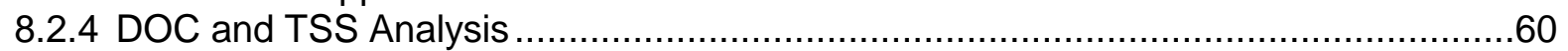

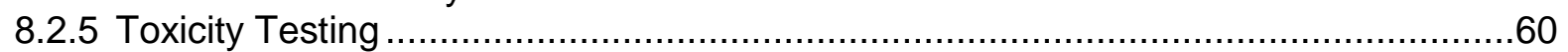

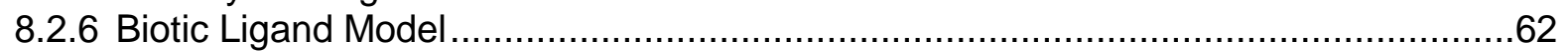

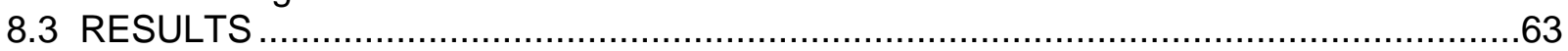

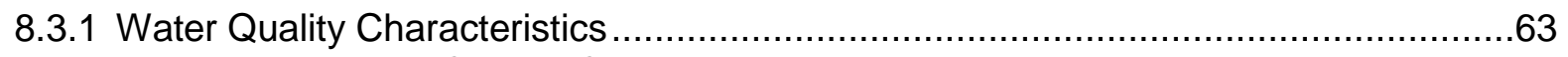

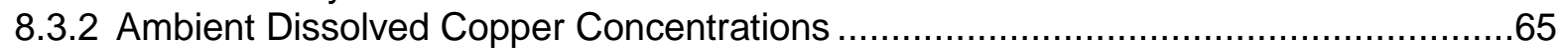

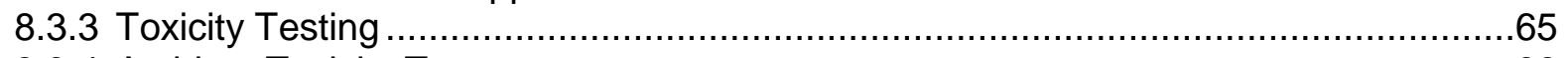

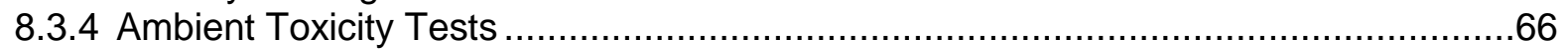

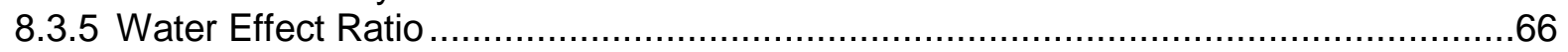

8.3.6 Toxicity and DOC

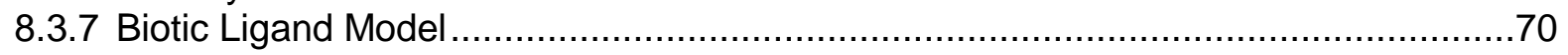

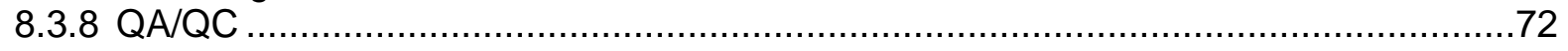

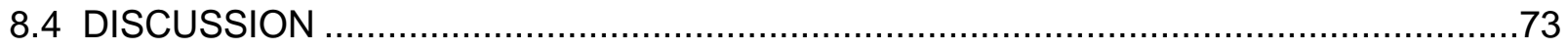

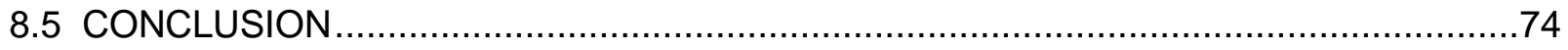

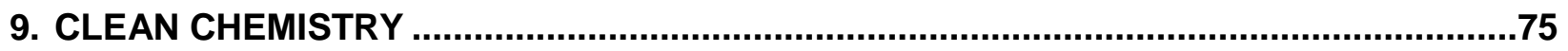

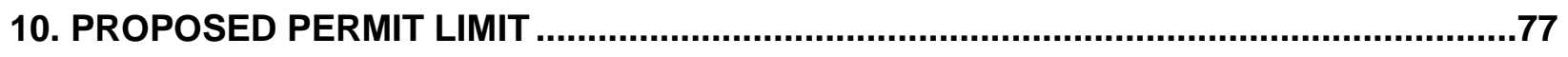

APPENDICES (SEE ACCOMPANYING CD)

A: CORMIX RESULTS

B: COPPER RECALCULATION

C: NICKEL RECALCULATION

D: EXCERPT OF USEPA ALUMINUM CRITERIA

E: EXCERPT OF FLORIDA DEPE (1997) ALUMINUM CRITERIA 


\section{Figures}

ES-1. Technical approach for the development of a NPDES permit limit for effluents from the Apra Harbor WWTP.... vii

2-1. Detailed location of NPDES outfall in Tipalao Bay, Guam (NOAA, 2006) ....................... 5

2-2. Existing outfall in Tipalao Bay ............................................................................... 7

2-3. Conceptualized model of port configuration for discharge analysis ............................ 8

2-4. Water column ADCP current meter observations in Tipalao Bay, Guam .......................... 9

2-5. Dilution factors associated with a $3.5-\mathrm{mpg}$ flow considering variable current speeds .........14

2-6. Dilution factors associated with a 6.6 -mpg flow considering variable current speeds ..........15

2-7. Dilution factors associated with a 12.1-mpg flow considering variable current speeds .......16

2-8. Dilution factors associated with a 17.7-mpg flow considering variable current speeds .......17

3-1. Cumulative toxicity probability: blue are species in national data set occurring at the site; red are site-specific additions..............................................................26

4-1. Photos of long-spined sea urchins Diadema savignyi (top) and Diadema setosum (bottom).....

4-2. Cumulative toxicity probability, site-specific data set. Red text represents species present in Guam, bold text represents species that were added to the data set, and non-bold text represents species that were retained from the original 1986 USEPA data set.

7-1. Plots of nickel chemical translator ( $f_{D}$ nickel) vs. pH (top), salinity (center), and temperature $\left({ }^{\circ} \mathrm{C}\right.$, bottom), in the Apra Harbor WWTP effluent (triangles), 2.6 dilution fraction translator mixture (circles), and seawater from Reference Site TB5 (squares). The narrow range in these properties resulted in negligible influence in $f_{D}$ nickel. Temperature measurements in the mixture were not measured.

7-2. Plots of copper chemical translator ( $f_{D}$ copper) vs. pH (top), salinity (center), and temperature $\left({ }^{\circ} \mathrm{C}\right.$, bottom), in the Apra Harbor WWTP effluent (triangles), 2.6 dilution fraction translator mixture (circles) and seawater from Reference Site TB5 (squares). The narrow range in these properties resulted in negligible influence in $f_{D}$ copper. Temperature measurements in the mixture were not measured....

7-3. Plot of unfiltered vs. filtered nickel $(\mu \mathrm{g} / \mathrm{L})$ for the mixture of Apra Harbor Wastewater Treatment Plant with seawater from Reference Site TB5 in a 2.6 mixing ratio

7-4. Plot of unfiltered vs. filtered copper $(\mu \mathrm{g} / \mathrm{L})$ for the mixture of Apra Harbor Wastewater Treatment Plant with seawater from Reference Site TB5 in a 2.6 mixing ratio......

8-1 Sampling locations in near-shore areas around Guam, including overview of all 16 locations, with the focus in and around Tipalao Bay and Apra Harbor. Ambient toxicity testing and the Biotic Ligand Model was used to predict copper toxicity at all 16 stations. The Water Effect Ratio study was conducted for stations G1, G3, G8, and for two samples collected at G13....

8-2. Results from embryo-larval development toxicity tests performed with mussel (Mytilus galloprovincialis) on laboratory control (LC) waters and the ambient site samples collected from Guam. Test acceptability in the laboratory control for this endpoint is $70 \%$ normal alive larvae (ASTM 1999), which was met.

8-3. Dose response curves for the laboratory water (Granite Canyon [GC]) and each of the five site water samples collected around Guam for the WER study....

8-4. Relationship between dissolved EC50 and dissolved organic carbon (DOC) from the WER testing $(\mathrm{N}=6)$

8-5. WER- and BLM-based criteria derived for Guam by station. The national water quality criterion (WQC) of 3.1- $\mu \mathrm{g} / \mathrm{L} \mathrm{DCu}$, measured $\mathrm{DCu}$, and mean discharge monitoring data from Tipalao Bay from 2008 and 2009 are shown for reference 
8-6. Arithmetic means and standard deviations for Guam site specific criterion and equivalent estimated chronic limits (ECL) generated from WER and BLM procedures, respectively. BLM calculations were conducted using both field and laboratory water chemistry data, and for the five WER stations and all 16 stations sampled at Guam. The average ambient DCu from the 16 stations and the national WQC of $3.1 \mu \mathrm{g} / \mathrm{L}$ are shown for comparison.

9-1. Title slide for the presentation on trace-metal clean techniques for quantification of heavy metals in water samples at environmentally relevant concentrations.

\section{Tables}

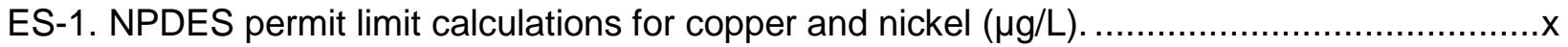

1-1. Number of samples collected for each study element ....

2-1. Variables applied during CORMIX modeling runs for the Tipalao Bay outfall. Under the numbering matrix, $\mathrm{C}$ denotes model runs associated with copper and $\mathrm{N}$ denotes model runs associated with nickel

2-2. Dilution factor at the edge of the 120 -foot (36.57-meter) mixing zone considering variable current speed and discharge rates

2-3. Model results for copper discharge simulations establishing minimum distance required to meet compliance endpoints....

2-4. Model results for nickel discharge simulations establishing minimum distance required to meet compliance endpoints.....

3-1. Genus mean acute values for the four most sensitive species in the national data set for dissolved copper (USEPA, 1995a)

3-2. BLM-normalized species mean acute values for the four most sensitive species in the updated national data set for dissolved copper (HDR | HydroQual, 2012) .................20

3-3. Non-BLM-normalized genus mean acute values for the four genera approximating the 5th percentile in the site-specific data set for dissolved copper......

4-1. Nickel water quality criteria calculations using acute species sensitivity distribution provided by USEPA (1986). Data expressed as total recoverable nickel.

4-2. Nickel WQC calculations using acute species sensitivity distribution provided by Hunt et al. (2002). Data expressed as dissolved nickel....

4-3. Nickel WQC calculations using chronic species sensitivity distribution provided by new data from DeForest and Schlekat (2013). Data expressed as dissolved nickel....

4-4. Genus mean acute values (GMAV) for the four most sensitive genera in the site-specific data set for dissolved nickel

5-1. Response of $D$. savignyi to nickel in two concurrent tests with different embryo suspensions. Bold values are statistically different from the laboratory control. $N=4$ replicates per concentration

5-2. No observed effect concentration (NOEC), lowest observed effect concentration (LOEC), median effective concentration (EC50), and 95\% confidence intervals (C.I.) for all toxicity tests with $D$. savignyi

5-3. Response of $D$. savignyi embryos to copper. Bold values are statistically different from the laboratory control. $\mathrm{N}=4$ replicates per concentration.

7-1. Sampling dates and ancillary data for samples collected for the Chemical Translator study at Apra Harbor Wastewater Treatment Plant. $\mathrm{T}^{\circ} \mathrm{C}$ is temperature in degree Celsius. Ancillary data measured on 29 April 2013. Std. Dev. is standard deviation. 95th \% is 95th percentile, 25 th $\%$ is 25 th percentile, Geomean is geometric mean. 
7-2. Dissolved $\left(C_{D}\right)$ and total $\left(C_{T}\right)$ nickel, and chemical translator ( $f_{D}$ nickel) measured in samples from the 2.6 dilution of effluent from Apra Harbor WWTP with seawater from Reference Site TB5.

7-3. Dissolved $\left(C_{D}\right)$ and total $\left(C_{T}\right)$ copper, and chemical translator (fD Copper) measured in samples from the 2.6 dilution of effluent from Apra Harbor Wastewater Treatment Plant with seawater from Reference Site TB5

8-1. Sample collection times and site descriptions ....

8-2. Bivalve embryo development test specifications

8-3. Water quality parameters as measured during sample collection

8-4. Water quality parameters as measured upon receipt at the SSC Pacific Bioassay Laboratory

8-5. Water quality characteristics for Granite Canyon Laboratory water (GC) and the 16 site waters from Guam

8-6. Results two different endpoints from toxicity tests performed with mussel (Mytilus galloprovincialis) embryos collected from 16 stations around Guam. LC = Laboratory Control

8-7. Median effective concentrations (EC50), site-specific criteria based on WER (SSC WER $_{\text {), }}$ site-specific criteria based on WER and Recalculation (SSC WER+Recalc $_{\text {), DCu concen- }}$ trations and water effect ratios (WER) for the five WER stations and laboratory control ....69

8-8. Measured dissolved copper concentrations for each of the test concentrations used in the WER study for the five site water stations and the GC laboratory water station used for calculating EC50 values

8-9. Biotic Ligand Model (BLM) calculated ECL and EC50 values for copper ( $\mu \mathrm{g} / \mathrm{L}$ ) from all Guam sampling stations, using water chemistry data collected from the field and under laboratory toxicity testing conditions. Ambient dissolved copper data shown for eference. All values other than DOC are expressed as dissolved copper ( $\mu \mathrm{g} / \mathrm{L})$.........

10-1. NPDES permit limit calculations for copper and nickel $(\mu \mathrm{g} / \mathrm{L})$ 


\section{ABBREVIATIONS AND ACRONYMS}

\begin{tabular}{|c|c|c|c|}
\hline ACR & Acute-Chronic Ratio & HTCO & High Temperature Catalytic \\
\hline \multirow[t]{2}{*}{ ADCP } & Acoustic Doppler Current & & Oxidation \\
\hline & Profiler & ICP-MS & Inductively Coupled Plasma- \\
\hline \multirow[t]{2}{*}{ ASTM } & American Society for Testing & & Mass Spectrometer \\
\hline & and Materials & LOEC & Lowest Observed Effect \\
\hline \multirow[t]{2}{*}{ AWQC } & Ambient Water Quality & & Concentration \\
\hline & Criteria & MGD & Million Gallons per Day \\
\hline BLM & Biotic Ligand Model & MZ & Mixing Zone \\
\hline \multirow[t]{2}{*}{ CCC } & Criterion Continuous & NAVFAC & Naval Facilities \\
\hline & Concentration (chronic limit) & NDIR & Non-dispersive Infrared \\
\hline $\mathrm{CHT}$ & Collect, Hold and Transfer & & Detector \\
\hline \multirow[t]{2}{*}{ CMC } & Criterion Maximum & NOEC & No Observed Effect \\
\hline & Concentration (acute limit) & & Concentration \\
\hline CT & Chemical Translator & NPOC & Non-purgeable Organic \\
\hline CWA & Clean Water Act & & Carbons \\
\hline DI & Deionized & NPDES & National Pollutant Discharge \\
\hline DOM & Dissolved Organic Matter & & Elimination System \\
\hline DM & Dissolved Metal & PNNL & Pacific Northwest National \\
\hline DMR & Discharge Monitoring Report & & Laboratory \\
\hline DOC & Dissolved Organic Carbon & PPT & Parts per Thousand \\
\hline \multirow[t]{2}{*}{ EC50 } & Effect Concentration for 50th & QA & Quality Assurance \\
\hline & percentile & $\mathrm{QC}$ & Quality Control \\
\hline ECL & Estimated Chronic Limit & SOP & Standard Operating Procedure \\
\hline \multirow[t]{2}{*}{ ELAP } & Environmental Laboratory & SRM & Standard Reference Material \\
\hline & Accreditation Program & SSC & Site Specific Criterion \\
\hline USEPA & $\begin{array}{l}\text { United States Environmental } \\
\text { Protection Agency }\end{array}$ & SSC Pacific & $\begin{array}{l}\text { Space and Naval Warfare } \\
\text { Systems Center Pacific }\end{array}$ \\
\hline FAV & Final Acute Value & SSD & Species Sensitivity \\
\hline \multirow[t]{2}{*}{ FFCA } & Federal Facilities Compliance & & Distribution \\
\hline & nent & TOC & Total Organic Carbon \\
\hline FIAM & Free Ion Activity Model & TRM & Total Recoverable Metal \\
\hline \multirow[t]{2}{*}{ FIAS } & Flow Injection Analysis & TSS & Total Suspended Solids \\
\hline & System & USEPA & United States Environmental \\
\hline FISC & Fleet Industrial Service Center & & Protection Agency \\
\hline GLP & Good Laboratory Practices & WER & Water Effect Ratio \\
\hline GWA & Guam Waterworks Authority & WET & Whole Effluent Toxicity \\
\hline HDPE & High Density Polyethylene & WQC & Water Quality \\
\hline \multirow[t]{2}{*}{$\mathrm{HNO}_{3}$} & Nitric Acid & & Criteria/Criterion \\
\hline & & WWTP & Wastewater Treatment Plant \\
\hline
\end{tabular}




\section{INTRODUCTION}

The United States Environmental Protection Agency (USEPA) placed the Apra Harbor Wastewater Treatment Plant (WWTP) in Agat, Guam, on its Significant Non-compliance list in April 2005. This designation is the most serious level of violation noted in USEPA databases, and indicates if violations or non-compliance events occur at a given facility they may pose a more severe level of concern for the environment or program integrity. On 10 June 2010, the Naval Facilities Engineering Command Marianas (NAVFAC Marianas) Environmental Compliance team contacted the Environmental Sciences Division at Space and Naval Warfare Systems Center Pacific (SSC Pacific) to request technical assistance in compliance issues related to its National Pollution Discharge Elimination System (NPDES) Permit No. GU0110019 for Apra Harbor WWTP, located in Agat, Guam. Subsequently, on 25 March 2011 NAVFAC Marianas and USEPA entered into a Federal Facilities Compliance Agreement (FFCA) for the Apra Harbor WWTP as part of a roadmap to compliance with their NPDES permit.

The FFCA contains a schedule of corrective actions for the Navy to complete to achieve consistent compliance with the NPDES permit along with specific key dates for meeting these requirements. NAVFAC Marianas offered to develop site-specific criteria for discharge limits for metals of contention based on USEPA-approved procedures to begin collaborating with Guam EPA. SSC Pacific developed a technical approach to meet the requirements of the FFCA in as timely, technically sound, and cost-effective manner as possible. The study design was in accordance with appropriate USEPA guidance documents for the development of site-specific permit limits (USEPA, 1991, 1994a, 1994b, 1996a\&b, 2001), and in consultation with Guam EPA. This approach is similar to successfully executed projects for copper at U.S. Navy installations in Pearl Harbor, HI (Earley et al., 2007) and Sinclair and Dyes Inlets, Puget Sound, WA (Rosen et al., 2009). It incorporates various aspects of the latest state of the science (Rivera-Duarte et al., 2005; Rosen et al., 2005, 2008; Chadwick et al., 2008; Earley et al., 2010). The ultimate goal of the study design was to provide scientific information supporting site-specific discharge limits using USEPA approved procedures, including (1) a chemical translator for copper and nickel, (2) an assessment of the applicability of the Recalculation Procedure, (3) Water Effect Ratio (WER), and (4) a mixing zone analysis of the discharge environment. The team then applied these elements to the current NPDES Permit. Finally, we present the use and application of a Marine Biotic Ligand Model (BLM) for calculating permit limitations for copper discharges as an alternative to the resource-intensive WER approach to integrate the latest EPA-acknowledged science towards effective compliance at sites.

\subsection{OVERALL TECHNICAL APPROACH}

The technical approach consisted of the following elements:

- Conduct a pollutant fate and transport study to establish a Regulatory Mixing Zone requested within a Mixing Zone application submitted to Guam EPA in June 2010

- Develop site-specific water quality criteria (WQC) for copper and nickel using the Recalculation Procedure (USEPA 1994a)

- Conduct a Preliminary WER to derive empirically defined site-specific WQC for copper, and compare to the Marine Biotic Ligand Model for copper (HDR | HydroQual, 2012)

- Conduct an analysis of the aluminum criterion established within the current permit and its applicability and relevance to the Apra Harbor WWTP discharge environment 
- Perform a chemical translator study to derive a site-specific formula for converting between total recoverable metals in the effluent and dissolved metal in the receiving waters and for copper and nickel

- Train NAVFAC Marianas chemistry and analytical laboratory personnel on techniques for trace metal sampling and analysis.

When the study elements are combined, a new permit limit can be established, expressed as total recoverable metals (TRM). The limit is derived as follows: the Recalculation of WQC (Recalc WQC), expressed as dissolved metals (DM) multiplied by the WER expressed as DM, multiplied by any calculated Mixing Zone (MZ) divided by the Chemical Translator (CT). This is better expressed as a simple formula, as shown in Equation 1-1:

$$
\text { Permit Limit } \text { TRM }=\frac{\left(\text { Recalc }_{\mathrm{WQC}} \mathrm{DM}\right) \times\left(\mathrm{WER}_{\mathrm{DM}}\right) \times(\mathrm{MZ})}{(\mathrm{CT})}
$$

Equation 1-1. In this formula, the Recalculation of Water Quality Criteria (Recalc WQC) is expressed as dissolved metals (DM) and multiplied by the Water Effects Ratio (WER), also expressed as DM, which is multiplied by a Mixing Zone (MZ); the product of these three values are divided by the Chemical Translator (CT), resulting in a final permit limit expressed as total recoverable metal (TRM).

We adjusted the elements within this formula to include or exclude various elements of this study. For example, a WER was not performed for nickel, and any calculation would therefore exclude this term.

The team used the following USEPA guidance documents for national water quality assessment and regulation to establish permit limits at NAVFAC Marianas in this approach:

- 1993 Metals Policy (Prothro Memo): "It is now the policy of the Office of Water that the use of dissolved metal to set and measure compliance with water quality standards is the recommended approach, because dissolved metal more closely approximates the bioavailable fraction of metal in the water column than does total recoverable metal.”

- USEPA Memo: “Office of Water Policy and Technical Guidance on Interpretation and Implementation of Aquatic Life Metals Criteria” and 40 CFR 121.36(b)(1).

- EPA-823-B-94-001 (1994) promotes refined WQS based on site-specific receiving water characteristics and resident species (WER, Recalculation, and the Resident Species Procedure).

- EPA-823-B-96-007 (1996) Translator Guidance for Conversion between Total Recoverable and Dissolved Metals.

- $\quad$ EPA 64 FR 58409 (October 29 1999) issued plans to revise copper criteria based on the Biotic Ligand Model to address bioavailability.

The recommendations and approaches within these guidance documents have been successfully implemented throughout the United States, promoting environmental stewardship and supporting scientifically defensible regulatory discharge limits. Numerous studies throughout the nation have examined the application of WERs to provide regulatory relief (Gauthier et al., 1995). One of the earliest WER studies for copper in an urban harbor was the New York/New Jersey Harbor study (USEPA, 1994b). This study, which developed a site-specific WER, also increased the national criterion to the existing values for acute and chronic effects (USEPA, 1994a). Two other key studies in estuaries were conducted in San Francisco Bay and Hampton Roads Harbor (Norfolk). The City of San Jose, California, funded the development of a Total Maximum Daily Load (TMDL) and the 
adoption of site-specific water quality objectives for copper (6.9 $\mu \mathrm{g} / \mathrm{L}$ chronic, $10.8 \mu \mathrm{g} / \mathrm{L}$ acute) in the South San Francisco Bay (Mumley and Speare, 2002). This study was a successful example of adoption of site-specific water quality objectives. The Hampton Roads study was a comprehensive four-part project incorporating a WER, Recalculation, translators, and mixing zones, completed by the Navy and implemented by the Virginia Department of Environmental Quality (CH2M Hill, 2000). As a result of these efforts, in 2004 the Virginia Department of Environmental Quality adopted a revised WQC for copper of 10.5 and $16.3 \mu \mathrm{g} / \mathrm{L}$, for chronic and acute values, respectively. When combined in conjunction with the translator value, a site-specific recalculation and mixing zone dilution factor yielded waste load allocations for copper, which are achievable by Navy dry docks (CH2M Hill, 2000).

\subsection{REGULATORY FRAMEWORK}

States and territories are required to review their water quality standards (WQS) every 3 years and submit the results of their review to USEPA (CWA section 303(c)(1)). USEPA regional offices approve these standards if they are scientifically defensible and protective of designated uses (40 CFR § 131.11). The Guam WQS (Guam EPA, 2001) established WQC for copper, and it is based on national USEPA recommended criteria (USEPA, 1995a) citing $4.8 \mu \mathrm{g} / \mathrm{L}$ for the acute (24-hour average) and $3.1 \mu \mathrm{g} / \mathrm{L}$ for the chronic (4-day average) values. The Guam WQS for nickel is 74 and $8.2 \mu \mathrm{g} / \mathrm{L}$ acute and chronic, respectively, and the WQS for aluminum is $0.2 \mathrm{mg} / \mathrm{L}(200 \mu \mathrm{g} / \mathrm{L})$ as a maximum limit (Guam EPA, 2001). The NPDES permit limits issued to the Apra Harbor WWTP cannot exceed the Guam WQS that are set by Guam EPA, but the regulations allow for consideration of site-specific criteria and establishment of mixing zones. The goal of this comprehensive study is to apply USEPA-approved methods to calculate a scientifically based permit limit for copper and nickel discharges at the Apra Harbor WWTP to support ongoing industrial operations while still maintaining and protecting the designated uses of the discharge environment.

\subsection{METHODS}

This document describes a technically sound, cost effective approach designed to meet FCCA requirements by using USEPA-approved methods and recommendations. In conjunction with Guam EPA, SSC Pacific used the following guidance documents to establish the scientific principles and procedures to derive site-specific water quality criteria and maintain environmental protection standards.

- USEPA Technical Support Document for Water Quality-based Toxics Control (USEPA, 1991)

- USEPA Interim Guidance on Determination and Use of Water Effect Ratios for Metals (USEPA, 1994c)

- USEPA Water Quality Standards Handbook: Second Edition (USEPA, 1994c)

- The Metals Translator: Guidance for Calculating a Total Recoverable Permit Limit from a Dissolved Criterion (USEPA, 1996a)

- USEPA Streamlined Water Effect Ratio Procedure for Discharges of Copper (USEPA, 2001)

- Compilation of EPA Mixing Zone Documents (USEPA, 2006a)

\subsubsection{Field Methods}

Water samples were collected for three main purposes:

1. Support a site-specific WER for Tipalao Bay and the surrounding discharge area. 
2. Establish a site-specific translator examining the partitioning of copper after the effluent enters into and mix with ambient receiving water.

3. Characterize the potential range of concentrations of discharges and the effects of temporal variability in the receiving waters.

Samples supporting the WER were taken during one scheduled event on April 29, 2013.

Table 1 lists all samples taken during the WER sampling event. During this study, samples were collected from 16 ambient stations (Figure 1) over a 2-day period as well as supporting data described below.

Table 1-1. Number of samples collected for each study element.

\begin{tabular}{|c|c|c|c|}
\hline Study type & Acronym & $\begin{array}{l}\text { Number of } \\
\text { samples }\end{array}$ & Type of samples \\
\hline \multirow{2}{*}{ Mixing Zone } & \multirow{2}{*}{$M Z$} & 7751 & ADCP data \\
\hline & & 12 & Model Runs \\
\hline Copper Recalculation & Recalc WQC & 90 & Bibliographic references \\
\hline Nickel Recalculation & Recalc WQC & 30 & Bibliographic references \\
\hline $\begin{array}{l}\text { Toxicity studies on Diadema } \\
\text { savigny }\end{array}$ & & 3 & \\
\hline Aluminum Criteria & & 3 & Bibliographic references \\
\hline Chemical Translator & CT & 22 & $\begin{array}{l}\text { Ambient and Apra Harbor WWTP } \\
\text { waters }\end{array}$ \\
\hline \multirow{2}{*}{ Water Effect Ratio } & \multirow{2}{*}{ WER } & 16 & Ambient waters \\
\hline & & 60 & Spiked samples \\
\hline Copper Biotic Ligand Model & BLM & 16 & $\begin{array}{c}\text { Ambient parameters and waters } \\
\text { (DOC) }\end{array}$ \\
\hline
\end{tabular}

The team used clean sampling techniques to collect water samples, and analyzed them for total and dissolved copper using clean methods for trace metal analysis (USEPA, 1996b). We took samples at each ambient station to support toxicity tests (USEPA, 1994c), and other parameters measured at all sampling locations including total suspended solids (TSS), total and dissolved organic carbon (TOC and DOC), oxygen, salinity, temperature, and $\mathrm{pH}$. 


\section{A MIXING ZONE ANALYSIS FOR DISCHARGES FROM THE APRA HARBOR WASTEWATER TREATMENT PLANT, TIPALAO BAY, GUAM}

The current Apra Harbor WWTP NPDES Permit No. GU0110019 is amended by a FFCA with a schedule of corrective actions for the Navy to complete to achieve consistent compliance with the NPDES permit along with specific key dates for meeting these requirements. In addition to these requirements, NAVFAC Marianas chose to develop site-specific discharge limits for metals based on USEPA-approved procedures. As part of the permit development, the team conducted a mixing zone analysis to evaluate the behavior of discharge plumes from the industrial outfall in Tipalao Bay, Guam. The team selected the mixing zone model CORMIX (v7.0GT, Mixzone, 2011) to evaluate the behavior of the discharge.

\subsection{DISCHARGE LOCATION}

The discharge is located at approximately $13^{\circ} 24.916^{\prime} \mathrm{N}, 144^{\circ} 38.637^{\prime} \mathrm{E}$ (WGS 84 Datum) along the western coast of Guam (Figure 2-1).

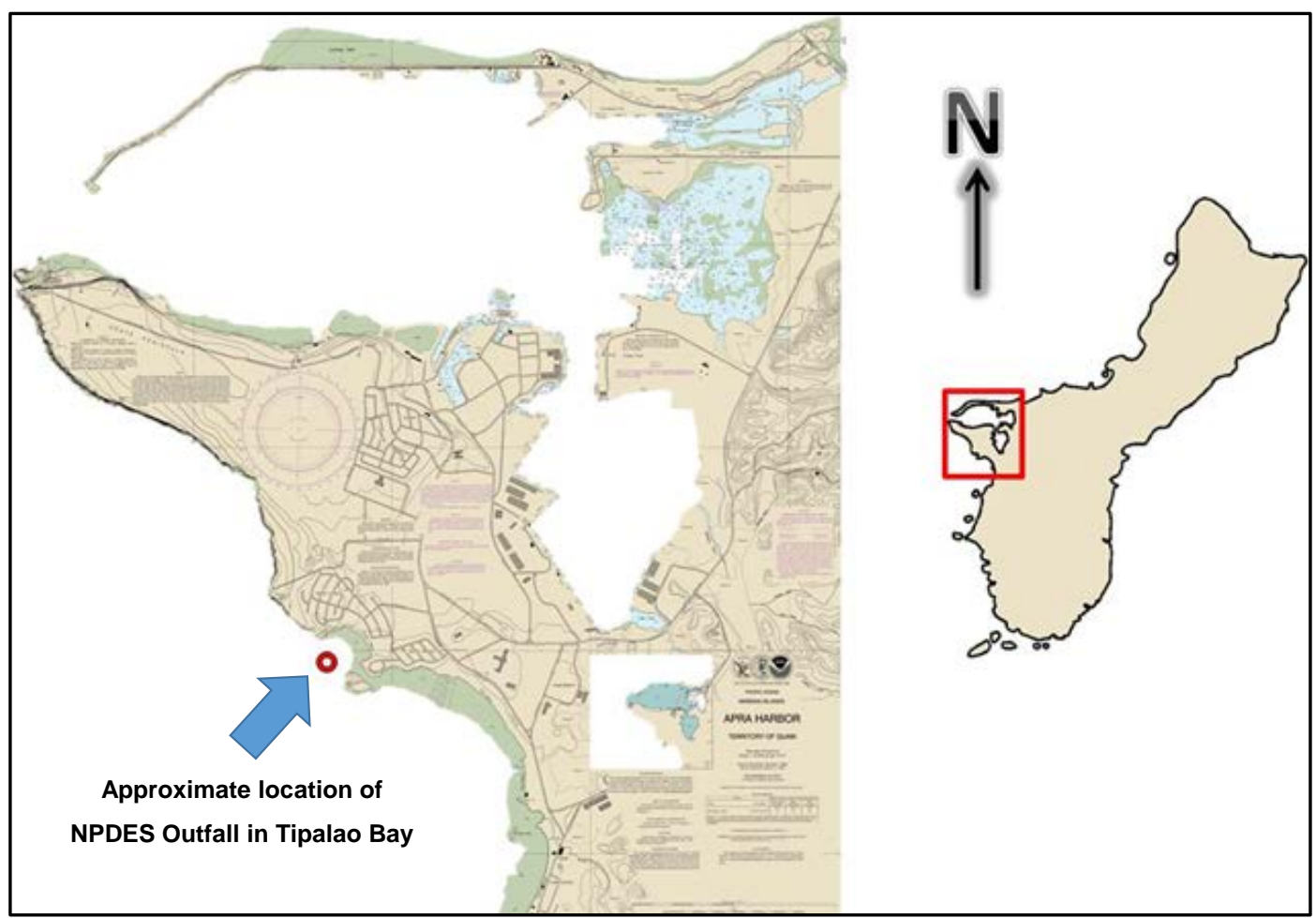

Figure 2-1. Detailed location of NPDES outfall in Tipalao Bay, Guam (NOAA, 2006).

\subsection{DISCHARGE MODELING}

CORMIX is a USEPA-supported mixing zone model and decision support system for environmental impact assessment of regulatory mixing zones resulting from continuous point source NPDES discharges. We used the CORMIX model (v7.0GT, Mixzone, 2011) to evaluate the discharge from the industrial outfall of the Apra Harbor WWTP. The CORMIX modeling framework simulates theoretical steady-state discharges using the existing data on the discharge geometry, effluents, ambient conditions, and discharge characteristics to estimate mixing zone dimensions needed to meet water quality standards. This modeling was supplemented by the deployment of an 
acoustic Doppler current profiler (ADCP) in the area of the discharge for a 37-day period to quantify ambient currents. The model emphasizes the role of boundary interaction to predict steady-state mixing behavior and plume geometry (Doneker and Jirka, 2007). The hypothetical simulations of discharges neglect the effects of tidal action, intermittent discharges, and complex topography and terrain present near the outfall. Therefore, the CORMIX results reported in this document are provided to inform the permit development process and do not represent actual conditions present in the receiving waters of Tipalao Bay. A combination of 12 CORMIX simulations were run for the outfall, evaluating three different ambient currents and four variable discharge flow rates (Table 2-1).

Table 2-1. Variables applied during CORMIX modeling runs for the Tipalao Bay outfall.

\begin{tabular}{|l|l|c|c|}
\hline \multicolumn{4}{|c|}{ Variables } \\
\hline Flow rate & & & \\
\hline & Minimum dry weather & 3.5 & $\mathrm{mgd}$ \\
\hline & Average dry weather & 6.6 & $\mathrm{mgd}$ \\
\hline & Peak dry weather flow & 12.1 & $\mathrm{mgd}$ \\
\hline Current speed & Maximum wet weather peak flow & 13.3 & $\mathrm{mgd}$ \\
\hline & $10^{\text {th }}$ percentile & & \\
\hline & $50^{\text {th }}$ percentile & 3.5 & $\mathrm{~cm} / \mathrm{sec}$ \\
\hline & $90^{\text {th }}$ percentile & 10.4 & $\mathrm{~cm} / \mathrm{sec}$ \\
\hline
\end{tabular}

\subsubsection{Baseline Modeling Parameters}

To account for the most environmentally conservative modeling results, the SSC Pacific team applied the following baseline parameters to each discharge simulation:

- Ambient wind speed (UW) was set to zero (0 m/s).

- All discharges simulations were designed to mimic the existing conditions associated with the current outfall and diffuser configuration currently installed in Tipalao Bay. All simulations discharge at 120-foot depth below the water's surface.

- The discharge was modeled as a freshwater/low salinity effluent, and the ambient receiving water salinity was set at $35 \mathrm{ppt}$ (CH2M Hill, 1992). The level of salinity has a direct influence on plume buoyancy and its associated behavior.

- The value of 0.02 was applied as a Darcy-Weisbach " $\mathrm{f";} \mathrm{this} \mathrm{is} \mathrm{a} \mathrm{mathematical} \mathrm{description}$ (Doneker and Jirka, 2007) of the relatively smooth, earthen bottom topography near the discharge at Tipalao Bay (CH2M Hill, 1992).

- Tipalao Bay was modeled as an unbounded water body. 
- Initial discharge concentrations of $11-\mu \mathrm{g} / \mathrm{L}$ copper and $27.5-\mu \mathrm{g} / \mathrm{L}$ nickel were utilized. These values represent the highest monthly average of DMR data from January 2003 until September 2005 (Guam EPA, 2009).

- CORMIX is not capable of modeling a single riser/dual port configuration with two ports parallel to the ocean bottom as currently exists for the Tipalao Bay outfall (Figure 2-2).

Therefore, after consultation with the Model developers, we modeled the worst-case configuration consisting of a single port riser pointing parallel to the surface with the discharge co-flowing with ambient currents. (Figure 2-3). In this hypothetical configuration, the discharge velocity is maintained constant for the most accurate, conservative results.(Doneker, 2013)

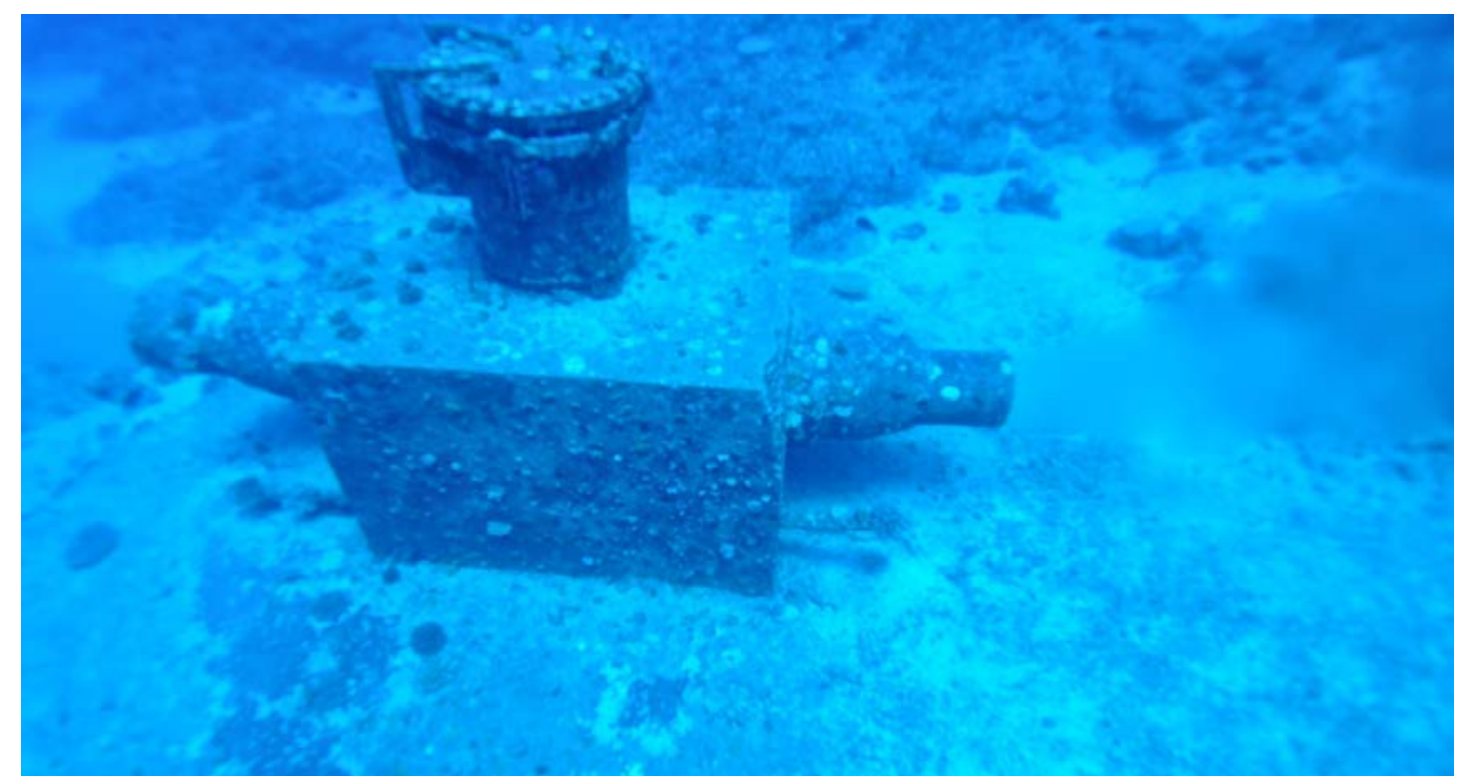

Figure 2-2. Existing outfall in Tipalao Bay. 


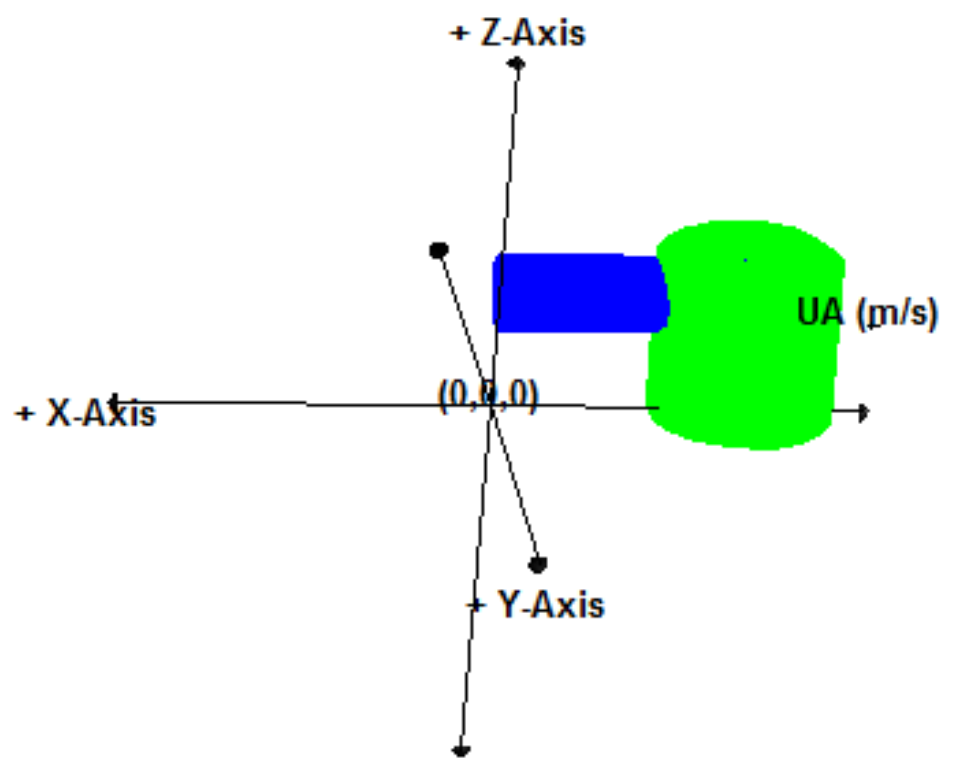

Figure 2-3. Conceptualized model of port configuration used in discharge analysis.

\subsection{VARIABLE DISCHARGE CONDITIONS}

\subsubsection{Currents}

The team obtained current velocity data during an ADCP current meter deployment in Tipalao Bay. The meter was deployed approximately 36 meters deep and 30 meters away from the outfall (i.e., out of any direct influence associated with the discharge) over 37 days. A total of 7751 measurements were collected over an entire lunar cycle to capture the full range of possible tidal impacts. The lower $10^{\text {th }}$ percentile observed current speed was $3.5 \mathrm{~cm} / \mathrm{sec}$, the $50^{\text {th }}$ percentile was $10.4 \mathrm{~cm} / \mathrm{sec}$, and the upper $90^{\text {th }}$ percentile current speed was $18 \mathrm{~cm} / \mathrm{sec}$ (Figure 2-4). These current velocities were applied in the modeling simulations and assumed to bracket the range of actual conditions, and therefore, represent the range of mixing present in the receiving waters of Tipalao Bay. Additionally, the lower $10^{\text {th }}$ percentile data matches very closely with a previous drogue study conducted by Duenas and Associates (CH2M Hill, 1992) that established a $3.0 \mathrm{~cm} / \mathrm{sec}$ current velocity as a $10^{\text {th }}$ percentile. 


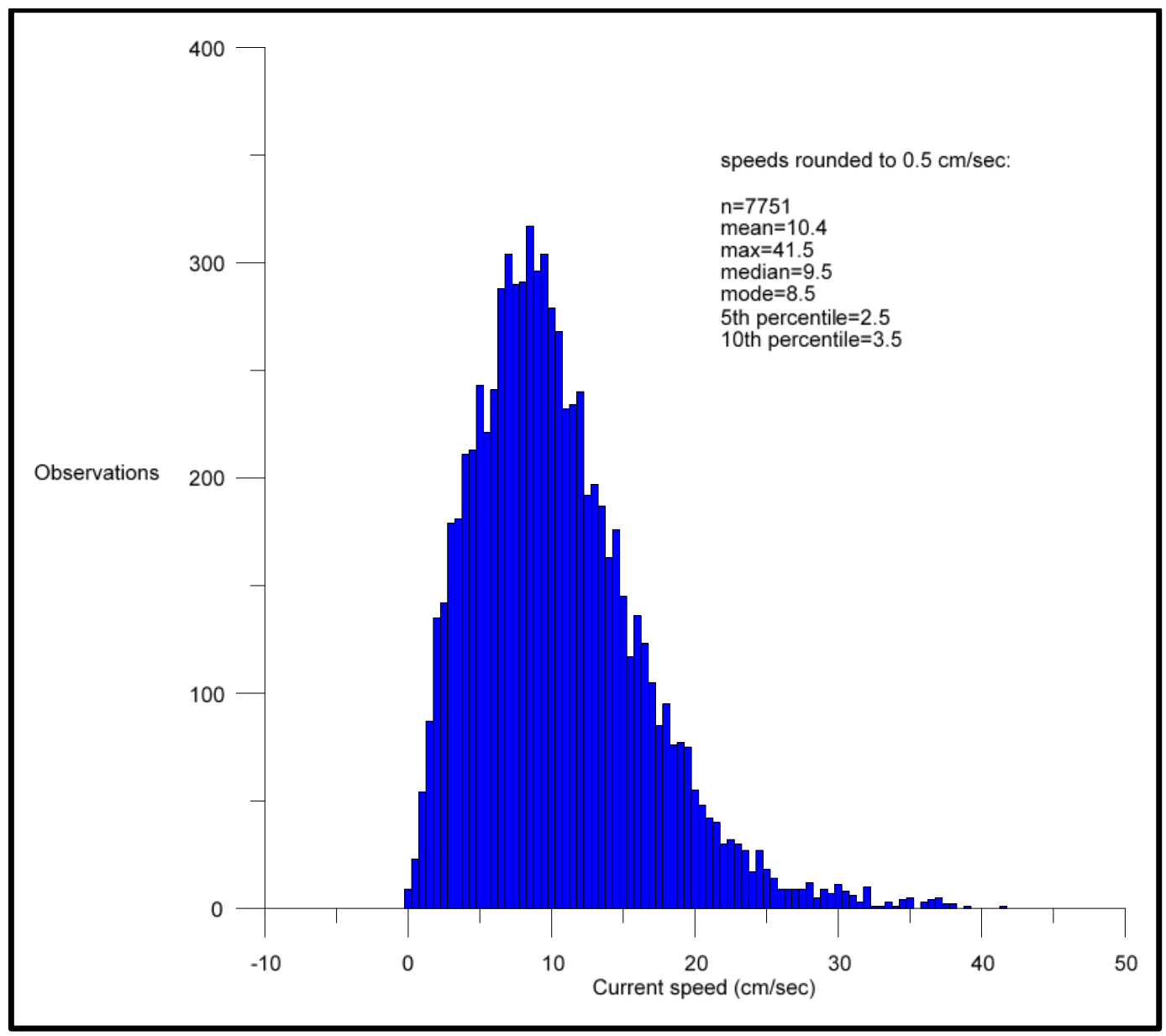

Figure 2-4. Water column ADCP meter observations in Tipalao Bay, Guam. 


\subsubsection{Effluent}

The team evaluated four effluent scenarios based on data from the 1995 mixing zone application for the Tipalao outfall (CH2M Hill, 1992), which correspond as follows:

- $\quad$ The minimum dry weather flow (3.5 MGD)

- $\quad$ The average dry weather flow (6.6 MGD)

- The peak dry weather flow (12.1 MGD)

In addition, the Guam Waterworks Authority recently established the maximum wet weather peak flow capability from all current and planned developments that will discharge through the combined outfall (GWA, 2015):

- The maximum wet weather peak flow (13.3 MGD)

\subsubsection{Endpoint Evaluation}

The team then compiled modeling results to determine the point of compliance, or the distance from the discharge origin required to meet various established criteria. The model simulates various concentrations and endpoints as they are input; however, the fundamental mixing that occurs is constant and the criteria serve as a point of comparison. Discharge concentrations of $11-\mu \mathrm{g} / \mathrm{L}$ copper and $27.5-\mu \mathrm{g} / \mathrm{L}$ nickel were utilized, as these values represent the highest reported monthly average from January 2003 until September 2005 (Guam EPA, 2009)

\subsection{RESULTS}

The Guam Water Quality Standards for mixing zone allowance establish that a mixing zone “...shall be equal in depth to the depth of the water over the diffuser, in width to twice the depth of the water plus the width of the diffuser, and in length to twice the depth of the water plus the length of the diffuser with the diffuser geographically centered within the mixing zone, but in no case shall the discharge be permitted into near shore water" (CH2M Hill, 1992).

Following this guideline, the configuration for the Apra Harbor Wastewater Discharge Mixing Zone consists of a cylinder that is 36.58 meters (120 feet) deep and 73.16 meters (240 feet) wide centered on the discharge.

The team used the CORMIX model to simulate 12 discharge scenarios for the Tipalao Bay outfall to assess mixing required to meet acute and chronic discharge limits for copper and nickel from the Apra Harbor WWTP. All current speeds allow CORMIX to generate physically realistic results and provided detailed information about the boundary conditions for mixing from the outfall within the limitations imposed by the CORMIX modeling framework. Model runs included considerations of the $10^{\text {th }}, 50^{\text {th }}$, and $90^{\text {th }}$ current speeds and four variable discharge volumes. Table 2-2 presents the dilution factors at the edge of the mixing zone utilizing the most variable model parameters described above. Considering all scenarios, the acute $10^{\text {th }}$ percentile current $(3.5 \mathrm{~cm} / \mathrm{sec})$ combined with the maximum wet weather peak flow (13.3 MGD) resulted in the least amount of mixing (39.2) at the edge of the 120 -foot mixing zone. This scenario is environmentally conservative because the conditions associated with a wet weather peak flow are associated with storm activity and the acute $10^{\text {th }}$ percentile current flow is not encountered during high storm activity.

The team performed additional analysis to provide a better understanding of the discharge environment. Results show that for any combination of variables, the water quality standards for copper and nickel will be achieved well within the established mixing zone. Table 2-3 and Table 2-4 present results including initial discharge concentrations, flow rates, current speed, and the plume 
dimensions associated with each model run. The dimensions given are the centerline concentration of the plume given as $\mathrm{x}, \mathrm{y}$ (linear) and $\mathrm{z}$ (depth) coordinates, the calculated trajectory from the port opening to the specific endpoint, and the associated dilution factor at the water quality criterion for copper and nickel. The longest modeled distance, 8.95 meters (29.36 feet) (Run \#10C Table 2-3), was calculated to achieve compliance with the water quality standard for copper and consisted of the low $10^{\text {th }}$ percentile current and the maximum wet weather peak flow. Model results indicate that effluent concentrations would have to increase by (approximately) an order magnitude of the concentrations modeled to impact water quality beyond the established 120-foot mixing zone.

Considering normal conditions expected daily (average dry weather flow, the $50^{\text {th }}$ percentile ambient current, and the highest average discharge concentrations), the predicted water quality criteria for copper are met within $6.2 \mathrm{~m}$ (20.6 feet) of the outfall diffuser (Run \#5C, Table 2-3), and water quality criteria for nickel are met within 3.12 meters (10.24 feet) of the outfall diffuser (Run \#5N, Table 2-4).

Figure 2-5 through Figure 2-8 present the results for all model runs associated with the edge of the 120-foot mixing zone. The CORMIX program files (CMX) and prediction files (PRD) are available in Appendix A.

Table 2-2. Dilution factor at the edge of the 120-foot (36.57-meter) mixing zone considering variable current speed and discharge rates.

\begin{tabular}{|c|c|c|}
\hline \hline & Dilution Factor & Distance (meters) \\
\hline \hline \multicolumn{3}{|c|}{3.5 MGD - Minimum dry weather flow } \\
\hline $3.5 \mathrm{~cm} / \mathrm{sec}$ & 77.3 & 36.57 \\
\hline $9.5 \mathrm{~cm} / \mathrm{sec}$ & 112.7 & 36.57 \\
\hline $18.0 \mathrm{~cm} / \mathrm{sec}$ & 150.8 & 36.57 \\
\hline \multicolumn{3}{|c|}{$6.6 \mathrm{MGD}$ - Average dry weather flow } \\
\hline $3.5 \mathrm{~cm} / \mathrm{sec}$ & 54.6 & 36.57 \\
\hline $9.5 \mathrm{~cm} / \mathrm{sec}$ & 69.6 & 36.57 \\
\hline $18.0 \mathrm{~cm} / \mathrm{sec}$ & 92.2 & 36.57 \\
\hline \multicolumn{3}{|c|}{$12.1 \mathrm{MGD}-$ Peak dry weather flow } \\
\hline $3.5 \mathrm{~cm} / \mathrm{sec}$ & 40.4 & 36.57 \\
\hline $9.5 \mathrm{~cm} / \mathrm{sec}$ & 45.5 & 36.57 \\
\hline $18.0 \mathrm{~cm} / \mathrm{sec}$ & 56.2 & 36.57 \\
\hline \multicolumn{3}{|c|}{$13.3 \mathrm{MGD}-$ Maximum wet weather flow } \\
\hline $3.5 \mathrm{~cm} / \mathrm{sec}$ & 33.0 & 36.57 \\
\hline $9.5 \mathrm{~cm} / \mathrm{sec}$ & 35.3 & 36.57 \\
\hline $18.0 \mathrm{~cm} / \mathrm{sec}$ & 41.8 & 36.57 \\
\hline
\end{tabular}


Table 2-3. Model results for copper discharge simulations establishing minimum distance required to meet compliance endpoints.

\begin{tabular}{|c|c|c|c|c|c|c|c|c|c|c|}
\hline \multirow{2}{*}{$\begin{array}{c}\text { Run } \\
\text { number }\end{array}$} & \multirow{2}{*}{$\begin{array}{c}\text { Effluent } \\
\text { Discharge } \\
\text { Conc. (ppb) }\end{array}$} & \multirow{2}{*}{$\begin{array}{l}\text { Flow } \\
\text { Rate } \\
\text { MGD } \\
\end{array}$} & \multirow{2}{*}{$\begin{array}{l}\begin{array}{l}\text { Current } \\
\text { Speed }\end{array} \\
\mathrm{cm} / \mathrm{sec} \\
\end{array}$} & \multirow{2}{*}{$\begin{array}{l}\text { CMC } \\
\text { Value }\end{array}$} & \multirow{2}{*}{$\begin{array}{l}\text { CCC } \\
\text { Value }\end{array}$} & \multicolumn{5}{|c|}{ Plume dimensions (Meters) using 2.9 WQC in Permit } \\
\hline & & & & & & $\mathrm{x}$ & $\mathrm{y}$ & z & Distance & $\mathrm{DF}$ \\
\hline $1 \mathrm{C}$ & 11 & 3.5 & 3.5 & 4.1 & 2.9 & 3.44 & 0 & 4.11 & 4.70 & 3.8 \\
\hline $2 \mathrm{C}$ & 11 & 3.5 & 9.5 & 4.1 & 2.9 & 3.6 & 0 & 3.62 & 4.50 & 3.8 \\
\hline $3 \mathrm{C}$ & 11 & 3.5 & 18 & 4.1 & 2.9 & 3.68 & 0 & 2.87 & 4.17 & 3.8 \\
\hline $4 \mathrm{C}$ & 11 & 6.6 & 3.5 & 4.1 & 2.9 & 5.64 & 0 & 4.17 & 6.51 & 3.8 \\
\hline $5 \mathrm{C}$ & 11 & 6.6 & 9.5 & 4.1 & 2.9 & 5.67 & 0 & 3.62 & 6.28 & 3.8 \\
\hline $6 \mathrm{C}$ & 11 & 6.6 & 18 & 4.1 & 2.9 & 5.62 & 0 & 2.92 & 5.97 & 3.8 \\
\hline $7 \mathrm{C}$ & 11 & 12.1 & 3.5 & 4.1 & 2.9 & 8.17 & 0 & 3.64 & 8.61 & 3.8 \\
\hline $8 \mathrm{C}$ & 11 & 12.1 & 9.5 & 4.1 & 2.9 & 8.02 & 0 & 3.15 & 8.33 & 3.8 \\
\hline $9 \mathrm{C}$ & 11 & 12.1 & 18 & 4.1 & 2.9 & 7.8 & 0 & 2.64 & 7.99 & 3.8 \\
\hline $10 \mathrm{C}$ & 11 & 13.3 & 3.5 & 4.1 & 2.9 & 8.57 & 0 & 3. 51 & 8.95 & 3.8 \\
\hline $11 \mathrm{C}$ & 11 & 13.3 & 9.5 & 4.1 & 2.9 & 8.38 & 0 & 3.04 & 8.65 & 3.8 \\
\hline $12 \mathrm{C}$ & 11 & 13.3 & 18 & 4.1 & 2.9 & 8.15 & 0 & 2.57 & 8.32 & 3.8 \\
\hline
\end{tabular}


Table 2-4. Model results for nickel discharge simulations establishing minimum distance required to meet compliance endpoints.

\begin{tabular}{|c|c|c|c|c|c|c|c|c|c|c|}
\hline \multirow{2}{*}{$\begin{array}{c}\text { Run } \\
\text { number }\end{array}$} & \multirow{2}{*}{$\begin{array}{c}\text { Effluent } \\
\text { Discharge } \\
\text { Conc. (ppb) } \\
\end{array}$} & \multirow{2}{*}{\begin{tabular}{|l|}
$\begin{array}{l}\text { Flow } \\
\text { Rate }\end{array}$ \\
MGD \\
\end{tabular}} & \multirow{2}{*}{\begin{tabular}{|c|}
$\begin{array}{l}\text { Current } \\
\text { Speed }\end{array}$ \\
$\mathrm{cm} / \mathrm{sec}$ \\
\end{tabular}} & \multirow{2}{*}{$\begin{array}{l}\text { CMC } \\
\text { Value } \\
\end{array}$} & \multirow{2}{*}{$\begin{array}{l}\text { CCC } \\
\text { Value }\end{array}$} & \multicolumn{5}{|c|}{ Plume dimensions (Meters)- using 8.29 WQC in Permit } \\
\hline & & & & & & $\mathbf{x}$ & $y$ & $\mathbf{z}$ & Distance & DF \\
\hline $1 \mathrm{~N}$ & 27.5 & 3.5 & 3.5 & 20.5 & 8.29 & 3.31 & 0 & 3.67 & 4.31 & 3.3 \\
\hline $2 \mathrm{~N}$ & 27.5 & 3.5 & 9.5 & 20.5 & 8.29 & 3.42 & 0 & 3.23 & 4.13 & 3.3 \\
\hline $3 \mathrm{~N}$ & 27.5 & 3.5 & 18 & 20.5 & 8.29 & 3.45 & 0 & 2.59 & 3.84 & 3.3 \\
\hline $4 \mathrm{~N}$ & 27.5 & 6.6 & 3.5 & 20.5 & 8.29 & 5.37 & 0 & 3.62 & 6.01 & 3.3 \\
\hline $5 \mathrm{~N}$ & 27.5 & 6.6 & 9.5 & 20.5 & 8.29 & 5.35 & 0 & 3.15 & 5.80 & 3.3 \\
\hline $6 \mathrm{~N}$ & 27.5 & 6.6 & 18 & 20.5 & 8.29 & 5.26 & 0 & 2.6 & 5.52 & 3.3 \\
\hline $7 \mathrm{~N}$ & 27.5 & 12.1 & 3.5 & 20.5 & 8.29 & 7.63 & 0 & 3.04 & 7.92 & 3.3 \\
\hline $8 \mathrm{~N}$ & 27.5 & 12.1 & 9.5 & 20.5 & 8.29 & 7.45 & 0 & 2.66 & 7.65 & 3.3 \\
\hline $9 \mathrm{~N}$ & 27.5 & 12.1 & 18 & 20.5 & 8.29 & 3.3 & 0 & 2.27 & 3.57 & 3.3 \\
\hline $10 \mathrm{~N}$ & 27.5 & 13.3 & 3.5 & 20.5 & 8.29 & 7.96 & 0 & 2.90 & 8.21 & 3.3 \\
\hline $11 \mathrm{~N}$ & 27.5 & 13.3 & 9.5 & 20.5 & 8.29 & 7.77 & 0 & 2.55 & 7.94 & 3.3 \\
\hline $12 \mathrm{~N}$ & 27.5 & 13.3 & 18 & 20.5 & 8.29 & 7.55 & 0 & 2.21 & 7.66 & 3.3 \\
\hline
\end{tabular}




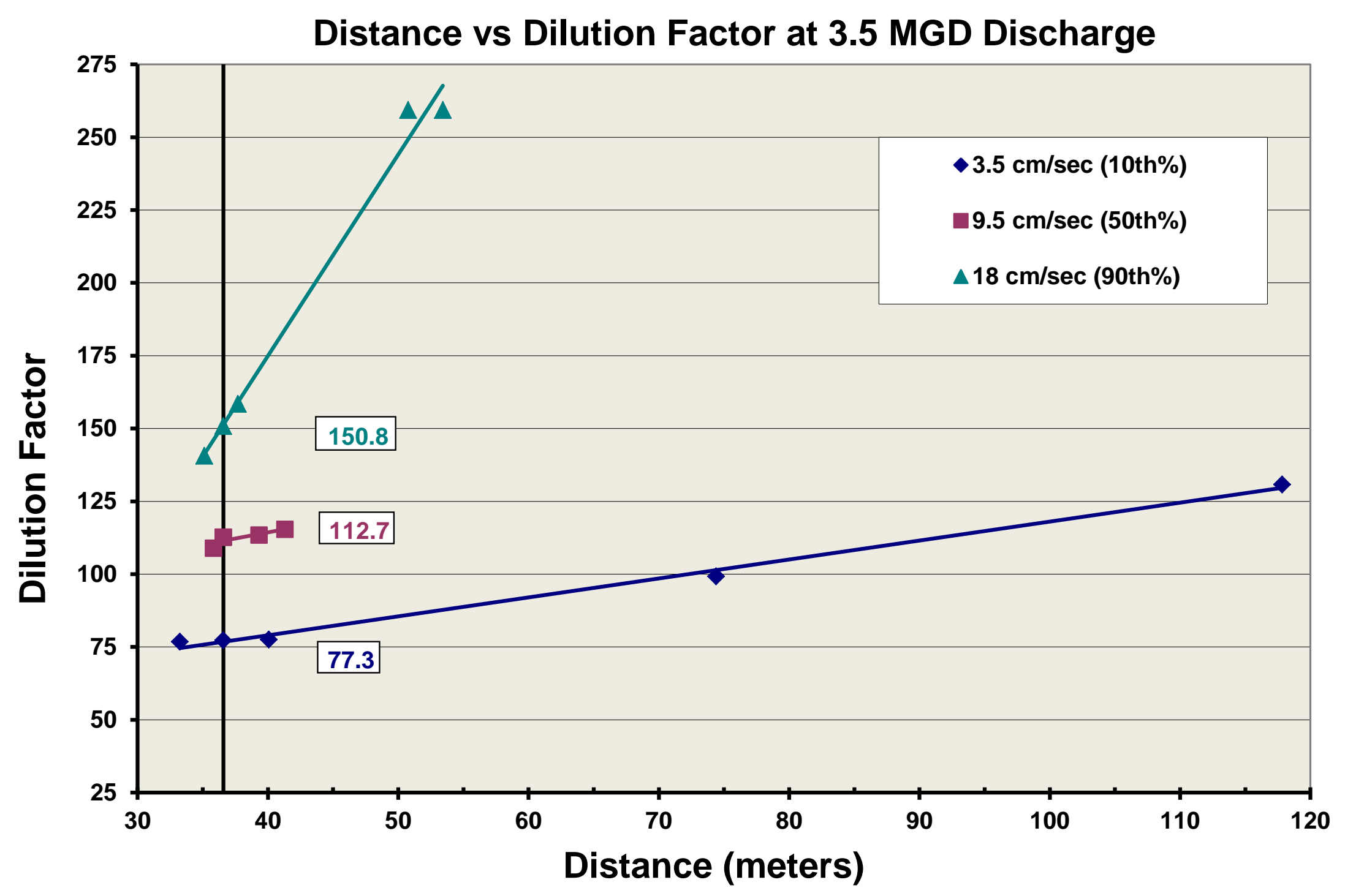

Figure 2-5. Dilution factors associated with a 3.5-mpg flow considering variable current speeds. 


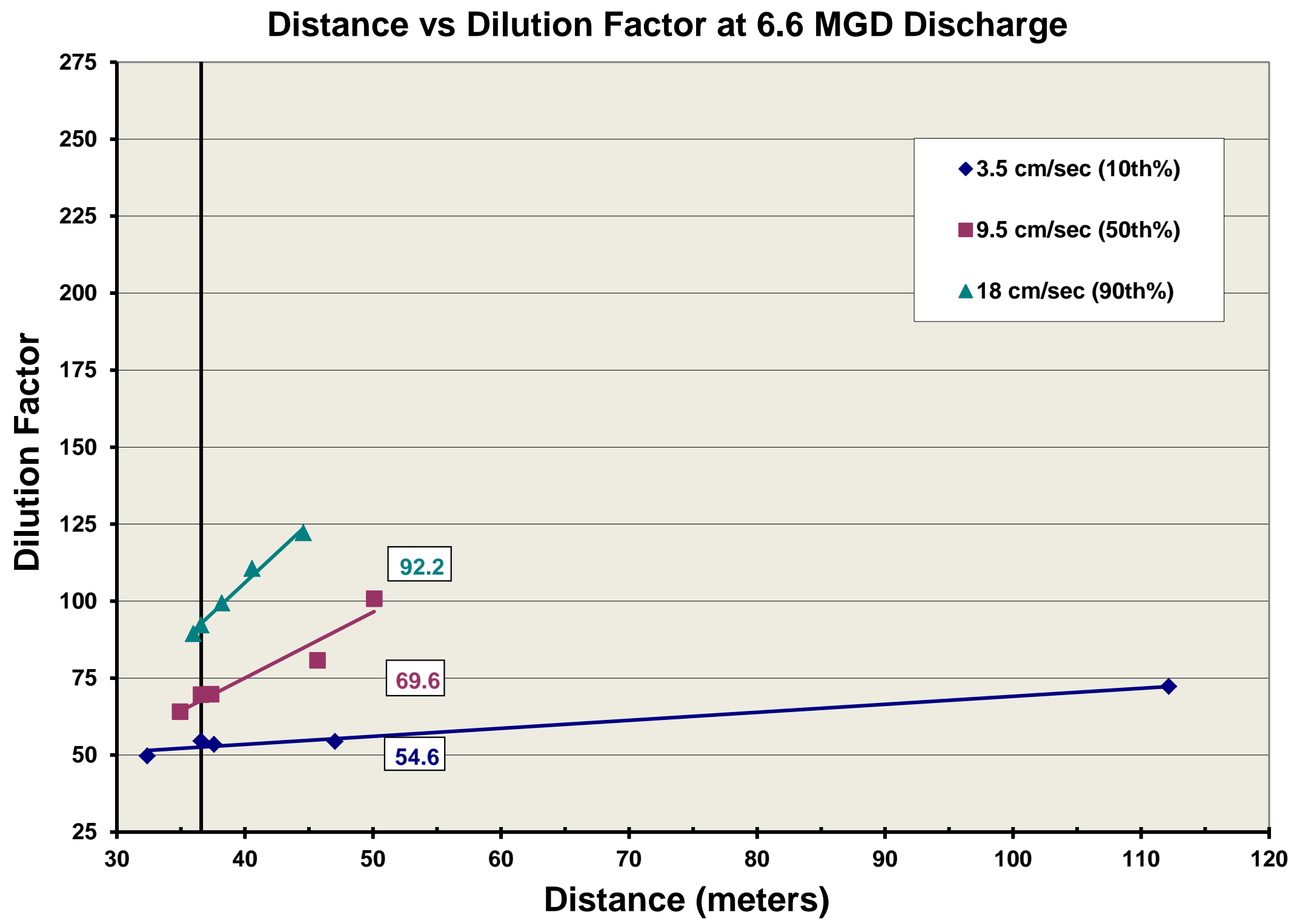

Figure 2-6. Dilution factors associated with a 6.6-mpg flow considering variable current speeds. 


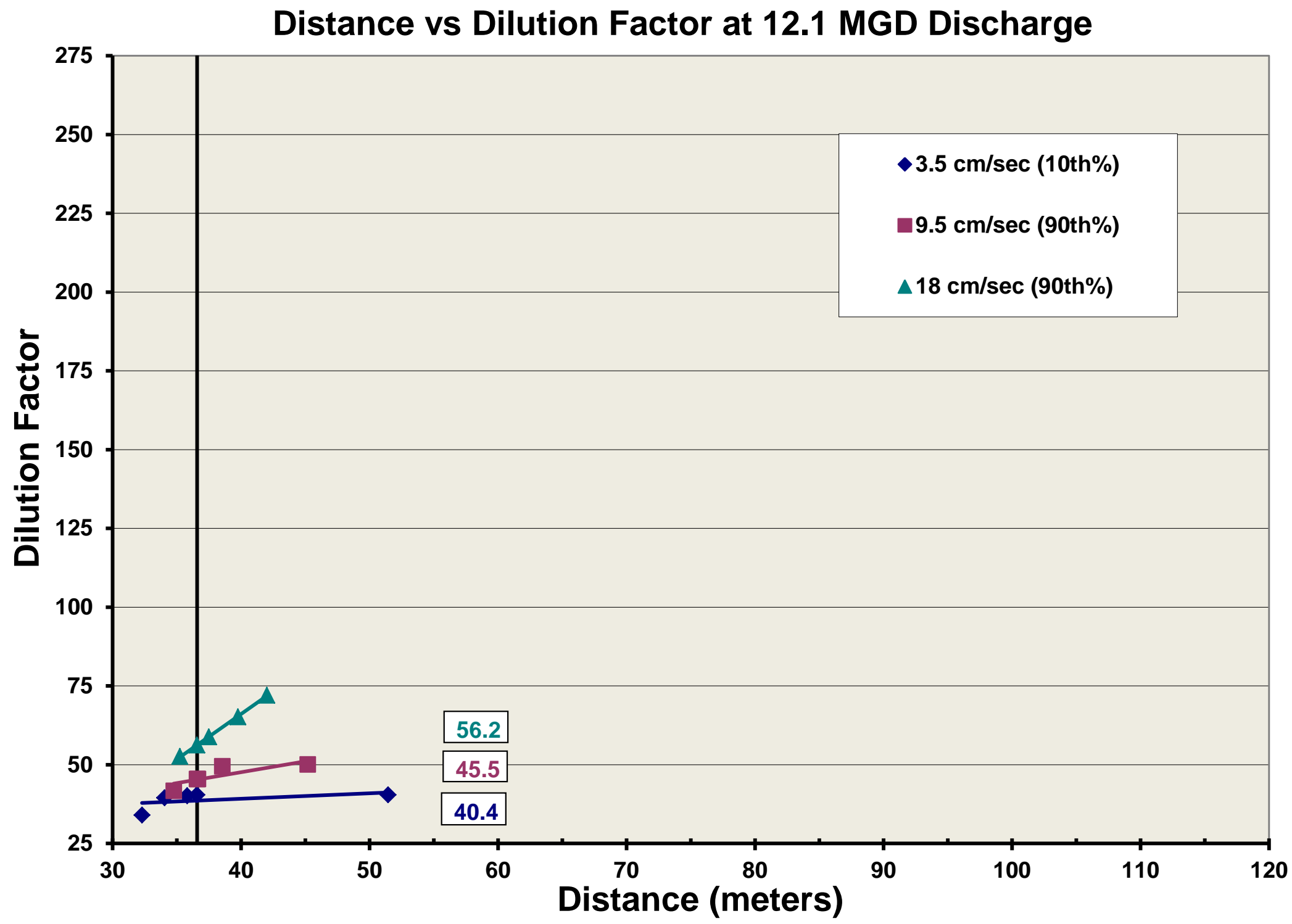

Figure 2-7. Dilution factors associated with a 12.1-mpg flow considering variable current speeds. 


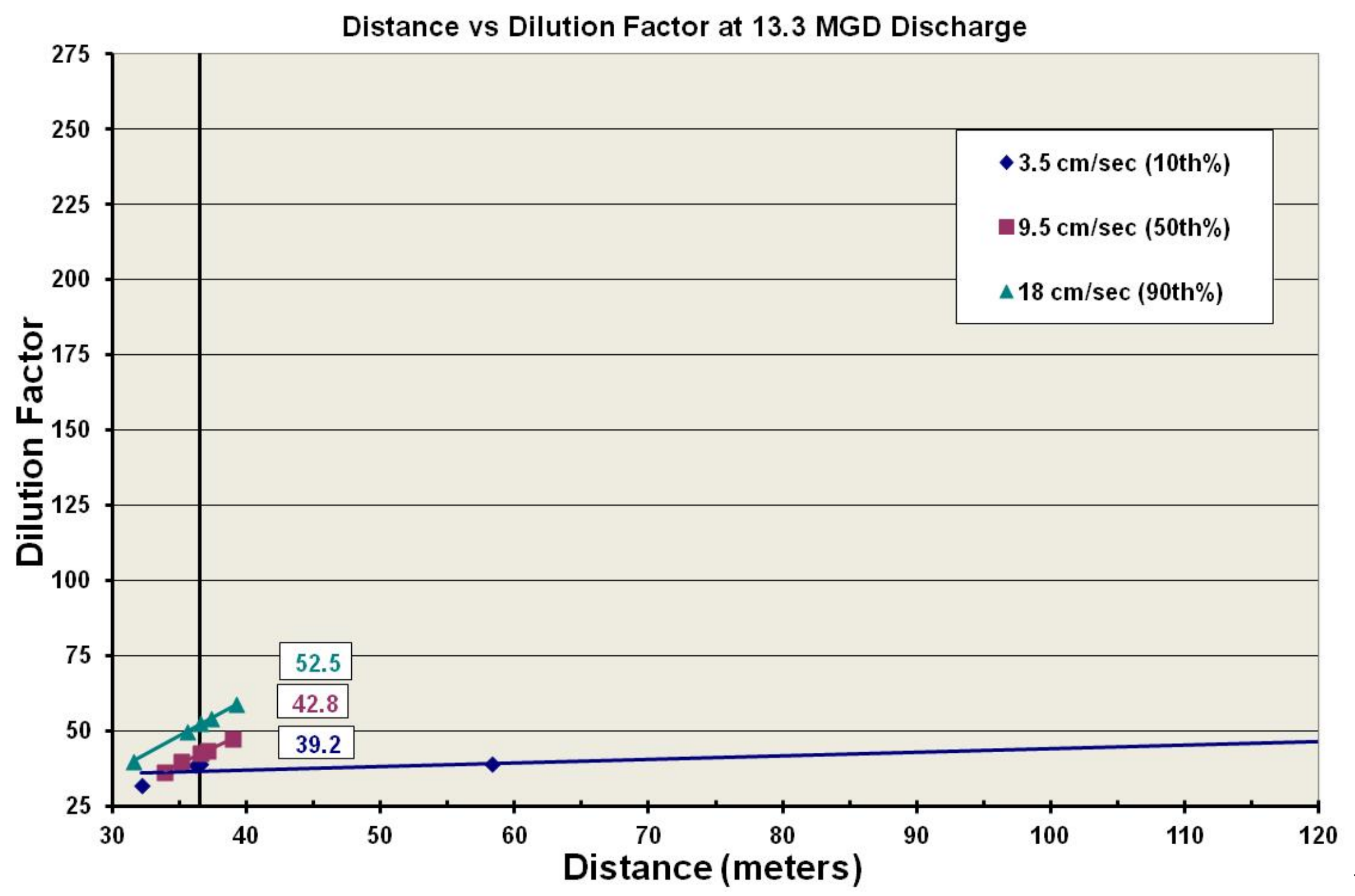

Figure 2-8. Dilution factors associated with a 13.3-mpg flow considering variable current speeds. 


\subsection{CONCLUSIONS}

The team applied the CORMIX modeling framework to simulate mixing characteristics for the discharge from the Apra Harbor WWTP in Agat, Guam, into the waters of Tipalao Bay. We used the results from an ADCP current meter deployment adjacent to the outfall to evaluate long-term current dynamics near the outfall. We used the CORMIX model to simulate 12 discharge scenarios for the outfall to assess the mixing required to meet acute and chronic limits for the discharge of copper and nickel. The mixing zone analysis provides a range of dilution trajectories for the outfall that site managers can use to support setting discharge limits under the NPDES.

Following Guam EPA guidance (Guam EPA, 2001), a mixing zone allowance at the edge of a 120 -foot zone around the discharge establishes a minimal dilution factor of 39.2, considering environmentally conservative parameters associated with the site. Combining the highest measured discharge concentrations with the lowest ambient current flow and the highest discharge flow rate generates the worst-case scenario. Note that using these parameters is conservative because it is extremely unlikely to encounter a high discharge rate (indicative of a significant wet weather storm event) without significant ambient currents (as opposed to the $10^{\text {th }}$ percentile current speed).

Additional analysis captured the conditions for any combinations of ambient currents and discharge rates, and demonstrated that water quality standards for copper and nickel will be achieved well within the allowed mixing zone of 120 feet. This section only addressed this nominal value or the MZ component of the permit limit equation (Equation 1-1). These results utilize the current Guam EPA criteria for comparison endpoints and do not include the additional efforts to adjust site-specific criteria described within this document, which EPA should consider for any final permit limits. 


\section{RECALCULATION OF A SITE-SPECIFIC COPPER WATER QUALITY STANDARD FOR THE MARIANAS REGION}

This Recalculation Procedure followed USEPA guidance (USEPA, 1994a) to adjust the current national recommended WQC for copper using a step-wise method that involves corrections, additions, and deletions to the national toxicity data set, rendering it more representative of species occurring at the site. The procedure addresses an outdated USEPA-recommended criterion of 3.1- $\mu \mathrm{g} / \mathrm{L}$ dissolved copper (USEPA, 1995a) that is the basis of the existing permit limit of $2.9 \mu \mathrm{g} / \mathrm{L}$ (total recoverable) (Guam EPA 2001). Using the procedures documented herein, a site-specific Criterion Maximum Concentration (CMC; acute) of 8.20- $\mu \mathrm{g} / \mathrm{L}$ copper (dissolved) and a site-specific Criterion Chronic Concentration (CCC; chronic) of 4.10- $\mu \mathrm{g} / \mathrm{L}$ copper (dissolved) were determined to be protective of aquatic life in marine waters of Guam. Using the USEPA's default dissolved: total recoverable copper ratio of $83 \%$ (USEPA, 1995a), this equates to acute and chronic criteria of 9.9 and $4.9 \mu \mathrm{g} / \mathrm{L}$, respectively.

\subsection{CURRENT CALCULATION}

The team derived the current criterion using USEPA guidelines (USEPA, 1985), which involved calculating a Final Acute Value (FAV) based on the number of genera in the data set and the toxicity values for the four most sensitive genera in that data set (Table 3-1). The resulting FAV of 10.39 $\mu \mathrm{g} / \mathrm{L}$ was above the genus mean acute value (GMAV) for the blue mussel Mytilus; therefore, it was lowered to $9.625 \mu \mathrm{g} / \mathrm{L}$ to protect this commercially important species, as dictated by the guidelines (USEPA, 1985). We then obtained the acute criterion by dividing the Mytilus GMAV (normally, it is the FAV) by 2, and the chronic criterion by dividing the FAV by a Final Acute-to-Chronic Ratio (FACR). We calculated the FACR of 3.127 as the geometric mean of mean acute-to-chronic ratios (ACRs) for four genera: Daphnia, Gammarus, Physa, and Mysidopsis.

Table 3-1. Genus mean acute values for the four most sensitive species in the national data set for dissolved copper (USEPA, 1995a).

\begin{tabular}{|c|c|c|}
\hline \hline Sensitivity Rank & Genus & GMAV $(\mu \mathrm{g} / \mathrm{L})$ \\
\hline \hline 4 & Sea urchin, Arbacia & 21.40 \\
\hline 3 & Coot clam, Mulinia & 17.70 \\
\hline 2 & Summer flounder, Paralichthys & 11.56 \\
\hline 1 & Blue mussel, Mytilus & 9.625 \\
\hline
\end{tabular}

\subsection{UPDATED DATA SET AND DRAFT BLM-NORMALIZED CALCULATION}

The team compiled a more comprehensive national toxicity data set to support draft criteria recommendations for protection of aquatic life in ambient saltwater from acute and chronic toxic effects from copper (HDR | HydroQual, 2012). This data set included 67 genera in 51 families in the database, and was used in conjunction with a newly developed Biotic Ligand Model (Chadwick et al., 2008) to draft an updated BLM-based water quality criterion applicable to marine and estuarine waters. BLM-normalized species mean acute values (SMAVs) ranged from $8.48 \mu \mathrm{g} / \mathrm{L}$ for the most sensitive species, Mytilus edulis, to $19407 \mu \mathrm{g} / \mathrm{L}$ for the least sensitive species, Gammarus duebeni. Molluscs were among the most sensitive species, with M. edulis, M. galloprovincialis, Crassostrea 
gigas, and C. virginica ranked fourth among the five most sensitive species (Table 3-2). Invertebrates in general were more sensitive than fish, representing the 20 lowest SMAVs.

Table 3-2. BLM-normalized species mean acute values for the four most sensitive species in the updated national data set for dissolved copper (HDR | HydroQual, 2012).

\begin{tabular}{|c|l|c|}
\hline \hline Sensitivity Rank & \multicolumn{1}{|c|}{ Species } & SMAV $(\mu \mathrm{g} / \mathrm{L})$ \\
\hline \hline 4 & Eastern oyster, Crassostrea virginica & 12.31 \\
\hline 3 & Summer flounder, Paralichthys dentatus & 11.68 \\
\hline 2 & Mediterranean mussel, Mytilus galloprovincialis & 10.11 \\
\hline 1 & Blue mussel, Mytilus edulis & 8.54 \\
\hline
\end{tabular}

The updated data set resulted in a BLM-normalized saltwater dissolved copper FAV of $14.14 \mu \mathrm{g} / \mathrm{L}$ and CMC of 7.07 $\mu \mathrm{g} / \mathrm{L}$ (HDR | HydroQual, 2012). For tests conducted on metals with embryos and larvae of barnacles, bivalve mollusks, sea urchins, lobsters, crabs, shrimp, and abalones, the USEPA Guidelines recommend the assumption of an ACR of two. However, HDR | HydroQual (2012) noted that recent analysis of the steep dose-response associated with copper effects to Mytilus (a bivalve mollusk) revealed that dividing the GMAV by two is unnecessarily overprotective . Ratios of $\mathrm{EC}_{50} \mathrm{~S}$ to $\mathrm{EC}_{10}$ for Mytilus show that a geometric mean ratio of 1.2 can be applied to the GMAV to protect this species (HDR | HydroQual, 2012). $\mathrm{EC}_{10}$ values for sensitive mollusks are typically very close to $\mathrm{EC}_{50}$ values, and division by 1.2 is suitably protective in chronic exposures. The FAV divided by 2 is lower than the estimated $\mathrm{EC}_{10}$ for these sensitive invertebrates, including $M$. edulis, which is the lowest SMAV in the saltwater database (HDR | HydroQual, 2012). Therefore, the draft criterion proposed by HDR | HydroQual (2012) recommends that the BLM-normalized saltwater dissolved copper CCC be defined as the FAV $(14.14 \mu \mathrm{g} / \mathrm{L})$ divided by 2, or $7.07 \mu \mathrm{g} / \mathrm{L}$.

\subsection{METHODS}

USEPA had not yet approved the BLM-based methodology for non-freshwater WQC derivation, so we derived a site-specific WQC adjustment for copper at Guam and the Islands throughout the Marianas region, by combining the USEPA's Recalculation Procedure (USEPA, 1994a; USEPA, 1997b) with the 2012 data set. This procedure involved corrections, additions, and deletions that led to a data set that is more representative of the fauna present at the site. Once we made the appropriate modifications to the data set, we used USEPA guidelines (USEPA, 1985) to calculate a new criterion.

\subsubsection{Site-specific Data Set Modifications}

The team compiled species information for Guam from several sources, primarily volume 35 and 36 (July 2003) of the journal Micronesica. A complete listing of data sources and species occurrence utilized in this effort is in Appendix B. Species nomenclature follows that of the Integrated Taxonomic Identification System (ITIS) (http://www.itis.gov, accessed on 3 August 2012) to the maximum extent practicable.

\subsubsection{Species of Concern}

No Endangered Species Act (ESA)-listed fish or invertebrate species occur in the area of concern (FWS, 2012); however, several candidate species of coral (Brainard et al., 2011) and two fish species 
of concern, the bumphead parrotfish (Bolbometopon muricatum, also designated a candidate species) and the humphead wrasse (Cheilinus undulatus), are present (NOAA, 2012).

\subsubsection{Data Set Deletions}

No species were removed from the updated national data set for the following considerations:

\section{Blue Mussel (Mytilus edulis)}

This species does not occur in Guam; however, the data for $M$. edulis were not deleted from the updated national data set due to the presence of other genera of the family Mytilidae at Guam (Carpenter and Niem, 1998a; Paulay, 2003b). The updated data set's non-BLM-normalized SMAV is $7.41 \mu \mathrm{g} / \mathrm{L}$ (dissolved copper) for the larval life stage for this species. The updated national data set also contained an acute toxicity value of $122 \mu \mathrm{g} / \mathrm{L}$ (total copper) for juvenile M. edulis (Nelson, Miller, and Calabrese, 1988); however, this datum was not included in this effort due to the existence of data for the more sensitive life stage.

\section{Mediterranean Mussel (Mytilus galloprovincialis)}

This species does not occur at Guam; however, the data for M. galloprovincialis were not deleted from the updated national data set due to the presence of other genera of the family Mytilidae at Guam (Carpenter and Niem, 1998a; Paulay, 2003b). The updated data set's non-BLM-normalized SMAV is $18.32 \mu \mathrm{g} / \mathrm{L}$ (dissolved copper) for this species.

\section{Pacific Oyster (Crassostrea gigas)}

This species was introduced into the Marianas Islands for culture purposes but is likely extirpated, possibly due to sustained high temperatures in the waters around Guam and the Marianas Islands (Braley, 1984; Carpenter and Niem, 1998a; Paulay, 2003b). The data for C. gigas were not deleted from the updated national data set due to the presence of other genera of the family Ostreidae at Guam (Carpenter and Niem, 1998a; Denton et al., 1999; Paulay, 2003b). The updated data set's nonBLM-normalized SMAV is $12.22 \mu \mathrm{g} / \mathrm{L}$ (dissolved copper) for this species.

\section{Eastern Oyster (Crassostrea virginica)}

This species does not occur at Guam. The data for $C$. virginica were not deleted from the updated national data set due to the presence of other genera of the family Ostreidae at Guam (Carpenter and Niem, 1998a; Denton et al., 1999; Paulay, 2003b). The updated data set's non-BLM-normalized SMAV is $19.18 \mu \mathrm{g} / \mathrm{L}$ (dissolved copper) for this species.

\subsubsection{Data Set Additions}

The recalculation guidelines (USEPA, 1994a) provide the option of submitting additional toxicity data for consideration by USEPA, which is especially important where critical (i.e., endangered, threatened, or commercially or recreationally important) species are concerned. We based the addition of toxicity data for resident species at Guam on their presence in the water body and relevancy based on the guidelines (USEPA, 1985).

Five species were added to the data set based on their reported presence at Guam, ecological or economic significance, and the availability of relevant toxicity data that meets USEPA requirements (USEPA, 1985). The added species are Penaeus monodon (tiger shrimp), Scylla serrata (mud crab), and Liza vaigiensis (diamond-scaled mullet), Hawaiian collector urchin (Tripneustes gratilla), and lace coral (Pocillopora damicornis). The latter two species were also included in a prior WQC recalculation effort undertaken for Pearl Harbor, Hawaii (Earley et al., 2007). None of these species are currently listed as endangered or threatened under the ESA. 


\section{Tiger Shrimp (Penaeus monodon)}

This species is widely distributed in the Indo-West Pacific, including Guam and the Marianas Islands (Paulay et al., 2003), from the eastern coast of Africa to the Red Sea, Japan, Australia, and Fiji. It inhabits waters from the coastline to depths of about 150 meters, usually less than 30 meters, on bottoms of sand, mud, or silt. Juveniles usually inhabit seagrass beds, mangrove swamps, and estuaries. This species is of major economic importance, both as a fishery and as an aquaculture resource (Carpenter and Niem, 1998b).

Chen and Lin (2001) reported the results of a study to determine the acute and chronic toxicity of copper sulfate for juveniles of Penaeus monodon. They reported the 96-hour median lethal concentrations ( $\mathrm{LC}_{50}$ ) of copper on juvenile P. monodon as 3130 and $7730 \mu \mathrm{g} / \mathrm{L}$ in seawater of 15\%o (i.e., PSU) and 25\%, respectively. During longer term tests, the 30-day $\mathrm{EC}_{50}$ (concentration that resulted in a $50 \%$ reduction of weight gain relative to the controls) and 60 -day $\mathrm{EC}_{50}$ were reported at 2820- and 1890- $\mu \mathrm{g} / \mathrm{L}$ copper, respectively (Chen and Lin, 2001). Because the data are apparently based on nominal concentrations, we used a 0.9 conversion factor (USEPA, 1995a) to calculate a dissolved SMAV of $4226.95 \mu \mathrm{g} / \mathrm{L}$, which we used as the GMAV in the site-specific data set.

\section{Mud Crab (Scylla serrata)}

The mud crab was originally thought to belong to a single, widely distributed species, Scylla serrata; however, it has recently been shown that the genus includes four species with a wide IndoWest Pacific distribution, including Guam and the Marianas Islands (Keenan, Davie, and Mann, 1966; Paulay, Knopp, Ng, and Eldredge, 2003). S. serrata prefers more oceanic waters, usually found just offshore on soft muddy bottoms. Species of Scylla are important aquaculture and fishery resources; and are collected mainly using trawls, traps, baited wire mesh pots, hooking, and by hand throughout their ranges. Mud crabs can be caught up to 50 kilometers offshore as they migrate there to spawn. The other three species of Scylla prefer mangroves in continental shelves with less saline waters. All species of Scylla dig deep burrows in mangroves and soft substrates in shallow or intertidal waters (Carpenter and Niem, 1998b).

Ramachandran, Patel, and Colbo (1997) reported a 48-hour copper EC $_{50}$ for S. serrata zoeae of $0.080 \mu \mathrm{g} / \mathrm{mL}(80 \mu \mathrm{g} / \mathrm{L})$. As this was based on nominal toxicant concentrations, a conversion factor of 0.9 (USEPA, 1995b) was used to calculate a dissolved SMAV of $72 \mu \mathrm{g} / \mathrm{L}$ and incorporated into the site-specific data set.

\section{Diamond-scale Mullet (Liza vaigiensis)}

Mullets (Mugilidae) occur in all tropical and temperate seas, usually near shore, frequently in brackish estuaries and occasionally in freshwater (Nelson, 2006). Several species are of moderate to major importance to large-scale, small-scale, and subsistence fisheries, and are frequently cultivated in ponds (Carpenter and Niem, 1999).

The diamond-scaled mullet is an important fishery resource, and is distributed throughout Guam and the Marianas Islands (Myers and Donaldson, 2003). The species commonly forms shoals along shallow coastal areas and protected sandy shores in lagoons, reef flats, estuaries, and coastal creeks. It is usually found within tidally influenced waters, but it may enter freshwater, ascending about 10 kilometers into rivers. Juveniles might be found in rice fields and mangroves. Spawning probably occurs at sea. It is usually caught in cast nets, stake nets, beach seines, and gill nets, and juveniles are a major seasonal fishery on Guam (Hensley and Sherwood, 1993; Carpenter and Niem, 1999; Amesbury and Hunter-Anderson, 2003). In Fiscal Year (FY) 2000, L. vaigiensis comprised 3\% of the total inshore harvest on Guam (DAWR, 2000). 
Toxicity tests with juvenile (15 to $20 \mathrm{~mm}$ ) L. vaigiensis conducted at salinities of 20\%o (brackish water) and 36\% (seawater) resulted in reported 96-hour dissolved copper $\mathrm{LC}_{50}$ values of $2650 \mu \mathrm{g} / \mathrm{L}$ and $2550 \mu \mathrm{g} / \mathrm{L}$, respectively (Denton and Burdon-Jones, 1986). The calculated SMAV was 2599.52 $\mu \mathrm{g} / \mathrm{L}$. These data were added to the site-specific data set.

\section{Collector Sea Urchin (Tripneustes gratilla)}

Tripneustes gratilla is a very common species of the Indo-Pacific region, including Guam and the Marianas Islands, living in bays and lagoons on various substrates (Clark, 1954; Clark and Rowe, 1971; Paulay, 2003a). Copper toxicity data are available for two different endpoints with this species: fertilization success and embryo-larval development.

USEPA finalized and published (USEPA, 2012) the fertilization success endpoint as a chronic whole effluent toxicity (WET) test. The successful use of this test method is reportedly complicated by such factors as satisfactory egg condition, organism availability, difficulty in attaining optimum sperm-to-egg ratios, and the potential for variability in results among test batches leading to false assessments of biological impacts (Vazquez, 2003). More importantly, this endpoint does not qualify for use in WQC development tests (Stephan et al., 1985) because tests with single-celled organisms are not considered acute tests.

Therefore, the available embryo-larval development data were used, as this endpoint is acknowledged as acceptable in the USEPA guidelines (Stephan et al., 1985). A mean $\mathrm{EC}_{50}$ value of 15.66$\mu \mathrm{g} / \mathrm{L}$ copper was reported in 96-hour exposures (Wagner and Nacci, 2012). The coefficient of variation for the three exposures was $4.33 \%$, suggesting low variability among the three experiments. Because the data are based on nominal concentrations, a 0.9 conversion factor (USEPA, 1995b) was used to calculate a dissolved concentration of $14.09 \mu \mathrm{g} / \mathrm{L}$, which was used as the GMAV in the sitespecific data set.

\section{Lace Coral (Pocillopora damicornis)}

Coral planulae survival has been used to a limited extent as an experimental toxicity test endpoint. Although adult corals have been reported as more sensitive than the planula larvae, assessment of death in adults is difficult (Esquivel, 1986) and no adult coral tests exist that satisfy the USEPA guidelines for deriving WQC (Stephan et al., 1985). Esquivel (1986) observed a total recoverable $\mathrm{EC}_{50}$ of $63-\mu \mathrm{g} / \mathrm{L}$ copper after a 96-hour static exposure to $P$. damicornis planula larvae at $27^{\circ} \mathrm{C}$.

Shorter exposures indicated less sensitivity, with 120-, 115-, and 90- $\mu$ g/L EC50 values after 12, 24, and 48 hours of exposure, respectively. The most sensitive result (96 hours) was added to the database. Because the data appear to be based on nominal concentrations, the 0.9 correction factor (USEPA, 1995b) was used to convert the $\mathrm{EC}_{50}$ to a dissolved concentration of $56.70 \mu \mathrm{g} / \mathrm{L}$.

\subsubsection{Recalculation Additions Considered, But Not Included}

Several species with limited available toxicity data were considered for addition but not added to the site-specific data set. These species are listed below with the associated reasons.

\section{Acropora longicyathus (Coral), Acropora. tenuis (Coral), Goniastrea retiformis (Coral) and Lobophytum compactum (Soft Coral)}

Toxicity data for several additional Scleractinian and Alcyonacean species were considered for addition to the site-specific data set. Reichelt-Brushett and Harrison (1999) showed a 50\% reduction in Goniastrea aspera (Faviidae, Scleractinia) fertilization success $\left(\mathrm{EC}_{50}\right)$ at $14.5-\mu \mathrm{g} / \mathrm{L}$ copper. Reichelt-Brushett and Harrison (2005) provided additional information showing a 50\% reduction in fertilization success $\left(\mathrm{EC}_{50}\right)$ in Goniastrea aspera, G. retiformis, Acropora tenuis, and A. longicyathus 
(Acroporidae, Scleractinia) at copper concentrations ranging from 15 to $40 \mu \mathrm{g} / \mathrm{L}$. A fertilization success EC50 of 261- $\mu \mathrm{g} / \mathrm{L}$ copper for the soft coral Lobophytum compactum (Alcyoniidae, Alcyonacea) was reported by Reichelt-Brushett and Michalek-Wagner (2005). As with the fertilization success endpoint of Tripneustes gratilla, this endpoint does not qualify for use in WQC development tests because tests with single-celled organisms are not considered acute tests. Therefore, these data were not considered for inclusion in the revised data set.

\section{Mangrove Oyster (Isognomon californicum)}

Mangrove oysters are small (up to 11/2 inches) bivalves that have characteristics of oysters and mussels. While five species of mangrove oysters (Isognomon ephippium, I. isognomum, I legumen, I. nucleus, and I. perna) have been recorded from Guam and the Marianas Islands, I. californicum has not (Paulay, 2003b). Isognomon shells were used by the prehistoric people of Guam and the Marianas Islands to make fishhooks, and fragments of the shells are found in virtually all coastal prehistoric (c. 3500 to 1000 years before present) sites of Guam (Amesbury, 1999; Amesbury and Hunter-Anderson, 2003; Amesbury and Hunter-Anderson, 2008).

Ringwood (1992) demonstrated successful use of embryos and larvae of I. californicum in 48-hour toxicity exposures with copper, and reported an embryo copper (total recoverable) EC $_{50}$ value of $7 \mu \mathrm{g} / \mathrm{L}$. However, no copper toxicity data for native Marianas Island species of Isognomon were found, so it was not considered as a substitute for other species of Ostreoida present in the updated national data set.

\section{Four-toothed Shore Crab (Paragrapsus quadridentatus)}

The Grapsoidea (Brachyura) is a large, widely-distributed group of crabs (at least 27 genera in six families) of shore and shallow water crabs, including some that inhabit freshwater or are semiterrestrial (Rathbun, 1918; Ng, Guinot, and Davies, 2008; ITIS Standard Report Page: Grapsoidea, http://www.itis.gov/servlet/SingleRpt/SingleRpt?search_topic=TSN\&search_value=206961, accessed 17 August 2012).

The four-toothed shore crab was considered as a possible surrogate for the numerous species of grapsoid crabs that occur at Guam and the Marianas Islands (Paulay et al., 2003). Acute toxicity tests carried out on the larvae of Paragrapsus quadridentatus resulted in a reported 96-hour LC50 value of $0.17 \mathrm{mg} / \mathrm{L} \mathrm{(=} 170 \mu \mathrm{g} / \mathrm{L}$ ) (Ahsanullah and Arnott, 1978); however, no copper toxicity data for native Marianas Island species were found, so $P$. quadridentatus was not added as a substitute for other species of Brachyura present in the updated national data set.

\section{Reef/Long-spined Sea Urchin (Diadema setosum)}

Diadema setosum is widely distributed throughout the Indo-Pacific region, including Guam and the Marianas Islands. It is commonly associated with coral reefs, but is also found on sand flats and in seagrass beds (Clark, 1925; Clark, 1954; Clark and Rowe, 1971; Paulay, 2003a).

Ramachandran et al. (1997) tested the toxicity of copper to gametes and four larval stages. The

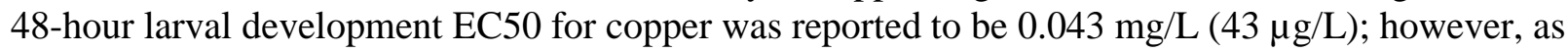
the copper concentration was nominal (not measured), the data was not selected as a replacement for the Diadema antillarum dissolved copper toxicity data present in the updated national data set.

\subsection{RESULTS}

The final data set consists of toxicity values for 83 species in 60 families (Figure 3-1). As the number of genera exceeded 59, the four genera in the site-specific data set that approximate the 5th percentile were used for recalculation efforts (Stephan et al., 1985). From the plot, the 5th percentile 
is approximately $16 \mu \mathrm{g} / \mathrm{L}$. The genera utilized for the recalculation efforts are listed in Table 3-3, and the entire data set is in Appendix B. Two of the four species are recorded from Guam, although it is possible that Crassostrea gigas has been extirpated from the waters around Guam and the Marianas Islands (Paulay, 2003b). The ranked data set used for the recalculation is provided in Appendix C.

Table 3-3. Non-BLM-normalized genus mean acute values for the four genera approximating the 5th percentile in the site-specific data set for dissolved copper.

\begin{tabular}{|c|l|c|}
\hline \hline Sensitivity Rank & \multicolumn{1}{|c|}{ Species } & GMAV $(\mu \mathrm{g} / \mathrm{L})$ \\
\hline \hline 5 & Purple/Green sea urchin, Strongylocentrotus spp. & 17.26 \\
\hline 4 & Long-spined sea urchin, Diadema antillarum & 16.58 \\
\hline 3 & Pacific/Eastern oyster, Crassostrea spp. & 15.70 \\
\hline 2 & Collector sea urchin, Tripneustes gratilla & 14.09 \\
\hline
\end{tabular}

For tests conducted on metals with embryos and larvae of barnacles, bivalves, sea urchins, lobsters, crabs, shrimp, and abalones, the guidelines (Stephan et al., 1985) recommend the assumption of an ACR of 2. The 1995 Saltwater Copper Addendum set a Final ACR of 3.127 (USEPA, 1995b); however, the draft 2012 update demonstrated that dividing the FAV by 2 was suitably protective of the most sensitive species (HDR | HydroQual, 2012). The 1995 Saltwater Copper Addendum also lowered the FAV from a calculated 10.39 to $9.625 \mu \mathrm{g} / \mathrm{L}$ to protect the commercially important species, Mytilus edulis; however, as the genus Mytilus does not occur in the waters around Guam and the Marianas Islands, the FAV calculated in this effort was not so amended.

Using the site-specific data set, a FAV of $16.4 \mu \mathrm{g} / \mathrm{L}$ was calculated in accordance with USEPA guidelines (Stephan et al., 1985). The FAV is calculated using a series of EPA-promulgated equations that incorporate the number of Genera represented and the magnitude of the GMAVs derived, with the most sensitive Genera (top four or five) being most heavily weighted. Utilizing the calculated FAV and the Stephan et al. (1985)/HDR | HydroQual (2012) ACR of 2, site-specific CMC (acute) and CCC (chronic) values of 8.20 and $4.10 \mu \mathrm{g} / \mathrm{L}$, respectively, were derived. The CMC of $8.20 \mu \mathrm{g} / \mathrm{L}$ was obtained by dividing the FAV $(16.4 \mu \mathrm{g} / \mathrm{L}$ ) by the 2 (as recommended by Stephan et al., 1985). The CCC of $4.10 \mu \mathrm{g} / \mathrm{L}$ was obtained by dividing the CMC by 2 (also recommended by Stephan et al., 1985) 


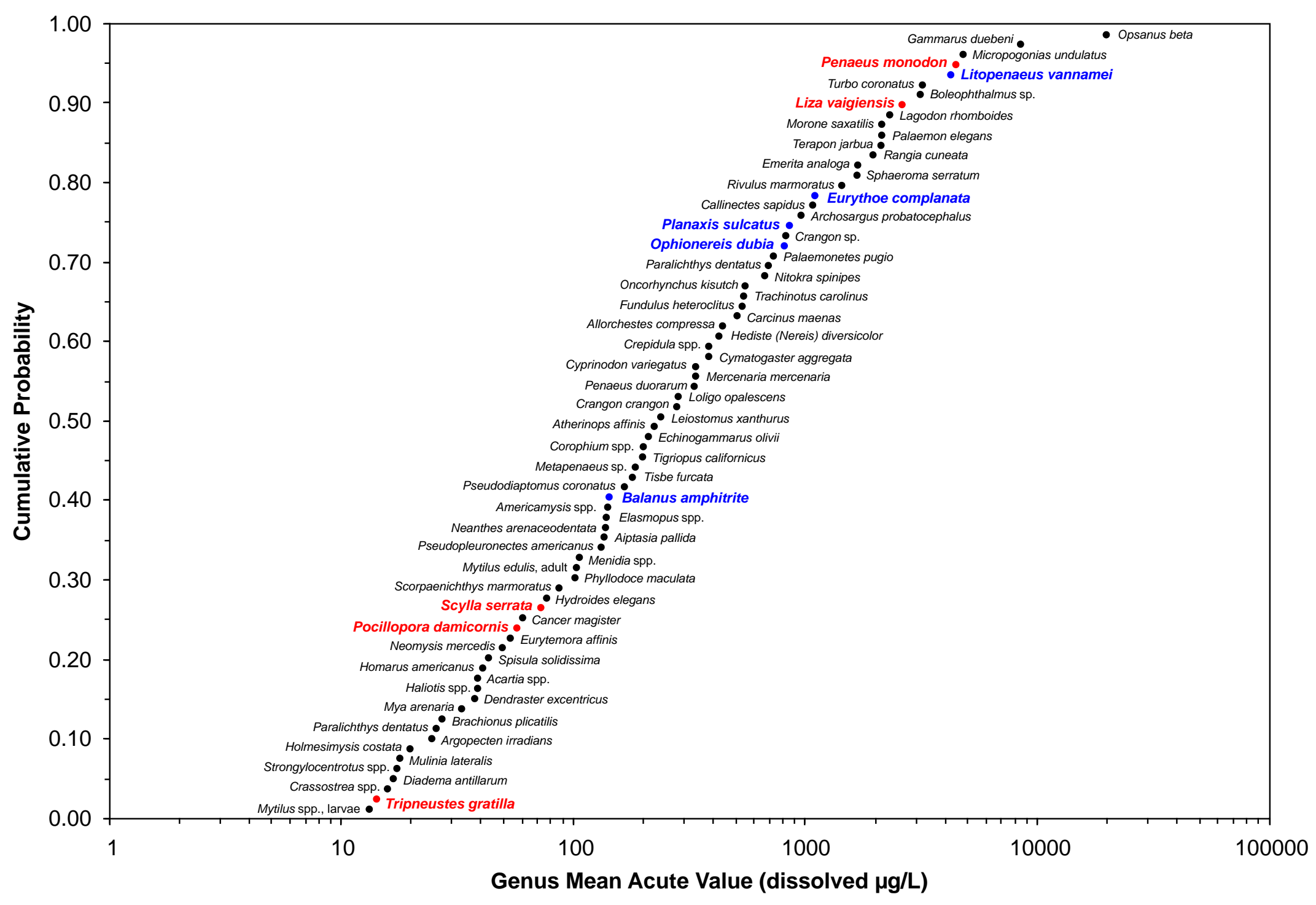

Figure 3-1. Cumulative toxicity probability: blue are species in national data set occurring at the site; red are site-specific additions. 


\section{RECALCULATION OF A SITE-SPECIFIC NICKEL WATER QUALITY STANDARD FOR THE MARIANAS REGION}

In 1986, the USEPA published recommended aquatic life criteria for nickel (Ni) in saltwater, which resulted in acute and chronic criteria of 75 and $8.3 \mu \mathrm{g}$ total $\mathrm{Ni} / \mathrm{L}$, respectively. Other than an update to express these guidelines as dissolved concentrations (74 and 8.2, $\mu \mathrm{g} / \mathrm{L}$, respectively), there has been no official update to that guidance, even though considerably more qualifying toxicity data are available. Some of the more recent contributions have been used to update the criterion include a peer-reviewed journal article that provides additional acute and chronic toxicity data, thereby updating the data set both in terms of numbers of genera represented, and towards calculation of a more robust acute-chronic ratio (Hunt et al., 2002). More recently, a study was conducted to develop a chronic species sensitivity distribution (SSD), further summarizing qualifying toxicity data that could be integrated into a USEPA standard (DeForest and Schlekat, 2013).

\subsection{CURRENT CALCULATION}

The current criterion was derived using USEPA guidelines (Stephan et al., 1985), which involved calculating a final acute value (FAV) based on the number of genera in the data set and the toxicity values for the four most sensitive genera (Table 4-1). The resulting FAV of $149.2 \mu \mathrm{g} / \mathrm{L}$ was divided by 2 to obtain a Criterion Maximum Concentration (CMC; acute) of $75 \mu \mathrm{g} / \mathrm{L}$ (total nickel). The Criterion Chronic Concentration (CCC; chronic) of $8.3 \mu \mathrm{g} / \mathrm{L}$ (total nickel) was calculated by dividing the FAV by a final acute-to-chronic ratio (FACR). The FACR of 17.99 was based on a comparison of acute and chronic responses for the sole saltwater species for which test data were available, and two freshwater species (USEPA, 1986). Later, conversion to dissolved concentrations for ambient water quality criteria resulted in slightly lower values of 8.2 and $74 \mu \mathrm{g} / \mathrm{L}$, respectively, using a 0.99 conversion factor for nickel.

Table 4-1. Nickel water quality criteria calculations using acute species sensitivity distribution provided by USEPA (1986). Data expressed as total recoverable nickel.

\begin{tabular}{|c|c|c|c|c|c|c|c|}
\hline $\begin{array}{c}\text { Sensitivity } \\
\text { Rank }\end{array}$ & Genus & $\begin{array}{l}\text { GMAV } \\
(\mu \mathrm{g} / \mathrm{L})\end{array}$ & $\begin{array}{c}\text { GMAVs } \\
\text { (n) }\end{array}$ & FAV & $\mathrm{CMC}$ & FACR & $\mathrm{CCC}$ \\
\hline 4 & Pacific oyster, Crassostrea virginica & 1180 & \multirow{4}{*}{20} & \multirow{4}{*}{149.2} & \multirow{4}{*}{75} & \multirow{4}{*}{17.99} & \multirow{4}{*}{8.29} \\
\hline 3 & Mysid, Mysidopsis (bahia and bigelowi) & 567.5 & & & & & \\
\hline 2 & Hard clam, Mercenaria mercenaria & 310.0 & & & & & \\
\hline 1 & Mysid, Heteromysis formosa & 151.7 & & & & & \\
\hline
\end{tabular}

\subsubsection{Updates from Hunt et al. (2002)}

In 2002, new saltwater toxicity data for nickel were made available (Hunt et al., 2002), providing additional data for three North American west coast marine species (topsmelt, red abalone, and mysids) for both acute and chronic exposures. This enlarged the USEPA data set, somewhat altered the four most sensitive genera due to greater sensitivity for some species (Table 4-2), and provided for a more robust ACR. The freshwater nickel ACRs (35.58 and 29.86) used previously for chronic criterion derivation from the acute data set was substantially different from the single available saltwater ACR (5.478) for the marine mysid, Americamysis bahia, at that time (USEPA, 1986). The addition of ACRs for the red abalone H. rufescens (5.505), the mysid Mysidopsis intii (6.727), and topsmelt Atherinops affinis (6.220) resulted in a geometric mean of 5.960 when including the 
previously established ACR for A. bahia. The net result of the Hunt et al. (2002) study was a slight lowering of the CMC due to the addition of more sensitive species to the SSD, but an increase in the CCC due to the use of a more robust saltwater ACR (Table 4-2).

Table 4-2. Nickel WQC calculations using acute species sensitivity distribution provided by Hunt et al. (2002). Data expressed as dissolved nickel.

\begin{tabular}{|c|c|c|c|c|c|c|c|}
\hline $\begin{array}{c}\text { Sensitivity } \\
\text { Rank }\end{array}$ & Genus & $\begin{array}{l}\text { GMAV } \\
(\mu \mathrm{g} / \mathrm{L})\end{array}$ & $\begin{array}{c}\text { GMAVs } \\
\text { (n) }\end{array}$ & FAV & CMC & FACR & $\mathrm{CCC}$ \\
\hline 4 & Hard clam, Mercenaria mercenaria & 310.0 & \multirow{4}{*}{23} & \multirow{4}{*}{122.5} & \multirow{4}{*}{61} & \multirow{4}{*}{5.960} & \multirow{4}{*}{20.5} \\
\hline 3 & Mysid, Heteromysis formosa & 151.7 & & & & & \\
\hline 2 & Mysid, Mysidopsis intii & 148.6 & & & & & \\
\hline 1 & Red abalone, Haliotis rufescens & 145.5 & & & & & \\
\hline
\end{tabular}

\subsubsection{Chronic Toxicity Data Updates (Deforest and Shlekat, 2013)}

More recently, a study was conducted to generate a SSD based on chronic toxicity data developed primarily within the last 10 years (DeForest and Schlekat, 2013). This data set provides more USEPA qualifying data for updating the national criterion (USEPA, 1986). Although the study was conducted to generate WQC for Europe, which uses different calculations, 13 data points were applicable to the development of the updated site-specific criterion for the Marianas, including Guam. The data set focuses on chronic test data, yet many of the test endpoints (e.g., embryo-larval development tests) used in WQC derivation in the USA still apply.

One of the more curious findings from the DeForest and Schlekat (2013) study is the inclusion of published nickel toxicity data for the long-spined sea urchin (Diadema antillarum), which substantially influenced the calculation of a CCC (Table 4-3). When the D. antillarum data were included, a CCC of $3.9 \mu \mathrm{g} / \mathrm{L}$ was calculated. Following USEPA guidance (USEPA, 1994b) on recalculation procedures, deletion of the urchin data resulted in a CCC of $20.9 \mu \mathrm{g} / \mathrm{L}$. The sole reported EC50 for D. antillarum is $15 \mu \mathrm{g} / \mathrm{L}$ (Bielmyer, Brix, Capo, and Grosell, 2005), but the chronic criterion derived by DeForest and Schlekat (2013) used the EC10 (2.9 $\mu \mathrm{g} / \mathrm{L})$ based on current European methods for criterion development. As part of the nickel recalculation effort, a Guamrelevant long-spined sea urchin species, $D$. savignyi, from the same genus, was the subject of additional toxicity testing with nickel to verify that it was being sufficiently protected in the sitespecific calculation for Guam (Rosen et. al., in review). Because the D. antillarum data have not yet been approved and incorporated in EPA criteria for Nickel, and because the data for $D$. savignyi are more relevant to Guam, the latter were ultimately selected for development of the site-specific criterion.

\subsection{METHODS}

The Recalculation Procedure followed USEPA guidance (USEPA, 1994b) to adjust the current national recommended Water Quality Criteria (WQC) for nickel using a step-wise method that involves corrections, additions, and (optionally) deletions to the national toxicity data set, rendering it more representative of species occurring at the site. The procedure addressed an outdated USEPArecommended criterion of acute and chronic criteria of 74 and $8.2 \mu \mathrm{g} / \mathrm{L}$, respectively (USEPA, 1986), which is used in the current NPDES permit. Once the appropriate modifications were made to the data set, a new criterion was calculated using USEPA guidelines (Stephan et al., 1985). Using the procedures documented herein, a site-specific Criterion Maximum Concentration (CMC; acute) of 
67.4- $\mu \mathrm{g} / \mathrm{L}$ nickel (dissolved) and a site-specific Criterion Chronic Concentration (CCC; chronic) of 22.6- $\mu \mathrm{g} / \mathrm{L}$ nickel (dissolved) were determined to be protective of aquatic life in marine waters of the Marianas region. Using the dissolved/total conversion factor for nickel in saltwater (USEPA, 2009), this equates to acute and chronic values of 68.1 and $22.8 \mu \mathrm{g} / \mathrm{L}$, respectively.

Table 4-3. Nickel WQC calculations using chronic species sensitivity distribution provided by new data from DeForest and Schlekat (2013). Data expressed as dissolved nickel.

\begin{tabular}{|c|l|c|c|c|c|c|c|}
\hline \hline $\begin{array}{c}\text { Sensitivity } \\
\text { Rank }\end{array}$ & \multicolumn{1}{|c|}{ Genus } & $\begin{array}{c}\text { SMAV } \\
(\mu \mathrm{g} / \mathrm{L})\end{array}$ & $\begin{array}{c}\text { SMAVs } \\
(\mathrm{n})\end{array}$ & FAV & CMC & FACR & CCC $^{2}$ \\
\hline \hline 4 & Red abalone, Haliotis rufescens & 36.4 & & & & & \\
\hline 3 & $\begin{array}{l}\text { Polychaete, Neanthes } \\
\text { arenaceodentata }\end{array}$ & 22.5 & \multirow{2}{*}{17} & NA & NA & NA & $\begin{array}{c}20.9 / \\
3.9\end{array}$ \\
\cline { 1 - 3 } 2 & $\begin{array}{l}\text { Mysid, Americamysis bahia } \\
1\end{array}$ & $\begin{array}{l}\text { Long spine urchin, Diadema } \\
\text { antillarum }\end{array}$ & 2.9 & & & \\
\hline
\end{tabular}

${ }^{1}$ EC10 from chronic toxicity tests per European Union regulatory guidance (DeForest and Schlekat, 2013).

${ }^{2}$ Derived using chronic toxicity tests required for European Union criterion development. The CCC value of 20.9 does not include data for Diadema antillarum; however, the CCC value of $3.9 \mu \mathrm{g} / \mathrm{L}$ include data for Diadema antillarum.

\subsubsection{Site-Specific Data Set Modifications}

Species information for the Marianas was compiled from several sources, primarily Volume 35 to 36 (July 2003) of the journal Micronesica. A complete listing of data sources and species occurrence utilized in this effort is shown in Appendix B. Species nomenclature follows that of the Integrated Taxonomic Identification System (ITIS) (http://www.itis.gov, latest access on 17 December 2012) to the maximum extent practicable. Given the limited amount of data available for nickel-sensitive species, no data set deletions were executed in order to maintain a more robust data set of potentially relevant species.

\subsubsection{Species of Concern}

No Endangered Species Act (ESA)-listed fish or invertebrate species occur in the area of concern (FWS, 2012); however, several Candidate species of coral (Brainard et al., 2011) and two fish species of concern, the bumphead parrotfish (Bolbometopon muricatum - also a candidate species) and the humphead wrasse (Cheilinus undulatus) are present (NOAA, 2012).

\subsubsection{Data Set Additions}

The recalculation guidelines (USEPA, 1994b, 2013) provide the option of submitting additional toxicity data for consideration by USEPA, which is especially important where critical (i.e., endangered, threatened, or commercially or recreationally important) species are concerned. The addition of toxicity data for resident species in the Marianas was based on their presence in the region and relevancy based on USEPA guidelines (Stephan et al., 1985).

Twenty-one species were added to the data set based on their reported presence at the site, ecological or economic significance, and the availability of relevant toxicity data that meets USEPA requirements (Stephan et al., 1985). None of these species are currently listed as endangered or threatened under the ESA. Of the 21 species, three are found in Guam, while several others present important ecological significance. These species are listed below. 


\section{Mussels (Mytilus edulis, M. gallprovincialis, M. trossolus)}

These species do not occur at Guam; however, the data for Mytilus species were added to the data set due to the presence of other genera of the family Mytilidae at Guam (Carpenter and Niem, 1998a; Paulay, 2003b) for which no data are available. The SMAVs for M. edulis, M. gallprovincialis, and M. trossolus are 891, 555, and $150 \mu \mathrm{g} / \mathrm{L}$ (dissolved nickel), respectively.

\section{Bivalve (Notocallista sp.)}

It is unknown if this species occur at Guam; however, several species in the same family do occur that are not present in the data set (Paulay, 2003b). The SMAV is $2880 \mu \mathrm{g} / \mathrm{L}$ (dissolved nickel) for this species.

\section{Red Abalone (Haliotis rufescens)}

This species does not occur at Guam; however, the data for Haliotis was added to the data set due to the presence of other species in the genera Haliotis at Guam (Smith, 2003), and because of its use to generate a more robust FACR by Hunt et al. (2002). The SMAV is $145.5 \mu \mathrm{g} / \mathrm{L}$ (dissolved nickel), for this species.

\section{Sand Dollar (Dendraster excentricus)}

This species does not occur at Guam; however, data for this species was added because few echinoderms other than sea urchins are represented in the data set (Paulay, 2003a). The SMAV for this species $686 \mu \mathrm{g} / \mathrm{L}$ (dissolved nickel).

\section{Fish (Atherinops affinis, Cryprinodon variegatus)}

These species do not occur at Guam; however, the data for these fish species were added to the data set because Atherinops affinis belongs to the family Atherinidae, which is present in Guam but not represented elsewhere in the data set. Similarly, Cyprinodon variegatus belongs to the same order as A. affinis (Actinopterygii), but represents a different family (Cyprinodontidae; Myers and Donaldson 2003). The SMAV for A. affinis, is $26560 \mu \mathrm{g} / \mathrm{L}$ (dissolved nickel), and for C. variegatus the SMAV is $29946 \mu \mathrm{g} / \mathrm{L}$ (dissolved nickel).

\section{Crustaceans (Americamysis intii, Portunus pelagicus, Allochestes compressa, Apocyclops boreoensis)}

These species of mysid (Americamysis intii), sand crab (Portunus pelagicus), amphipod (Allochestes compressa), and copepod (Apocyclops boreoensis) do not occur in Guam. A. intii, with an SMAV of $149 \mu \mathrm{g} / \mathrm{L}$ (dissolved nickel), was added because it belongs to the same order (Mysida) as another species in the database. P. pelagicus has a SMAV of $1162 \mu \mathrm{g} / \mathrm{L}$ (dissolved nickel) and was added to the database because another species in the same genus is present in Guam (Paulay et al., 2003). A. compressa, with an SMAV of $10587 \mu \mathrm{g} / \mathrm{L}$ (dissolved nickel) was added because it represents a different family in the database in the order Amphipoda. Finally, A. boreoensis, with as SMAV of $13050 \mu \mathrm{g} / \mathrm{L}$ (dissolved nickel), was added because it belongs to the family Cyclopidae, which is present in Guam but not represented elsewhere in the database.

\section{Polychaete Worm (Hydroides elegans)}

This species is not present in Guam, but species in the same genus not yet represented in the data set are present (Bailey-Brock, 2003). H. elegans has an SMAV of $274 \mu \mathrm{g} / \mathrm{L}$ (dissolved nickel). 


\section{Banana Prawn (Penaeus merguiensis)}

This species does not occur in Guam; however, it belongs to the same genera as another species, Panaeus monodon, which is widely distributed in the Indo-West Pacific, including Guam and the Marianas Islands (Paulay et al., 2003), from the eastern coast of Africa to the Red Sea, Japan, Australia, and Fiji. P. monodon is of major economic importance both as a fishery and as an aquaculture resource (Carpenter and Niem, 1998b).

Denton and Burdon-Jones (1982) examined the effects of temperature and salinity on the acute toxicity of heavy metals to $P$. merguiensis. Bioassays of $P$. merguiensis survival were conducted at all combinations of 35,30 , and $20^{\circ} \mathrm{C}$ with 36- and 20-ppt salinity over 96 hours. This resulted in LC50 values ranging from 2800 to $21000 \mu \mathrm{g} / \mathrm{L}$ (dissolved nickel) for this species, and a calculated SMAV of $7645 \mu \mathrm{g} / \mathrm{L}$ (dissolved nickel).

\section{Sea Urchins (Heliocidaris tuberculata, Paracentrotus lividus, Strongylocentrotus purpuratus)}

These species do not occur at Guam; however, the data for these sea urchin species were added to the data set due to the presence of other genera of the class Echinoidea at Guam (Paulay, 2003a). The SMAVs for Heliocidaris tuberculata, Paracentrotus lividus, and Strongylocentrotus purpuratus species are 271357 and $561 \mu \mathrm{g} / \mathrm{L}$ (dissolved nickel), respectively.

\section{Sea Urchins (Diadema spp.)}

Recent research reports verify that Diadema spp., long-spined sea urchins, are relatively sensitive to nickel. D. antillarum is a Caribbean sea urchin species with a reported EC50 of $15 \mu \mathrm{g} / \mathrm{L}$ (dissolved nickel) for 48-hr embryo-larval development tests (Bielmyer et al., 2005). This is an order of magnitude lower than larval development-based EC50s for other common sea urchin species such as $H$. tuberculata, $P$. lividus, and $S$. purpuratus (see above). $D$. antillarum is not present in the Marianas, but phylogenetically similar sea urchins, including $D$. savignyi (Figure 4-1) and $D$. setosum, are widely distributed throughout the Indo-Pacific region. The latter two species are commonly associated with coral reefs, and also commonly used as a bioindicator species for assessing heavy metal contamination (Flammang et al., 1997; Paulay, 2003a). 


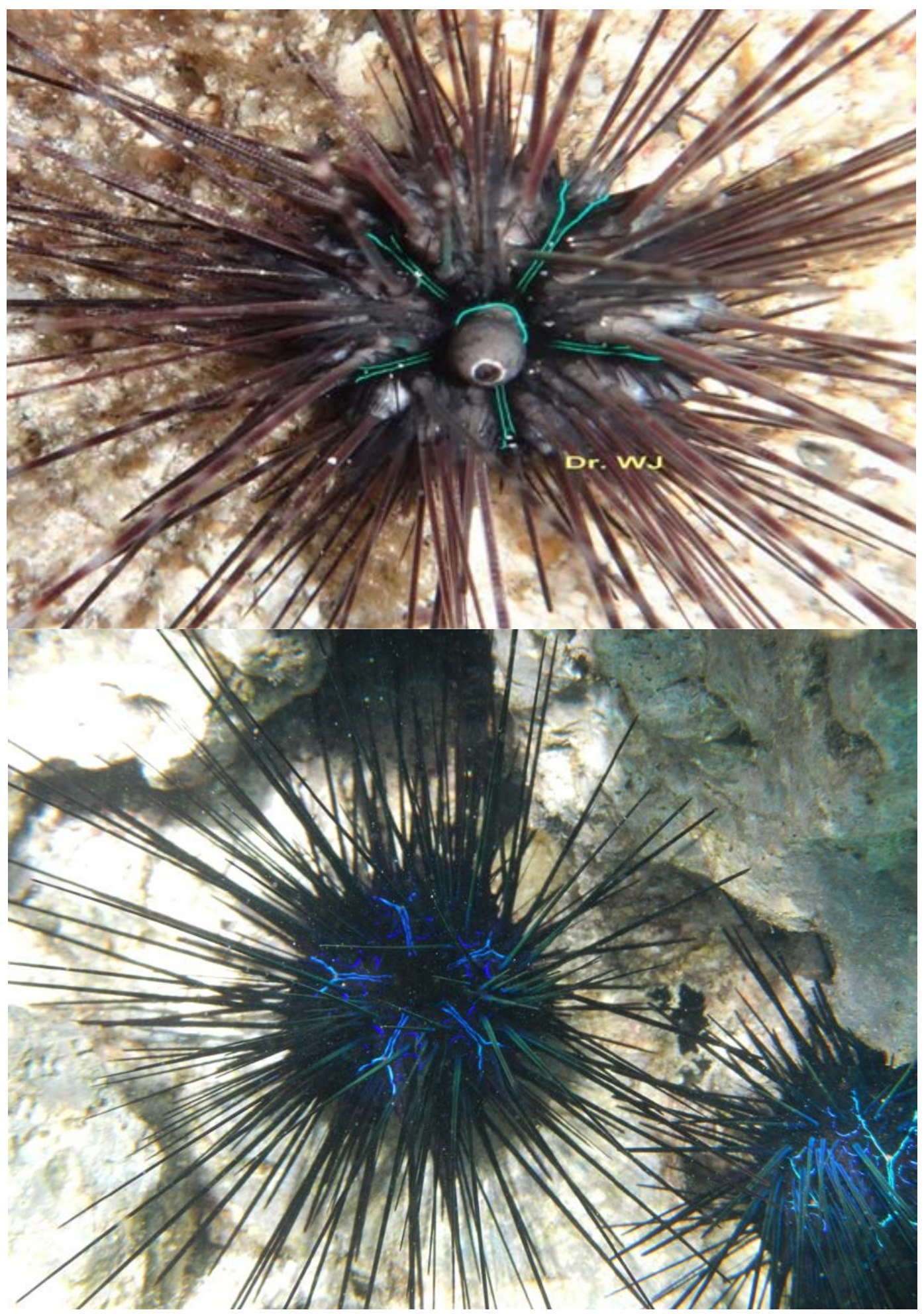

Figure 4-1. Photos of long-spined sea urchins Diadema savignyi (top) and Diadema setosum (bottom). The top photo is distributed under the Creative Commons License from the WoRMS Editorial Board (2016). World Register of Marine Species. Available at http://www.marine species.org at VLIZ. Accessed 15 July 2016. doi:10.14284/170. The bottom image was taken on 7 April 2016 by Patrick Earley with a Nikon ${ }^{\circledR}$ COOLPIX $^{\circledR}$ AW100 F4.1 camera. 
To our knowledge, no published nickel toxicity data were available for Guam- relevant longspined urchins. As part of this effort, qualifying toxicity data were developed with $D$. savignyi collected on Guam to ensure that this genus is protected at the site (see Section 5 for detailed reporting of the derivation of these data). The dissolved nickel 48-h EC50 for two tests were 72 and $117 \mu \mathrm{g} / \mathrm{L}$, the geometric mean of which was $92 \mu \mathrm{g} / \mathrm{L}$ ). Therefore, this species was somewhat less sensitive than the Caribbean species, but substantially more sensitive than other sea urchins. Therefore, the team added $D$. savignyi toxicity data to the site-specific data set. These data are in the process of publication in the peer-reviewed literature (Rosen et al, in review).

\subsubsection{Species in Guam and the Marianas}

\section{Pacific Oyster (Crassostrea gigas)}

This species was intentionally introduced into the Marianas Islands for culture purposes, but is likely extirpated, possibly due to sustained high temperatures in the waters around Guam and the Marianas Islands (Braley, 1984; Carpenter and Niem, 1998a; Paulay, 2003b).

The data for $C$. gigas were added to the site-specific data set due to the presence of other genera of the family Ostreidae at Guam (Carpenter and Niem, 1998a; Denton et al., 1999; Paulay, 2003b). The SMAV is $474 \mu \mathrm{g} / \mathrm{L}$ (dissolved nickel) for this species.

\section{Diamond-scaled Mullet (Liza vaigiensis)}

Mullets (Mugilidae) occur in all tropical and temperate seas, usually near shore, frequently in brackish estuaries and, occasionally, fresh water (Nelson, 2006). Several species are of moderate to major importance to large-scale, small-scale and subsistence fisheries, and are frequently cultivated in ponds (Carpenter and Niem, 1999). The diamond-scaled mullet is an important fishery resource, and is distributed throughout Guam and the Marianas Islands (Myers and Donaldson, 2003). In Fiscal Year 2000 (FY00; October 1999 through September 2000), L. vaigiensis comprised 3\% of the total inshore harvest on Guam (DAWR, 2000).

Toxicity tests with juvenile (15-20 mm) L. vaigiensis conducted at salinities of 20\%o (brackish water) and 36\% (seawater) resulted in reported 96-hour dissolved nickel LC50 values of 40000 and $55500 \mu \mathrm{g} / \mathrm{L}$, respectively (Denton and Burdon-Jones, 1986). The calculated SMAV is 47,117 $\mu \mathrm{g} / \mathrm{L}$ (dissolved nickel).

\section{Lace Coral (Pocillopora damicornis)}

Coral planula survival has been used to a limited extent as an experimental toxicity test endpoint. Although adult corals have been reported as more sensitive than the planula larvae, assessment of death in adults is difficult (Esquivel, 1986) and no adult coral tests exist that satisfy the USEPA guidelines for deriving WQC (Stephan et al., 1985). This species is commonly found in Apra Harbor is one of 13 species present in the Mariana Islands within the genera Pocillopora (Randall, 2003; Smith et al., 1999).

While direct determination of LC50 and EC50 values have not been reported for P. damicornis, effects on the mortality and settlement of planula larvae during recovery to nickel exposure have been examined. During recovery from nickel exposure at $9000 \mu \mathrm{g} / \mathrm{L}, 50 \%$ mortality was observed at 17.1 hours after a 48-hour exposure period, at 22.5 hours after a 24-hour period, and at 39.6 hours after a 12-hour period (Goh, 1991). 


\subsection{RESULTS}

The site-specific criterion for nickel was derived using USEPA guidelines (USEPA, 1985), which involved calculating a Final Acute Value (FAV) based on the number of genera in the data set and the toxicity values for the four most sensitive genera (Table 4-4). The resulting FAV of $134.8 \mu \mathrm{g} / \mathrm{L}$ was divided by 2 to obtain a Criterion Maximum Concentration (CMC; acute) of $67.41 \mu \mathrm{g} / \mathrm{L}$. To obtain the Criterion Chronic Concentration (CCC; chronic), the FAV was divided by the final acuteto-chronic ration (FACR) for a value of $22.62 \mu \mathrm{g} / \mathrm{L}$ nickel. The final acute-to-chronic ratio (FACR) was based on the comparison of acute and chronic responses for saltwater species for which test data were available. The FACR of 5.96 was used to derive the chronic criterion (Hunt et al., 2002). The final data set consists of toxicity values for 45 species in 37 families (Figure 4.2).

Recent reporting of the sensitivity of long-spined sea urchin (Diadema spp.) embryos to nickel (Bielmyer et al., 2005; DeForest and Schlekat, 2013) led to the development of Guam/Marianas relevant toxicity data that meet USEPA criteria (USEPA, 1985). Diadema savignyi was indeed the most sensitive in the site-specific data set, and strongly influenced the site-specific criterion calculation, as did increased robustness of the data set and the inclusion of an improved FACR.

Table 4-4. Genus mean acute values (GMAV) for the four most sensitive genera in the site-specific data set for dissolved nickel.

\begin{tabular}{|c|c|c|c|c|c|c|c|}
\hline $\begin{array}{c}\text { Sensitivity } \\
\text { Rank }\end{array}$ & Species & $\begin{array}{l}\text { GMAV } \\
(\mu \mathrm{g} / \mathrm{L})\end{array}$ & $\begin{array}{c}\text { GMAVs } \\
(\mathrm{n})\end{array}$ & FAV & $\mathrm{CMC}$ & FACR & $\mathrm{CCC}$ \\
\hline 4 & Heliocidaris tuberculata & 271 & \multirow{4}{*}{39} & \multirow{4}{*}{134.8} & \multirow{4}{*}{67.41} & \multirow{4}{*}{5.96} & \multirow{4}{*}{22.62} \\
\hline 3 & Heteromysis formosa & 151.7 & & & & & \\
\hline 2 & Haliotis rufescens & 145.5 & & & & & \\
\hline 1 & Diadema savignyi & 91.6 & & & & & \\
\hline
\end{tabular}

\subsection{CONCLUSION}

Using the USEPA Recalculation Procedure, the current chronic (CCC) and acute (CMC) nickel discharge limits for the Apra Harbor WWTP in Agat, Guam are recommended to be updated from 8.3 and $75 \mu \mathrm{g} / \mathrm{L}$, respectively, to 22.9 and $68.1 \mu \mathrm{g} / \mathrm{L}$ total recoverable nickel (22.6- and 67.4- $\mu \mathrm{g} / \mathrm{L}$ dissolved nickel), respectively. These criteria were calculated utilizing an updated nickel toxicity data set by surveying the peer-reviewed literature for qualifying data, as well as incorporating a more robust Final Acute-Chronic Ration (FACR) of 5.96, provided by Hunt et al. (2002). Data for 21 species were added to the site-specific data set, four of which occur in the Marianas, including Guam. The four most sensitive species used to calculate the criterion are listed in Table 4-4. No deletions were made from the national data set. The relatively high sensitivity of Diadema antillarum recently reported in the literature prompted the development of qualifying data for a Guam relevant species (D. savignyi), which was included in the data set, and was the most sensitive endpoint of a total of 45 species used for the site-specific calculations. The updated criteria should be considered in updates to regional NPDES discharge limits for nickel. 


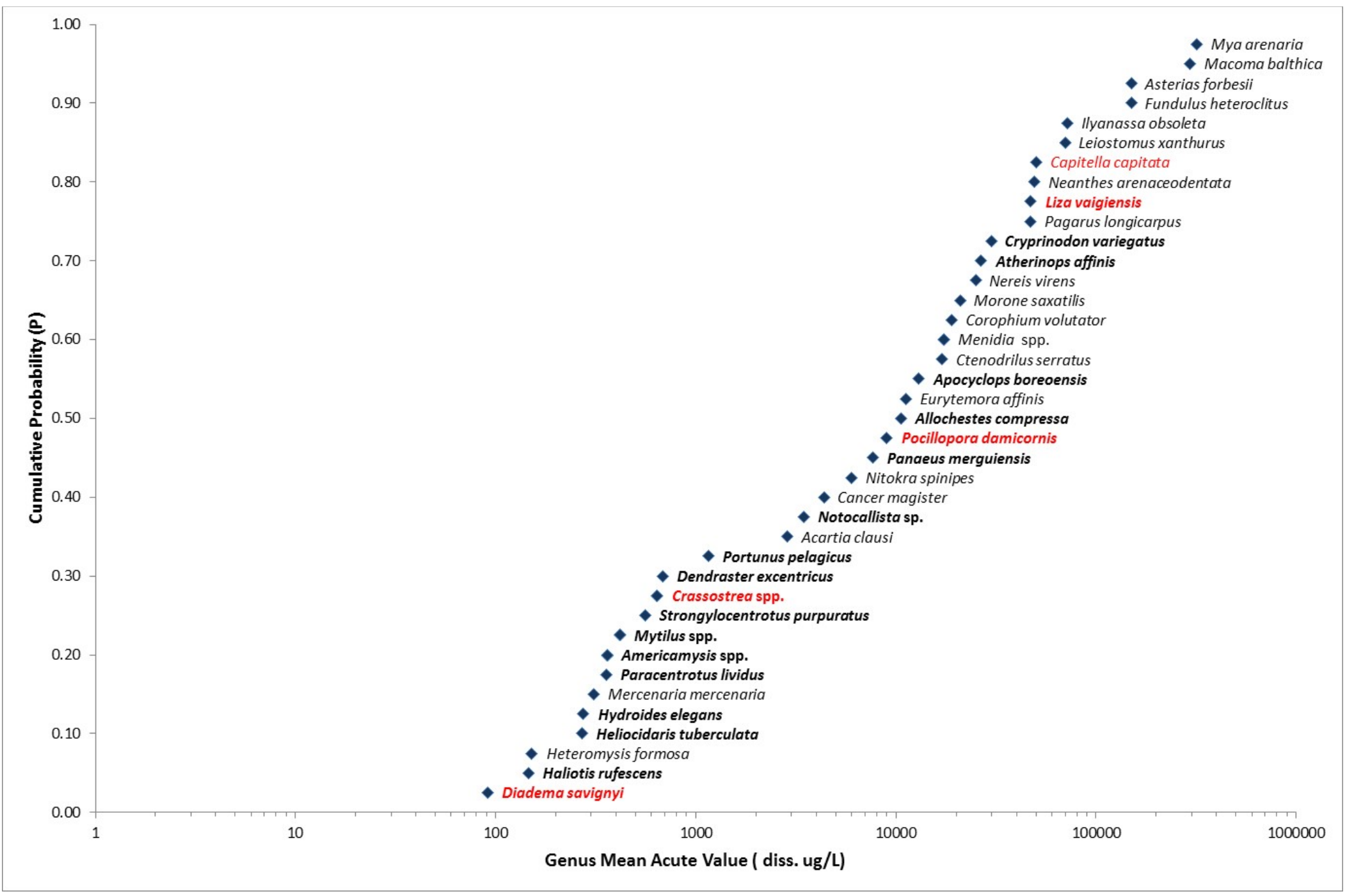

Figure 4-2. Cumulative toxicity probability, site-specific data set. Red text represents species present in Guam, bold text represents species that were added to the data set, and non-bold text represents species that were retained from the original 1986 USEPA data set. 



\section{NICKEL AND COPPER TOXICITY TO EMBRYOS OF THE LONG-SPINED SEA URCHIN, DIADEMA SAVIGNYI}

This section describes the results of studies conducted on Guam by SSC Pacific using long-spined sea urchins collected on the island to verify suspected nickel and copper sensitivity of early life stages of this locally important species. These studies were conducted using EPA-approved toxicity test methods used for derivation of ambient water quality criteria, with the intention of ensuring that a site-specific criterion for nickel and copper were sufficiently protective of sensitive species at Guam.

Sea urchin embryos are among the most sensitive species and life stage used in toxicity tests to derive AWQC for metals in saltwater. Most marine organisms used for developing species sensitivity distributions (SSD) in AWQC development by the USEPA have focused on continental North American species. Therefore, water quality in isolated tropical environments under U.S. jurisdiction may not be sufficiently protected if ecologically important species, including tropical sea urchins, are not accurately represented by the national criteria.

Copper $(\mathrm{Cu})$ and nickel $(\mathrm{Ni})$ are common metal constituents of wastewater and industrial discharges, with relatively low chronic WQC of 3.1 (USEPA, 1995a) and 8.2 (USEPA, 1986) $\mu \mathrm{g} / \mathrm{L}$, on a dissolved basis, respectively. Although copper toxicity to common temperate sea urchin species (e.g., Strongylocentrotus purpuratus and Paracentrotus lividus) is well established, no sea urchin species are represented in the USEPA's current national criterion for nickel, even though qualifying data have become available in the literature since the criterion document was published. No tropical species are represented for either metal, except for one species in a draft update for copper (HDR | Hydroqual, 2012).

Long-spined sea urchins of the genus Diadema occur in all tropical seas and play an essential ecological role in coral reef habitats as herbivorous grazers (Muthiga, 2003). The Caribbean longspined urchin $D$. antillarum is reportedly highly sensitive to nickel and copper, with 48-hour median effective concentrations (EC50s) of 15 and $11 \mu \mathrm{g} / \mathrm{L}$, respectively (Bielmyer et al., 2005). Data such as these could affect the regulation of discharges in tropical environments through development of site-specific water quality criteria, in addition to adjustments to national criteria through updates of the respective SSDs.

The purpose of this study was to assess the relative sensitivity of common Indo-Pacific Diadema spp. to nickel and copper, using standard toxicity test methods with short-term (48-hour) embryolarval development as the primary endpoint to determine whether this genus is protected under existing USEPA WQC at U.S. territories in the Indo-Pacific, such as Guam and other Marianas Islands. Toxicity metrics were then compared with ambient concentrations measured around Guam.

\subsection{METHODS}

\subsubsection{Specimen Collection}

The most widespread Diadema species is D. savignyi (Lessios, Kessing, and Pearse, 2001), which is highly common in tropical regions of the Indo-Pacific, from the coast of East Africa in the Indian Ocean to numerous islands in the Eastern Pacific. The sympatric species $D$. setosum is relatively difficult to distinguish from $D$. savignyi, yet is more widely used as a bioassay organism (Lessios, Kessing, and Pearse, 2001). These species are commonly associated with coral reefs, but are also found on sand flats and in sea grass beds (Paulay, 2003). 
Previous reports of the presence of both $D$. savignyi and D. setosum in Guam (e.g., Lessios, Kessing, and Pearse, 2001) resulted in initial attempts to collect specimens of each species for comparative toxicity testing. However, extensive near-shore evaluation of Diadema populations at multiple locations around the island during early 2013 (personal communication with L. Raymundo, C. Brunson, R. Burpee) indicated considerable populations of $D$. savignyi, but no observations of $D$. setosum. All sea urchins identified in this genus were characterized as having blue iridophores on the aboral surface, taking the form of lines (rather than spots as found in D. setosum). The lack of an orange ring along the periproctal cone was also used as verification that $D$. setosum was not present at the site (Muthiga, 2003).

Mature D. savignyi were field collected subtidally in late April 2013 from various near-shore locations (water depth $<3 \mathrm{~m}$ ) on the west coast of Guam, Marianas Islands, and held in outdoor tanks supplied with flowing seawater ( $\mathrm{pH} 8.1$ to 8.2, temperature 25 to $26^{\circ} \mathrm{C}$ ) from Pago Bay at the University of Guam (UoG) Marine Laboratory.

\subsubsection{Dilution Water}

Seawater from Pago Bay, Guam, adjacent to the UoG Marine Laboratory, was collected at a depth of 1 meter. Trace metal clean techniques (USEPA, 1996b) were used throughout preparation of sampling equipment, and during sampling, manipulation and analysis of the samples. This included acid cleaning of sampling material and equipment, and collection of water using clean hands-dirty hands techniques. Dilution water for the toxicity tests was filtered in place with acid-cleaned 0.45- $\mu \mathrm{m}$ PTFE membranes with polypropylene housings (Whatman ${ }^{\mathrm{TM}}$ disposable syringe filters) and collected in clean 5-gallon buckets. Spiked samples for toxicity tests were subsampled from the test solutions and stored in 125-mL acid-cleaned HDPE bottles, followed by placement in clean bags and placed in coolers with ice until shipment to the appropriate laboratory for metals analysis.

\subsubsection{Sea Urchin Spawning Inducement}

Within one week of collection, individual sea urchins were induced to spawn by injection of 0.5-M potassium chloride $(\mathrm{KCl})(1 \mathrm{~mL})$ through the peristomal membrane into the coelomic cavity. Several individuals were selected, at random, daily over a period of approximately 1 week until sufficient quantities of viable gametes were observed. Although minimal numbers of viable gametes were observed in days prior, copious quantities of mature gametes were collected on 30 April 2013, approximately 5 days after a full moon (25 April 2013). This timing is consistent with previous observations associated with Diadema spawning events (Muthiga, 2003).

\subsubsection{Toxicity Testing}

The team conducted testing at the UoG Marine Laboratory in a temperature- $\left(25^{\circ} \mathrm{C}\right)$ and lightcontrolled environment (ambient laboratory light, 16:8 hour light:dark photo period). Gametes from the 30 April 2013 spawn were collected and washed separately, followed by fertilization and testing according to standard methods for other sea urchin species (USEPA, 1995b), with some minor modifications. Unlike standard protocols for west coast USA species, exposures were conducted at a warmer temperature and limited to an exposure period of 48 hours, when the pluteus stage (pyramidal shaped larva with four highly developed skeletal rods and a distinct gut) was achieved. Contents of each vial, approximately 200 larvae in $10 \mathrm{~mL}$ of test solution, were preserved after the exposure period with $1 \mathrm{~mL}$ of $10 \%$ buffered formalin. The first 100 larvae observed in each vial at 40X magnification were scored as normal or abnormal based on larval characteristics above (USEPA, 1995b). All testing was conducted at $\mathrm{pH}$ 8.1, salinity $34 \mathrm{ppt}$, with dissolved oxygen remaining $>6 \mathrm{mg} \mathrm{L}^{-1}$ at all times. 
Stock nickel and copper solutions were made from reagent grade metals salts $\left(\mathrm{NiCl}_{2} \cdot 6 \mathrm{H}_{2} \mathrm{O}\right.$, and $\mathrm{CuSO}_{4} 5 \mathrm{H}_{2} \mathrm{O}$, respectively) and analyzed using inductively coupled plasma with detection by mass spectrometry (ICP-MS; see below) prior to testing. Nominal nickel exposure concentrations were $0,9,16,26,43,72,120,200,500$, and $1000 \mu \mathrm{g} / \mathrm{L}$, while nominal copper exposure concentrations were $0,6.25,12.5,25,50,100$, and $200 \mu \mathrm{g} / \mathrm{L}$. All metal-seawater mixtures were equilibrated for approximately 2 hours prior to initiation (addition of 4- to 8-cell stage embryos) of toxicity tests. Four replicates per treatment were used for all tests.

Dilution water consisted of uncontaminated Pago Bay, Guam surface seawater filtered to $\leq 0.45 \mu \mathrm{m}$. Uncontaminated 0.45- $\mu \mathrm{m}$ filtered seawater from near the mouth of San Diego Bay, California, and synthetic seawater (Crystal Sea Marinemix), were included as two additional laboratory controls to assess whether alternative seawater sources might be conducive to embryolarval development testing of this species for off-island experimentation.

The team conducted statistical analyses of the toxicity data using CETIS $^{\mathrm{TM}}$ (v1.8.7.16). Data from both nickel and copper exposures were verified as normally distributed with equal variances across all treatments using Shapiro-Wilk and Bartlett's tests, respectively. Dunnett's Multiple Comparisons test was used to determine whether nickel or copper treatments were significantly different from controls $(\alpha=0.05)$. Point estimates (e.g., EC50) were calculated using linear regression for the nickel exposures and the Trimmed Spearman-Karber Method for the copper exposure.

\subsubsection{Dissolved Organic Carbon}

The dissolved organic carbon (DOC) concentration was quantified for the Pago Bay dilution water, as DOC increasingly plays an important role in modeling of metal toxicity (Arnold 2005; Arnold et al., 2006; Deforest and Schlekat, 2013). We filtered seawater through 0.7- $\mu \mathrm{m}$ nominal pore size precombusted glass fiber filters and immediately transferred to 125-mL amber glass bottles containing $8-\mu \mathrm{L} 85 \% \mathrm{H}_{3}-\mathrm{PO}_{4}$. The bottles were quickly sealed and placed on ice for shipment. We analyzed the DOC samples using a high temperature catalytic oxidation (HTCO) method. The instrument is specially equipped with high-salt sample combustion tube kit and halogen scrubber for seawater analysis. Seawater samples were acidified to $\mathrm{pH}<2$ by concentrated hydrochloric acid (trace metal grade) prior to analysis, then sparged for 2 minutes to remove inorganic carbon. The non-purgeable organic carbons (NPOC) in samples were further converted to $\mathrm{CO}_{2}$ by oxidation at $680{ }^{\circ} \mathrm{C}$ with a platinum catalyst. A non-dispersive infrared detector was used to detect the converted $\mathrm{CO}_{2}$ for quantification of NPOC. Laboratory method detection limits and reporting limits for DOC were 0.030 and $0.095 \mathrm{mg} / \mathrm{L}$, respectively.

\subsubsection{Metal Analysis}

The team quantified metal concentrations in the spiked seawater used for the toxicity tests by dilution and direct injection into an ICP-MS. The samples were diluted $31 \mathrm{X}$ with $\mathrm{pH} \leq 218 \mathrm{M \Omega} / \mathrm{cm}$ water. Each run included two duplicates (average recovery \pm standard deviation, $106 \pm 14 \%$ for nickel, and $88 \pm 4 \%$ for copper), and one spiked sample (91\% recovery for nickel, and $89 \%$ recovery for copper). The team analyzed a blank made up of $0.45-\mu \mathrm{m}$ filtered seawater from outside San Diego Bay. We acidified the seawater to $\mathrm{pH} \leq 2$ with quartz still-grade nitric acid every five samples. We did this to ensure system cleanliness and provide a reference point for the background metal concentration with an average concentration of $0.13 \pm 0.22-\mu \mathrm{g} / \mathrm{L}$ nickel and $0.039 \pm 0.08-\mu \mathrm{g} / \mathrm{L}$ copper. The team also analyzed the standard reference material (SRM) 1643e trace elements in water from the National Institute of Standards \& Technology after every five samples. We did this to ensure that the instrument was measuring accurately and precisely with a recovery of $109 \pm 17.3 \%$ of the certified concentration of $62.41 \pm 0.69 \mu \mathrm{g} / \mathrm{L}$ for nickel, and $105 \pm 9.1 \%$ of the certified concentration of $22.76 \pm 0.31 \mu \mathrm{g} / \mathrm{L}$ for copper. 
In addition, dissolved nickel and copper concentrations in ambient water samples from the 16 nearshore locations around the island of Guam were quantified using in-line pre-concentration flow injection analysis using ICP-MS (Ndung'u et al., 2003). Samples were treated online with TOYOPEARL AF-Chelate-650M resin in a Perkin-Elmer Flow Injection Analysis System (FIAS) 400 to remove salt from the sample, and then transferred into the ICP-MS for metal concentration quantification. Each run included two duplicates (average recovery \pm standard deviation, $127 \pm 6 \%$ for nickel, and $104 \pm 7.1 \%$ for copper) and two spiked samples (93 $\pm 16 \%$ for nickel, and $92 \pm 24 \%$ for copper). For every five samples, a blank was analyzed. The blank consisted of $0.45-\mu \mathrm{m}$ filtered seawater from outside San Diego Bay, California, which had an average concentration of -0.037 $\pm 0.060 \mu \mathrm{g} / \mathrm{L}$ for nickel, and $0.23 \pm 0.06 \mu \mathrm{g} / \mathrm{L}$ for copper. The Standard Reference Material CASS 4 (coastal seawater), from the National Research Council of Canada, was also quantified after every five samples, and had an average recovery of $109 \pm 16.8 \%$ of the certified nickel concentration of $0.314 \pm 0.030 \mu \mathrm{g} / \mathrm{L}$, and $103 \pm 8.9 \%$ of the certified copper concentration of $0.592 \pm 0.055 \mu \mathrm{g} / \mathrm{L}$.

\subsection{RESULTS}

\subsubsection{Toxicity Tests}

The team conducted two nickel tests, concurrently using different embryo suspensions while one copper test was conducted. All tests met acceptability criteria, with high levels of normal pluteus larvae in each of three sets of laboratory (Pago Bay seawater) controls (average 91\%; range 86 to 96\%). Natural seawater from San Diego Bay, California, also resulted in acceptable larval development (92 $\pm 2.9 \%$ ), but the synthetic salt treatment resulted in a high degree of poorly developed larvae (33 $\pm 24 \%$ ).

For nickel, gradual dose responses were observed (Table 5-1) for both tests. EC50 values for Test $\# 1$ and \#2 were 117 and $71.6 \mu \mathrm{g} / \mathrm{L}$, respectively (Table 5-2). The 95\% confidence intervals did not overlap between the two nickel tests. For copper, a relatively steep dose response was observed (Table 5-3), resulting in an EC50 of $19.1 \mu \mathrm{g} / \mathrm{L}$ (Table 5-2).

Table 5-1. Response of $D$. savignyi to nickel in two concurrent tests with different embryo suspensions. Bold values are statistically different from the laboratory control. $\mathrm{N}=4$ replicates per concentration.

\begin{tabular}{|c|c|c|c|c|c|c|c|}
\hline \hline \multicolumn{2}{|c|}{$\begin{array}{c}\text { Dissolved Ni } \\
(\mu \mathrm{g} / \mathrm{L})\end{array}$} & \multicolumn{3}{|c|}{ Test \#1 } & \multicolumn{3}{c|}{ Test \#2 } \\
\hline Target & Measured & $\begin{array}{c}\text { Mean } \\
\% \\
\text { Normal }\end{array}$ & SD & $P$ & $\begin{array}{c}\text { Mean } \\
\% \\
\text { Normal }\end{array}$ & SD & $P$ \\
\hline \hline 0 & 0.16 & 92 & 4.97 & - & 86 & 3.88 & - \\
\hline 9 & 8.4 & 92 & 4.77 & 0.874 & 89 & 2.99 & 0.984 \\
\hline 16 & 15.3 & 89 & 4.57 & 0.477 & 86 & 2.08 & 0.881 \\
\hline 26 & 23.5 & 92 & 2.21 & 0.889 & 81 & 9.91 & 0.545 \\
\hline 43 & 36.5 & $\mathbf{8 2}$ & $\mathbf{7 . 8 7}$ & $\mathbf{0 . 0 1 6}$ & $\mathbf{6 7}$ & $\mathbf{3 . 0 9}$ & $\mathbf{0 . 0 0 4}$ \\
\hline 72 & 63.4 & $\mathbf{7 7}$ & $\mathbf{7 . 6 3}$ & $<\mathbf{0 . 0 0 1}$ & $\mathbf{4 2}$ & $\mathbf{9 . 7 5}$ & $<\mathbf{0 . 0 0 1}$ \\
\hline 120 & 120 & $\mathbf{3 4}$ & $\mathbf{2 . 9 9}$ & $<\mathbf{0 . 0 0 1}$ & $\mathbf{2 6}$ & $\mathbf{3 . 3 0}$ & $<\mathbf{0 . 0 0 1}$ \\
\hline 200 & 210 & $\mathbf{2 1}$ & $\mathbf{3 . 1 3}$ & $<\mathbf{0 . 0 0 1}$ & $\mathbf{1 2}$ & $\mathbf{8 . 1 7}$ & $<\mathbf{0 . 0 0 1}$ \\
\hline 500 & 482 & $\mathbf{1 1}$ & $\mathbf{4 . 0 1}$ & $<\mathbf{0 . 0 0 1}$ & $\mathbf{1 . 8}$ & $\mathbf{1 . 2 6}$ & $<\mathbf{0 . 0 0 1}$ \\
\hline 1000 & 938 & $\mathbf{0 . 8}$ & $\mathbf{1 . 5 0}$ & $<\mathbf{0 . 0 0 1}$ & $\mathbf{0 . 0}$ & $\mathbf{0 . 0 0}$ & $<\mathbf{0 . 0 0 1}$ \\
\hline
\end{tabular}


Table 5-2. No observed effect concentration (NOEC), lowest observed effect concentration (LOEC), median effective concentration (EC50), and 95\% confidence intervals (C.I.) for all toxicity tests with $D$. savignyi.

\begin{tabular}{|l|c|c|c|c|}
\hline \multicolumn{1}{|c|}{ Chemical } & NOEC & LOEC & EC50 & $95 \%$ C.I. \\
\hline Ni (Test \#1) & 23.5 & 36.5 & 117 & $(100-135)$ \\
\hline $\mathrm{Ni}$ (Test \#2) & 23.5 & 36.5 & 71.6 & $(63.1-80.2)$ \\
\hline $\mathrm{Cu}$ & 9.59 & 21.2 & 19.1 & $(18.3-19.9)$ \\
\hline
\end{tabular}

Table 5-3. Response of $D$. savignyi embryos to copper. Bold values are statistically different from the laboratory control. $N=4$ replicates per concentration.

\begin{tabular}{|c|c|c|c|c|}
\hline \multicolumn{2}{|c|}{ Dissolved Cu ( $\mu \mathrm{g} / \mathrm{L})$} & \multirow{2}{*}{$\begin{array}{l}\text { Mean \% } \\
\text { Normal }\end{array}$} & \multirow{2}{*}{ SD } & \multirow{2}{*}{$P$} \\
\hline Target & Measured & & & \\
\hline 0 & 0.43 & 96 & 2.0 & - \\
\hline 7.8 & 5.81 & 94 & 3.9 & 0.408 \\
\hline 15.6 & 9.59 & 95 & 3.0 & 0.615 \\
\hline 31.3 & 21.2 & 34 & 6.4 & $<0.001$ \\
\hline 62.5 & 53.1 & 0 & 0.0 & $<0.001$ \\
\hline 125 & 81.9 & 0 & 0.0 & $<0.001$ \\
\hline 250 & 171 & 0 & 0.0 & $<0.001$ \\
\hline
\end{tabular}

\subsubsection{Water Chemistry}

The DOC concentration in Pago Bay seawater was $0.806 \mathrm{mg} \mathrm{L}^{-1}$. This value was consistent with concurrently collected and analyzed near-shore seawater samples $(\mathrm{n}=15)$ at depths of $\sim 1$ meter, primarily from the west coast of Guam (range 0.662 to $2.09 \mathrm{mg} / \mathrm{L}$; Section 8 of this document).

\subsubsection{Metals Analysis}

Background dissolved nickel and copper concentrations were 0.16 and $0.43 \mu \mathrm{g} / \mathrm{L}$, respectively, for Pago Bay seawater (Table 5-1 and Table 5-3). For the toxicity tests, dissolved nickel concentrations averaged $94.1 \%$ of the target concentration (range $=85-105 \%$; Table 5-1), while dissolved copper concentrations averaged $70.0 \%$ of the target concentration (range $=61-85 \%$; Table 5-3).

\subsection{DISCUSSION}

Toxicity testing was successfully conducted for both metals following a significant collection of gametes from multiple individuals of D. savignyi on 30 April 2013, approximately 5 days after a full moon. The spawning of this species is tightly tied to the lunar phase, and spawns in East Africa during the same timeframe throughout the year (Muthiga, 2003).

Relative to other sea urchin species using 48- to 96-hour embryo-larval development endpoints, D. savignyi appears substantially more sensitive to nickel and similarly sensitive to copper, based on EC50 comparisons. The nickel data derived here for $D$. savignyi corroborate recent reports of relatively high sensitivity of embryonic stages of sea urchins of the genus Diadema. The Caribbean 
long-spined sea urchin (D. antillarum) EC50 for nickel was reported as only $15 \mu \mathrm{g} / \mathrm{L}$ (Bielmyer et al., 2005), and is the most sensitive species in a nickel species sensitivity distribution (SSD) recently derived using chronic endpoints for 17 species of invertebrates, fish, and algae (Deforest and Schlekat, 2013). The nickel EC50s for Diadema spp. are as much as one order of magnitude lower than other common sea urchins, including Stronglyocentrotus purpuratus (341 $\mathrm{kg} / \mathrm{L}$; Phillips et al., 2003) and Paracentrotus lividus (320 g/L; Novelli, Losso, Ghetti, and Ghirardini, 2003).

Copper EC50 values of $11 \mu \mathrm{g} / \mathrm{L}$ (D. antillarum; Bielmyer et al., 2005) and $43 \mu \mathrm{g} / \mathrm{L}$ (D. setosum; Ramachandran et al., 1997) are similar to the value of $19 \mu \mathrm{g} / \mathrm{L}$ reported in this study for $D$. savignyi. Sensitivity of copper to this genus, therefore, is similar to other common sea urchins, such as $S$. purpuratus (14.3 to $15.3 \mu \mathrm{g} / \mathrm{L}$; Phillips et al., 2003; Rosen et al., 2008) and $P$. lividus (62 $\mu \mathrm{g} / \mathrm{L}$; Novelli et al., 2003). Although these concentrations are relatively low in the copper species sensitivity distribution (SSD) (USEPA, 1995a), the presence of similar species and sensitivities of existing copper criteria suggest that Diadema spp. are sufficiently protected.

\subsubsection{Relevance of Nickel Sensitivity to Regulation of Permitted Discharges}

These data could have substantial implications for regulation of nickel at point discharges because many numerical discharge limits are based on outdated USEPA water quality criteria (WQC), which are based on the most sensitive species in SSDs (USEPA, 1985). The WQC for nickel has not been formally updated since 1986 (USEPA, 1986), but substantial qualifying toxicity data for potential use in derivation of an updated WQC have been derived. The newer toxicity data improve the number of species represented, and may formalize an improved and more robust acute-to-chronic ratio (Hunt et al., 2002), critical for developing chronic criteria using acute toxicity data sets.

Nickel toxicity to $D$. savignyi was somewhat less than that reported for D. antillarum; however, water quality characteristics (e.g., DOC) were not reported for the latter (Bielmyer et al., 2005). The authors of the $D$. antillarum study suggested phylogenetic differences between Diadema and other sea urchin genera (all from different superorders) as potentially explaining differences in sensitivity. Regardless, the results shown here corroborate high sensitivity, and the potential impacts on future updates of criteria and water quality standards, at least for tropical regions where such species are present and recognized as requiring protection.

\subsubsection{Dissolved Organic Carbon}

The low DOC concentrations measured in Pago Bay seawater, as well as 15 other locations around the island, was not surprising, with the majority of sampling locations occurring in open coastal areas. The collection of DOC data alongside toxicity tests, however, may be helpful for understanding its role in potentially reducing nickel toxicity. A Biotic Ligand Model for copper in seawater is well developed, and is largely driven by DOC concentration (Arnold, 2005; Arnold et al., 2006; Chadwick et al., 2008). The role of DOC is not nearly as well understood for nickel toxicity in saltwater, with no clear relationship recently observed using sensitive test endpoints at ranges between 0.22 and $2.7 \mathrm{mg} / \mathrm{L}$ (Deforest and Schlekat, 2013).

\subsubsection{Presence of Diadema in Guam}

Although both $D$. savignyi and $D$. setosum were sought, only the former was observed at Guam during this study. Approximately 10 locations, mostly along the western and southeastern shorelines were assessed. All observations were made by snorkel (i.e., no more than 100 meters from shore at 1- to 5-m depth). Although the two species are considered sympatric and been observed at Guam, Lessios, Kessing, and Pearse (2001) suggest that difficulties in distinguishing the two species, and the tendency for $D$. setosum to be tied more to continental margins than other Diadema spp. may explain the lack of observed presence of $D$. setosum. 


\section{REMOVAL OF ALUMINUM FROM THE APRA HARBOR NPDES PERMIT}

Aluminum is a unique permit requirement because neither the Guam Water Quality Standards (WQS) nor the USEPA Water Quality Standards have a valid marine WQS for aluminum. The U.S. Navy National Pollution Discharge Elimination System (NPDES) Apra Harbor Wastewater Treatment Plant (WWTP) permit number GU0110019 establishes a marine discharge limit for aluminum at $200 \mu \mathrm{g} / \mathrm{L}$ based on Guam Water Quality Standards or WQS (Guam EPA, 2001). The Navy believes that this permit limit is in error because the $200-\mu \mathrm{g} / \mathrm{L}$ limit should only be ascribed to freshwater discharge environments, as there is no published marine WQS for aluminum. Further evidence supporting this is the Guam WQS citation as the technical basis for this limit as adopted directly from the 1988 USEPA Ambient Water Quality Criteria for Aluminum USEPA 440/5-86-008 (USEPA, 1988). The introduction of this document, specifically states, "This document does not contain information concerning the effect of aluminum on saltwater species because adequate data and resources were not available." (Page 1). This line of evidence creates a challenging situation for the Navy to understand the technical basis for the permit limit and prevents the initiation of efforts to utilize USEPA established procedures to develop a site-specific criterion using the recalculation method and/or a Water Effect Ratio study.

The absence of current scientific literature necessitated a more thorough investigation into the history and applicability of this criterion for use in this study to establish a marine criterion for aluminum necessitated a more detailed evaluation of the criterion itself and its associated history. The 1972 Water Quality Criteria R3-73-033 (The Blue Book) initially established a marine aluminum criterion of $1.5 \mathrm{mg} / \mathrm{L}(1500 \mu \mathrm{g} / \mathrm{L})$. The Blue Book was a USEPA contracted effort to the Environmental Studies Board composed of individuals from the National Academy of Sciences and the National Academy of Engineering. The board's task was to deliver a report of the Committee on Water Quality Criteria or the 1972 Water Quality Criteria Document (aluminum criteria is excerpted in Appendix D) and represents one of USEPA's first attempts to establish water quality criteria. Currently, Florida is the only known state with a marine criterion for aluminum based on the 1972 blue book value. However, the validity of this value is also in question as it is based on the 1988 "criteria date" data set, which as stated above, is based on freshwater values and should not be used for marine criterion (Florida DEP, 1997 and Appendix E excerpt). Additionally, the USEPA has since established a more scientifically valid and rigorous approach to establishing criterion and does not endorse or support use of the criteria published within the Blue Book. (USEPA, 1973), as shown in the following quote:

"EPA and a predecessor agency have produced a series of scientific water quality criteria guidance documents. Early Federal efforts were the "Green Book" (FWPCA, 1968) and the "Red Book" (USEPA, 1976). USEPA also sponsored a contract effort that resulted in the "Blue Book" (NAS/NAE, 1973). These early efforts were premised on the use of literature reviews and the collective scientific judgment of Agency and advisory panels. However, when faced with the need to develop criteria for human health as well as aquatic life, the Agency determined that new procedures were necessary. Continued reliance solely on existing scientific literature was deemed inadequate because essential information was not available for many pollutants. USEPA scientists developed formal methodologies for establishing scientifically defensible criteria."

In 1988, adhering to newly established and scientifically rigorous methodologies, the USEPA published the Ambient Water Quality Criteria for Aluminum (USEPA, 1988). As part of this effort, USEPA established that "Criteria contained in this document replace any previously published 
USEPA aquatic life criteria for the same pollutant(s)." As described above, the marine criterion for aluminum was notably absent due to the lack of scientifically defensible data to support its direct establishment.

. Based on these findings, a comprehensive literature search of scientifically relevant data for use in marine organisms was conducted. A total of three publications were found that specified aluminum toxicity data relevant to saltwater organisms. Rayburn and Aladdin (2003) reported toxicity in estuarine shrimp (Palaemonetes pugio) embryo at $5.66 \mathrm{mg} / \mathrm{L}$ (5660 $\mathrm{gg} / \mathrm{L}$ ); however, the data set consisted of limited number of samples with a high coefficient of variation. Calabrese, Collier, Nelson, and MacInnes (1973) reported no acute aluminum toxicity in American oyster embryo (Crassostrea virginica) at the highest level tested $(7.5 \mathrm{mg} / \mathrm{L} ; 7500 \mu \mathrm{g} / \mathrm{L})$. Finally, Wilson and Hyne (1997) reported abnormal embryonic development in the rock oyster (Saccostrea commercialis), at levels of $180-\mu \mathrm{g} / \mathrm{L}$ aluminum; however, this was a sub-lethal assessment of a mixed metal test including iron concentrations, and examined acid-sulfate soil leachate from a land-based source. Information from this literature review, while instructive, was determined to be not substantial enough of a data set to derive a numeric water quality criterion, and thus the USEPA acceptance criteria were not used to review the information for possible inclusion in the development of an aluminum safety criterion.

\subsection{RECOMMENDATION}

Based on the evidence presented, we recommend that the Guam Marine Water Quality Standard for Aluminum be removed from current and future NPDES Permit limits until one is established by USEPA. This recommendation is based on the fact that the current limits are not based on scientific scientific guidelines established by the USEPA and currently have no scientifically based merit for their inclusion in the current permit . 


\section{CHEMICAL TRANSLATOR FOR APRA HARBOR WASTEWATER TREATMENT PLANT DISCHARGE IN TIPALAO BAY, GUAM}

Since the recognition by USEPA in 1993 that the dissolved fraction better represents the biologically active fraction of a metal than the total or total recoverable fractions (Prothro Memo ${ }^{1}$ ), the USEPA's Office of Water recommended the use of dissolved metal concentrations for application of aquatic life criteria (USEPA, 1996a). USEPA also recommended that state water quality standards for the protection of aquatic life be based on dissolved metals (USEPA, 1996a). The USEPA has provided guidance on developing a conversion factor, known as chemical translator, between the dissolved criterion that should not be exceeded in the water column and the total recoverable-based criterion at the end of pipe (USEPA, 1996a). Application of the chemical translator supports regulation at the end-of-pipe as total recoverable metal concentration, but is based on a dissolved metal concentration endpoint in the receiving body of water. In other words, the translator supports estimations of the fraction of metal in the effluent that will be dissolved in the receiving water. As of now, translators do not consider bioaccumulation of metals, as they represent equilibrium in short time scales (i.e., hours).

The metal translator is the dissolved metal fraction of effluent in the ambient water, and is defined as the fraction of total recoverable metal in the downstream water that is dissolved. It is calculated as the ratio of dissolved to total metal concentrations resulting from the mixing of effluent and ambient waters (USEPA, 1966a), as shown in Equation 7-1:

$$
f_{D}=\frac{C_{D}}{C_{T}}
$$

Equation 7-1. The dissolved metal fraction $\left(f_{D}\right)$ of effluent is calculated as the ratio of dissolved $\left(C_{D}\right)$ to total $\left(\mathrm{C}_{\mathrm{T}}\right)$ metal concentrations resulting from the mixing of effluent and ambient waters.

The two main factors that affect the chemical translator are derived from variability in the discharge water, and variability in the receiving (ambient) water. In general, the effluent from Apra Harbor WWTP is consistent throughout time because it is domestic wastewater processed by secondary treatment and disinfection (i.e., chlorination and dechlorination). The main variations in the effluent characteristics are anticipated from rain events.

In the aquatic environment, the partitioning of metals between dissolved and particulate fractions is affected by environmental conditions. Among the most predominant parameters affecting this ratio are water temperature, $\mathrm{pH}$, salinity, total suspended solids (TSS), and dissolved organic matter (DOM). USEPA recommends examination of the effect of these parameters on the calculated $\mathrm{f}_{\mathrm{D}}$ (USEPA, 1996a). In those cases where it is determined that there is no noticeable effect from these conditions, USEPA advises the use of the geometric mean of the $f_{D}$ values calculated from measurements on mixtures of ambient and effluent samples.

Adhering to the USEPA guidance, we apply the chemical translator to the permit calculation to convert the permit limit into total recoverable metal concentration in accordance with the permit limit equation (Equation 1-1).

\footnotetext{
${ }^{1} 1993$ Metals Policy (Prothro Memo): "It is now the policy of the Office of Water that the use of dissolved metal to set and measure compliance with water quality standards is the recommended approach, because dissolved metal more closely approximates the bioavailable fraction of metal in the water column than does total recoverable metal.”
} 


\subsection{APPROACH}

The guidance provided by USEPA includes several scenarios, and allows for flexibility in the process (USEPA, 1966a). While the guidance is not prescriptive for every scenario or discharge type, its intent is to capture the partitioning of metal between the particulate and dissolved fractions that would occur in the mixing between the effluent and ambient waters. In those cases where a mixing zone is allowed, then the guidance suggests collecting samples at or beyond the edge of the mixing zone (i.e., the point of regulation). To determine the minimum dilution required for attaining metal concentrations at or below the WQC, some preliminary CORMIX runs were executed with conservative model parameters to determine that a minimal 2.6 dilution would be required to meet the recalculated permit values for copper and nickel. This 2.6 factor helped informed the sample gathering efforts and determined the ratio for the sample mixing, and is more environmentally conservative than the final CORMIX results ultimately applied within this study.

Sample Collection. The team used 11 sample mixtures (Table 7-1) to evaluate the chemical translator for copper and nickel for the discharge of Apra Harbor WWTP, Agat, Guam, into Tipalao Bay of the Philippine Sea. We collected the samples to capture temporal (i.e., annual) variations in both effluent and ambient conditions at approximately one monthly interval from April 2013 to May 2014. The mixtures were prepared on the same day of collection by mixing $500 \mathrm{~mL}$ of water from Reference Site TB5 with 312 mL of Apra Harbor WWTP effluent (collected before mixing with effluent from Agat-Santa Rita Wastewater Treatment Plant). This mixing simulated the minimum effluent dilution of 2.6 required for attaining WQC metal levels in the ambient water. Note that mixture temperatures were measured in the laboratory after mixing, and do not represent the ambient conditions in the discharge environment and are not reflective of compliance status with the associated requirements.

\subsection{METAL QUANTIFICATION}

Total recoverable and dissolved copper and nickel concentrations in the effluent and ambient water mixtures were measured using in-line pre-concentration flow injection analysis into an inductively coupled plasma mass spectrometer (ICP-MS) (Ndung'u et al., 2003). Samples were acidified to pH $\leq 2$ with quartz-still grade nitric acid in a class 100 HEPA-filtered working bench. Prior to quantification in the ICP-MS, each sample was treated online with a Toyopearl AF-Chelate-650M resin to remove salts from the sample using a Perkin-Elmer Flow Injection Analysis System (FIAS) 400. The sample was then transferred into the ICP-MS where the metal concentration was quantified. Each run included two duplicates (average recovery \pm standard deviation, $94 \pm 9.4 \%$ for nickel, and $93 \pm 11.3 \%$ for copper). For every five samples, a blank was analyzed to ensure cleanliness of the system and to provide a reference point for the background metal concentration. The blank was 0.45- $\mu \mathrm{m}$ filtered seawater from outside San Diego Bay sampled on 1 September 2011, which had an average concentration of $0.048 \pm 0.092-\mu \mathrm{g} / \mathrm{L}$ nickel and $0.168 \pm 0.093-\mu \mathrm{g} / \mathrm{L}$ copper. The limit of detection is calculated as three times the standard deviation of the blanks, or/and $0.28 \mu \mathrm{g} / \mathrm{L}$ for nickel and $0.28 \mu \mathrm{g} / \mathrm{L}$ for copper. The team quantified the standard reference material CASS 4 (coastal seawater), from the National Research Council of Canada, every five samples to ensure that the instrument was measuring accurately and precisely. The samples had an average recovery of 101 $\pm 17.1 \%$ of the certified $0.314 \pm 0.030$ - $\mu \mathrm{g} / \mathrm{L}$ nickel concentration, and $94 \pm 6.2 \%$ of the certified copper concentration of $0.592 \pm 0.055 \mu \mathrm{g} / \mathrm{L}$. We do not correct reported concentrations for blank or SRM recoveries. Measured metal concentrations and calculated chemical translators are shown in Table 7-2 and Table 7-3. 
Table 7-1. Sampling dates and ancillary data for samples collected for the Chemical Translator study at Apra Harbor Wastewater Treatment Plant. $\mathrm{T}^{\circ} \mathrm{C}$ is temperature in degree Celsius. Ancillary data measured on 29 April 2013. Std. Dev. is standard deviation. $95^{\text {th }} \%$ is $95^{\text {th }}$ percentile, $25^{\text {th }} \%$ is $25^{\text {th }}$ percentile, and Geomean is geometric mean.

\begin{tabular}{|c|c|c|c|c|c|c|c|c|c|}
\hline \multirow{2}{*}{$\begin{array}{l}\text { Sampling } \\
\text { Date }\end{array}$} & \multicolumn{3}{|c|}{ Effluent } & \multicolumn{3}{|c|}{ Translator Mixture } & \multicolumn{3}{|c|}{ Reference Site TB5 } \\
\hline & $\mathrm{pH}$ & Salinity & $\mathrm{T}^{\circ} \mathrm{C}$ & $\mathrm{pH}$ & Salinity & $\mathrm{T}^{\circ} \mathrm{C}$ & $\mathrm{pH}$ & Salinity & $\mathrm{T}^{\circ} \mathrm{C}$ \\
\hline 25 Apr 13 & 7.39 & 4.30 & & & & & $8.19^{*}$ & $34.7^{\star}$ & $28.8^{\star}$ \\
\hline 1 May 13 & 7.38 & 4.40 & & 8.03 & 18.4 & 21.0 & $8.19 *$ & $34.7^{*}$ & $28.8^{\star}$ \\
\hline 8 May 13 & 7.34 & 4.27 & & 8.02 & 22.0 & 21.0 & 8.14 & 33.6 & 29.5 \\
\hline 20 Jun 13 & 7.48 & 4.90 & 31.8 & 7.88 & 22.6 & 20.0 & 8.13 & 33.4 & 29.9 \\
\hline 25 Jul 13 & 7.60 & 5.60 & 24.5 & 8.11 & 22.5 & 23.3 & 8.09 & 35.0 & 25.0 \\
\hline 20 Nov 13 & 7.60 & 1.70 & 26.0 & 8.13 & 21.2 & 21.2 & 8.15 & 32.7 & 28.8 \\
\hline 17 Dec 13 & 7.36 & 4.30 & 27.8 & 7.78 & 18.1 & 22.6 & 8.09 & 31.6 & 28.4 \\
\hline 24 Jan 14 & 6.68 & 2.20 & 23.8 & 7.82 & 21.0 & 24.0 & 8.42 & 32.9 & 31.4 \\
\hline 19 Mar 14 & 7.45 & 2.60 & 27.4 & 7.85 & 19.6 & 24.0 & 8.46 & 27.5 & 28.9 \\
\hline 16 Apr 14 & 7.63 & 4.90 & 27.5 & 8.04 & 21.3 & 19.9 & 7.93 & 32.2 & 28.6 \\
\hline 7 May 14 & 7.74 & 2.90 & 29.2 & 8.17 & 20.9 & 20.7 & 8.38 & 31.5 & 29.3 \\
\hline Mean & 7.42 & 3.82 & 27.3 & 7.98 & 20.8 & 21.8 & 8.20 & 32.7 & 28.9 \\
\hline Std. Dev & 0.28 & 1.26 & 2.6 & 0.14 & 1.6 & 1.6 & 0.16 & 2.1 & 1.5 \\
\hline $95^{\text {th }} \%$ & 7.69 & 5.25 & 30.9 & 8.15 & 22.6 & 24.0 & 8.44 & 34.9 & 30.7 \\
\hline $25^{\text {th }} \%$ & 7.37 & 2.75 & 25.6 & 7.86 & 19.9 & 20.8 & 8.11 & 31.9 & 28.7 \\
\hline Geomean & 7.42 & 3.60 & 27.1 & 7.98 & 20.7 & 21.7 & 8.20 & 32.6 & 28.8 \\
\hline
\end{tabular}


Table 7-2. Dissolved $\left(C_{D}\right)$ and total $\left(C_{T}\right)$ nickel, and chemical translator ( $f_{D}$ nickel) measured in samples from the 2.6 dilution of effluent from Apra Harbor WWTP with seawater from Reference Site TB5.

\begin{tabular}{|c|c|c|c|c|c|c|c|}
\hline $\begin{array}{l}\text { Sampling } \\
\text { Date }\end{array}$ & $\begin{array}{l}\text { LOD } \\
(\mu \mathrm{g} / \mathrm{L})\end{array}$ & $\begin{array}{c}\text { Dissolved } \\
\text { Nickel, } C_{D} \\
(\mu \mathrm{g} / \mathrm{L})\end{array}$ & $\begin{array}{c}\text { Std. Dev. } \\
C_{D} \\
(\mu \mathrm{g} / \mathrm{L})\end{array}$ & $\begin{array}{c}\text { Total Nickel, } \\
\mathrm{C}_{\mathrm{T}}(\mu \mathrm{g} / \mathrm{L})\end{array}$ & $\begin{array}{c}\text { Std. Dev. } \\
C_{T} \\
(\mu \mathrm{g} / L)\end{array}$ & $\begin{array}{c}\mathrm{f}_{\mathrm{D}} \text { Nickel, } \\
\mathrm{C}_{\mathrm{D}} / \mathrm{C}_{\mathrm{T}}\end{array}$ & Notes \\
\hline 25 Apr 13 & 0.28 & 0.84 & & 1.20 & & 0.70 & \\
\hline 1 May 13 & 0.28 & 1.27 & & 1.87 & & 0.68 & \\
\hline 8 May 13 & 0.28 & 2.20 & & 3.12 & & 0.71 & \\
\hline 20 Jun 13 & 0.28 & 1.54 & 0.0084 & 1.84 & 0.17 & 0.84 & \\
\hline 25 Jul 13 & 0.28 & 1.51 & & 1.83 & & 0.82 & \\
\hline 20 Nov 13 & 0.28 & 1.60 & & 2.29 & & 0.70 & \\
\hline $17 \mathrm{Dec} 13$ & 0.28 & 1.31 & & 2.05 & & 0.64 & \\
\hline 24 Jan 14 & 0.28 & 1.40 & & 1.51 & & 0.93 & \\
\hline 19 Mar 14 & 0.28 & 0.32 & & 0.33 & & 0.96 & \\
\hline 16 Apr 14 & 0.28 & 0.85 & & 1.34 & & 0.63 & \\
\hline 7 May 14 & 0.28 & 1.17 & & 1.15 & & $1.00^{*}$ & $f_{D}=1.02$ \\
\hline Mean & & 1.27 & & 1.68 & & 0.78 & \\
\hline Std. Dev & & 0.49 & & 0.72 & & 0.13 & \\
\hline $95^{\text {th }} \%$ & & 1.90 & & 2.71 & & 0.98 & \\
\hline $25^{\text {th }} \%$ & & 1.01 & & 1.27 & & 0.69 & \\
\hline Geomean & & 1.16 & & 1.50 & & 0.771 & \\
\hline
\end{tabular}

* Indicates that $\mathrm{f}_{\mathrm{D}}$ is 1.02 , following the USEPA (1996a) translator guidance, a value of 1.00 was used for the statistics and calculation of $f_{D}$. The standard deviation in measured concentration is provided for those samples analyzed in duplicate. 
Table 7-3. Dissolved $\left(C_{D}\right)$ and total $\left(C_{T}\right)$ copper, and chemical translator ( $f_{D}$ Copper) measured in samples from the 2.6 dilution of effluent from Apra Harbor Wastewater Treatment Plant with seawater from Reference Site TB5.

\begin{tabular}{|c|c|c|c|c|c|c|c|}
\hline $\begin{array}{l}\text { Sampling } \\
\text { Date }\end{array}$ & $\begin{array}{l}\text { LOD } \\
(\mu \mathrm{g} / \mathrm{L})\end{array}$ & $\begin{array}{c}\text { Dissolved } \\
\text { Copper, } C_{D} \\
(\mu \mathrm{g} / \mathrm{L})\end{array}$ & $\begin{array}{c}\text { Std. Dev. } \\
C_{D} \\
(\mu \mathrm{g} / \mathrm{L}) \\
\end{array}$ & $\begin{array}{c}\text { Total } \\
\text { Copper, } C_{T} \\
(\mu \mathrm{g} / \mathrm{L})\end{array}$ & $\begin{array}{c}\text { Std. Dev. } \\
C_{T} \\
(\mu \mathrm{g} / \mathrm{L}) \\
\end{array}$ & $\begin{array}{c}f_{D} \text { Copper, } \\
C_{D} / C_{T}\end{array}$ & $\begin{array}{c}\text { NOTE } \\
\mathrm{S}\end{array}$ \\
\hline 25 Apr 13 & 0.28 & 0.70 & & 1.22 & & 0.57 & \\
\hline 1 May 13 & 0.28 & 0.81 & & 1.46 & & 0.56 & \\
\hline 8 May 13 & 0.28 & 1.27 & & 2.63 & & 0.48 & \\
\hline 20 Jun 13 & 0.28 & 0.93 & 0.0049 & 1.52 & 0.18 & 0.61 & \\
\hline 25 Jul 13 & 0.28 & 1.13 & & 1.87 & & 0.61 & \\
\hline 20 Nov 13 & 0.28 & 0.97 & & 1.96 & & 0.49 & \\
\hline 17 Dec 13 & 0.28 & 1.20 & & 4.65 & & 0.26 & \\
\hline 24 Jan 14 & 0.28 & $0.11^{*}$ & & $0.19 *$ & & & $\begin{array}{l}\text { Below } \\
\text { LOD }\end{array}$ \\
\hline 19 Mar 14 & 0.28 & $0.18 *$ & & $0.22 *$ & & & $\begin{array}{l}\text { Below } \\
\text { LOD }\end{array}$ \\
\hline 16 Apr 14 & 0.28 & 0.81 & & 0.87 & & 0.93 & \\
\hline 7 May 14 & 0.28 & 0.70 & & 0.70 & & 0.99 & \\
\hline Mean & & 0.80 & & 1.88 & & 0.61 & \\
\hline Std. Dev & & 0.38 & & 1.19 & & 0.23 & \\
\hline $95^{\text {th }} \%$ & & 1.23 & & 3.84 & & 0.97 & \\
\hline $25^{\text {th }} \%$ & & 0.70 & & 1.22 & & 0.49 & \\
\hline Geomean & & 0.66 & & 1.61 & & 0.573 & \\
\hline
\end{tabular}

* indicates that those samples are below the limit of detection (LOD), and are not included in the statistics or calculation of $\mathrm{f}_{\mathrm{D}}$ (USEPA, 1996a). The standard deviation (Std. Dev.) of the measured concentration is provided for those samples analyzed in duplicate.

\subsection{MIXTURE RESULTS}

A dilution factor of 2.6 fulfills the NPDES regulatory requirements for the effluent from Apra Harbor WWTP. Change was greater than 0.2-pH units from Reference Site TB5 to the mixture, but for four out of the eleven samples, the $\mathrm{pH}$ in the mixtures was within the range of 6.5 and 8.5 . Therefore, the minimal effect in $\mathrm{pH}$ is already fulfilled with a dilution of 2.6. Salinity in the mixture was always lower than at Reference Site TB5, with an average \pm one standard deviation decrease of $11.61 \pm 2.08$, and a decrease range from 7.9 to 16.2 salinity units. The NPDES permit (U.S. Navy, Apra Harbor WWTP NPDES Permit No. GU0110019 Fact Sheet Page 10 of 30) indicates a regulatory limit of incrementing the salinity by 10 units; therefore, this dilution provides salinities at acceptable levels. Analysis of data associated with temperature was not conducted because the mixtures were done under laboratory conditions, which differ from those associated with the natural ambient mixing conditions. 
Similarly to ancillary parameters, a minimal dilution of 2.6 fulfills most of the regulatory requirements of the NPDES permit for Apra Harbor WWTP effluent (U.S. Navy, Apra Harbor WWTP NPDES Permit No. GU0110019 Fact Sheet Page 10 of 30). Out of 22 separate measurements of dissolved and total recoverable nickel, all were below the 8.2- $\mu \mathrm{g} / \mathrm{L}$ Criterion Chronic Concentration (CCC), and the 74- $\mu \mathrm{g} / \mathrm{L}$ Criterion Maximum Concentration (CMC) (Table 7-2). In the case of copper, only the 4.6- $\mu \mathrm{g} / \mathrm{L}$ total copper from the mixture of 17 December 2013 was above the CCC of $3.1 \mu \mathrm{g} / \mathrm{L}$, but it was still below the CMC of $4.8 \mu \mathrm{g} / \mathrm{L}$ (Table 7-3). This analysis indicates that a dilution better than 2.6 would assure that concentrations in the ambient waters will be within regulatory requirements.

The effect of the environmental properties $\mathrm{pH}$, salinity and temperature were determined to have negligible effects on the final chemical translator for both copper and nickel. Figure 7-1 and Figure 7-2 are plots of these properties in the seawater from reference site TB5, the effluent from Apra Harbor WWTP and the mixture in a 2.6 ratio of these waters. These figures clearly show the narrow range measured for these properties. The calculated correlation coefficients from the linear regressions lacked statistical significance, and thus would yield no confidence in applying them to the chemical translator prediction. In general, the range for each parameter was so small that the predicted chemical translator yielded a large degree of uncertainty. These results support the use of the direct approach described in the USEPA (1996a) guidance for determining the chemical translator directly from the mixture of effluent and receiving water.

There is chemical translator guidance associated with conditions where measured dissolved metal is larger than total recoverable metal concentrations. This is the case for nickel in the mixture from 7 May 2014, when the measured dissolved concentration was $0.02 \mu \mathrm{g} / \mathrm{L}$ larger than the total recoverable nickel, resulting in an $\mathrm{f}_{\mathrm{D}}$ of 1.02 for that sample (Table 7-2). In these instances, the USEPA guidance (USEPA, 1996a) directs to use a chemical translator of 1.00, as indicated in Table 7-2. The chemical translator guidance also includes considerations on the quality of the data obtained such as omission of measured concentrations that are below the limit of detection. This is the case for dissolved and total recoverable copper in the mixtures from 24 January 2014 and 19 March 2014, and these data were not included in the calculation of the copper chemical translator (Table 7-3).

The unfiltered and filtered nickel concentrations we measured for the chemical translator aligned consistently close to the linear regression (Figure 7-3). The linear regression for nickel had a slope larger than 1.0, which is expected for the correlation of unfiltered to filtered concentrations. It also had an intercept very close to zero, which indicates negligible contamination. The Nickel Chemical Translator ( $f_{D}$ Nickel) calculated for this data set was thus 0.771 (Table 7-2).

A plot of measured total recoverable metal versus dissolved metals provides information on data consistency. The plot for the copper measurements (Figure 7-4) shows that most of the data aligned around the regression line. The one exception was the 4.6- $\mu \mathrm{g} / \mathrm{L}$ total copper (data point $1.2,5.0$ ) measured on 17 December 2013, which plotted well above the rest of the data in reference to unfiltered copper concentrations (y-axis); however, it was within the range of filtered copper for all the samples. This information indicated that this sample was contaminated, and was thus not used during determination of the chemical translator. The USEPA did not provide guidance in these cases; however, standard Laboratory QA/QC procedures and data quality objectives generally exclude this type of outlying information. We calculated the copper chemical translator ( $f_{D}$ Copper) as 0.573 (Table 7-3), which is the geometric mean (geomean) of the individual $f_{D}$, provided within three decimal figures, as required by USEPA (1996a). 

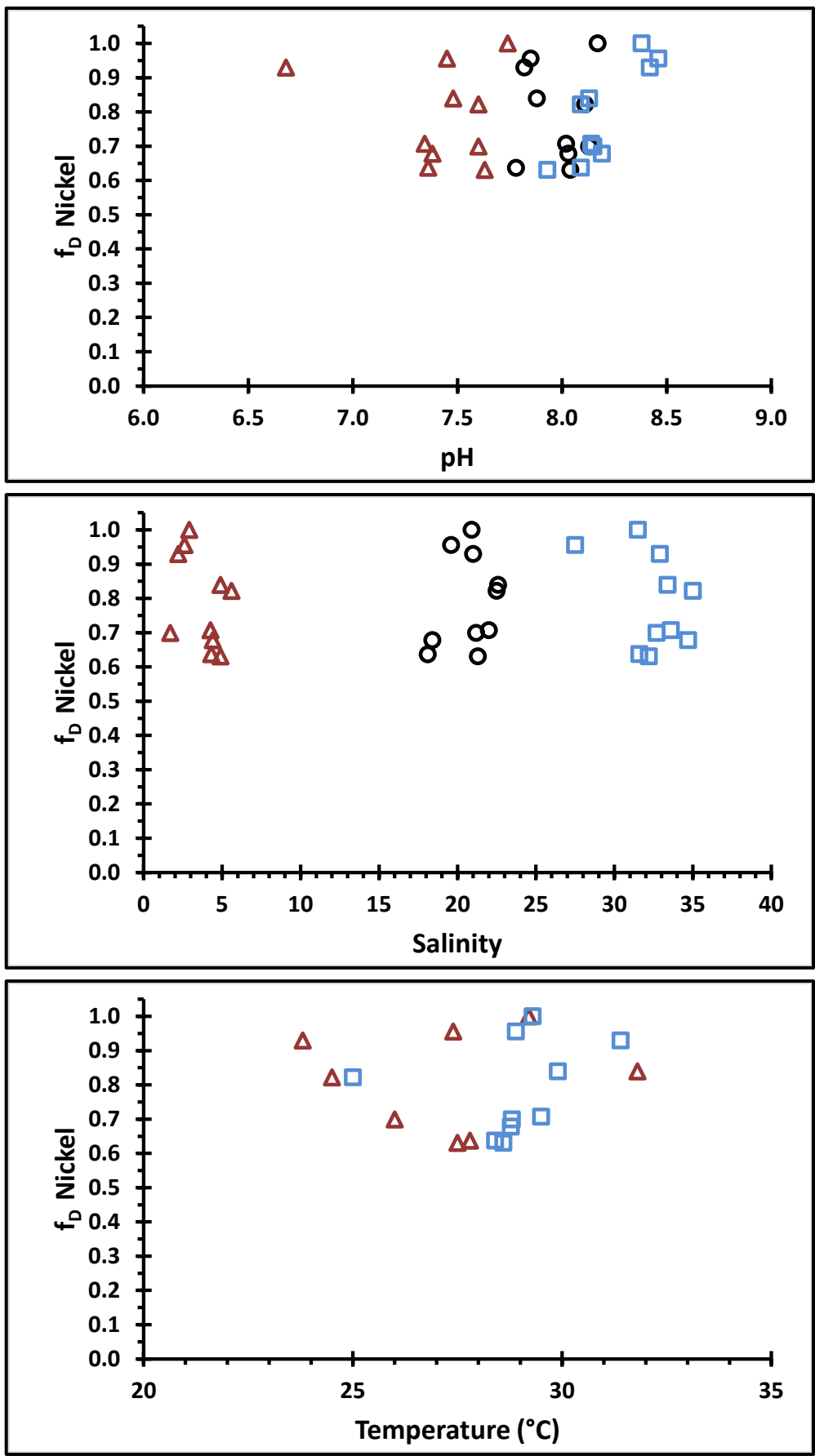

$\Delta$ Effluent $\quad$ O Translator mixture $\square$ Reference Site TB5

Figure 7-1. Plots of nickel chemical translator ( $f_{D}$ nickel) vs. $\mathrm{pH}$ (top), salinity (center), and temperature $\left({ }^{\circ} \mathrm{C}\right.$, bottom), in the Apra Harbor WWTP effluent (triangles), 2.6 dilution fraction translator mixture (circles), and seawater from Reference Site TB5 (squares). The narrow range in these properties resulted in negligible influence in $f_{D}$ nickel. Temperature measurements in the mixture were not measured. 

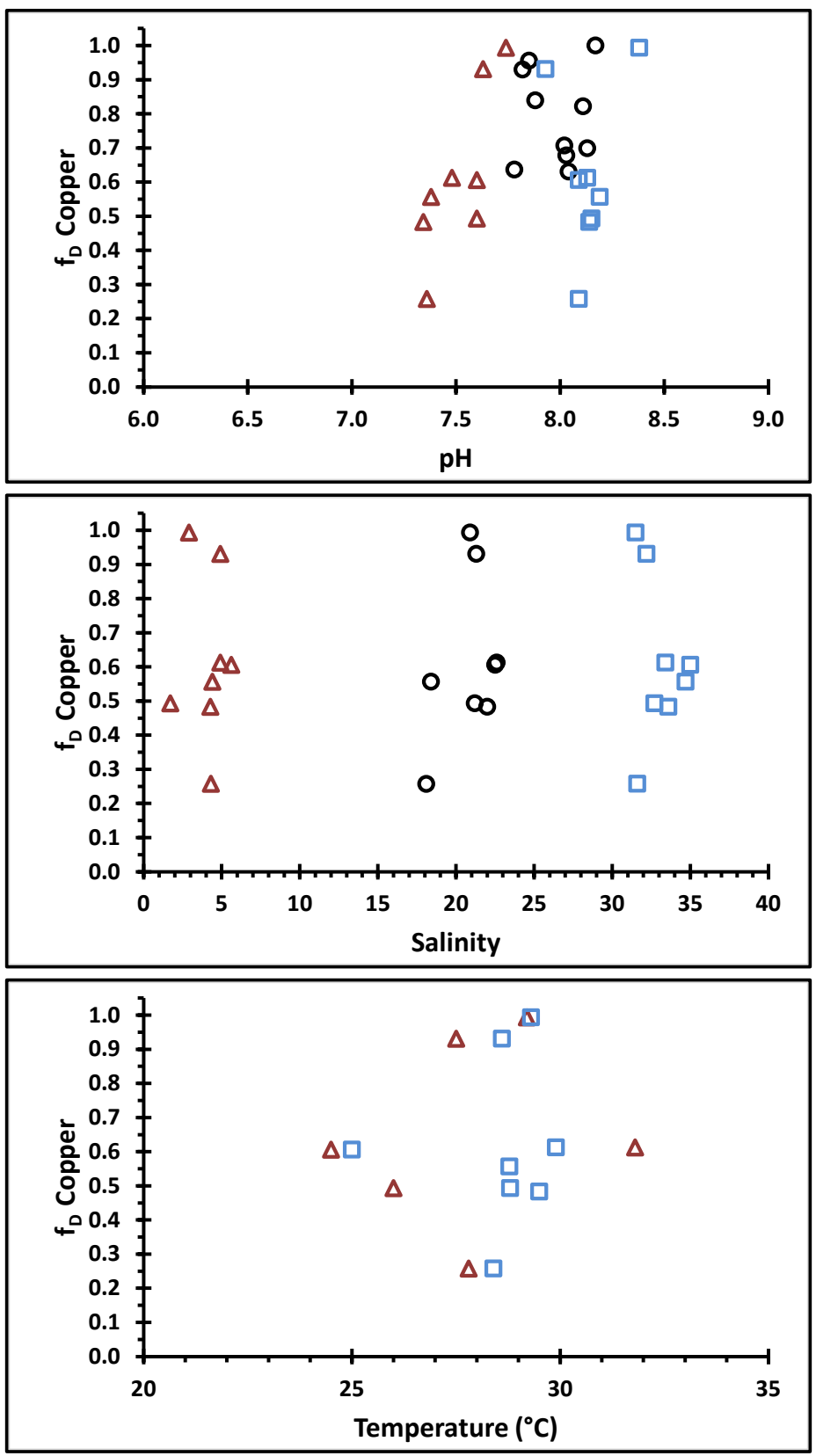

$\Delta$ Effluent $\quad$ T Translator mixture $\square$ Reference Site TB5

Figure 7-2. Plots of copper chemical translator ( $f_{D}$ copper) vs. $\mathrm{pH}$ (top), salinity (center), and temperature $\left({ }^{\circ} \mathrm{C}\right.$, bottom), in the Apra Harbor WWTP effluent (triangles), 2.6 dilution fraction translator mixture (circles), and seawater from Reference Site TB5 (squares). The narrow range in these properties resulted in negligible influence in $f_{D}$ copper. Temperature measurements in the mixture were not measured. 


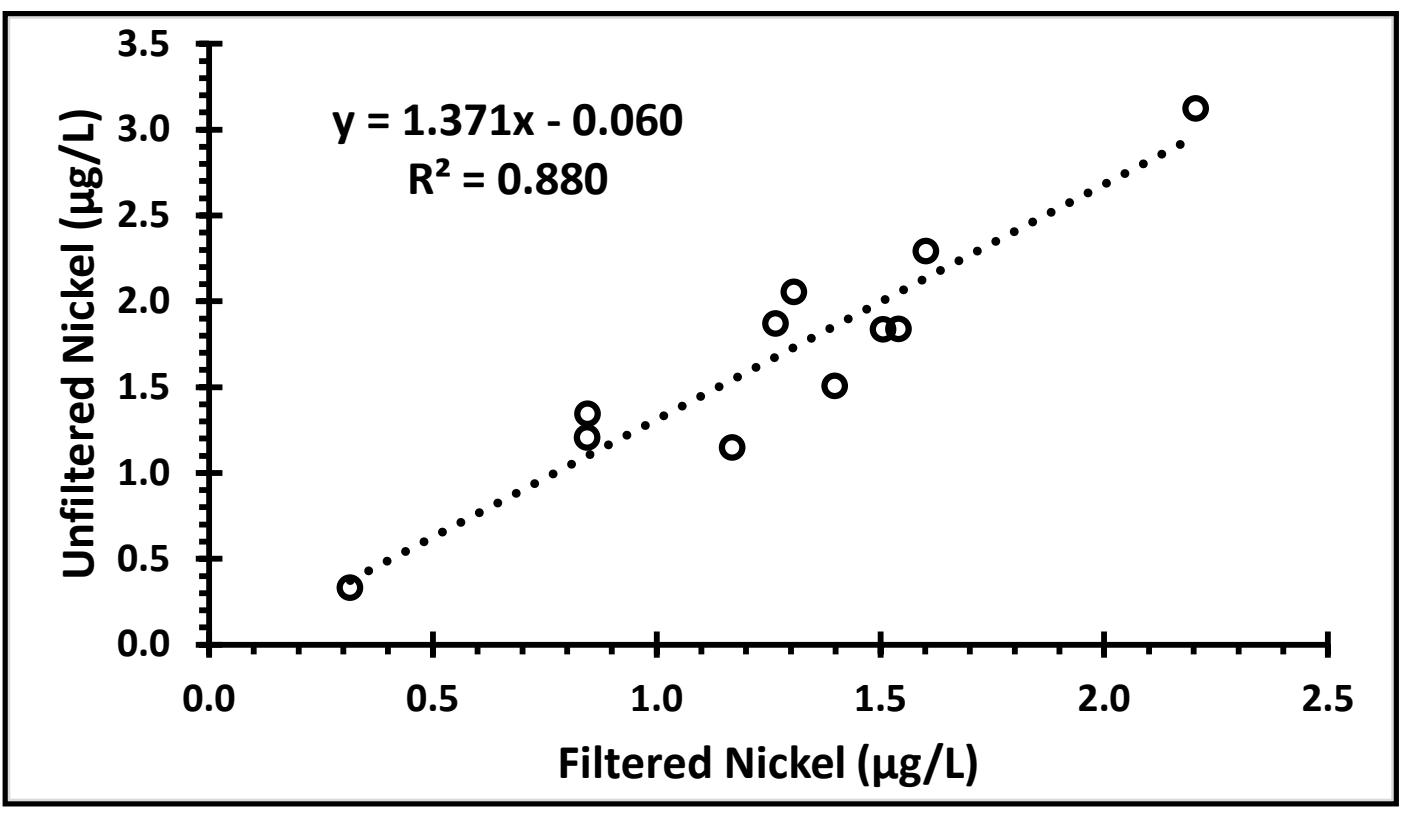

Figure 7-3. Plot of unfiltered vs. filtered nickel $(\mu \mathrm{g} / \mathrm{L})$ for the mixture of Apra Harbor Wastewater Treatment Plant with seawater from Reference Site TB5 in a 2.6 mixing ratio.

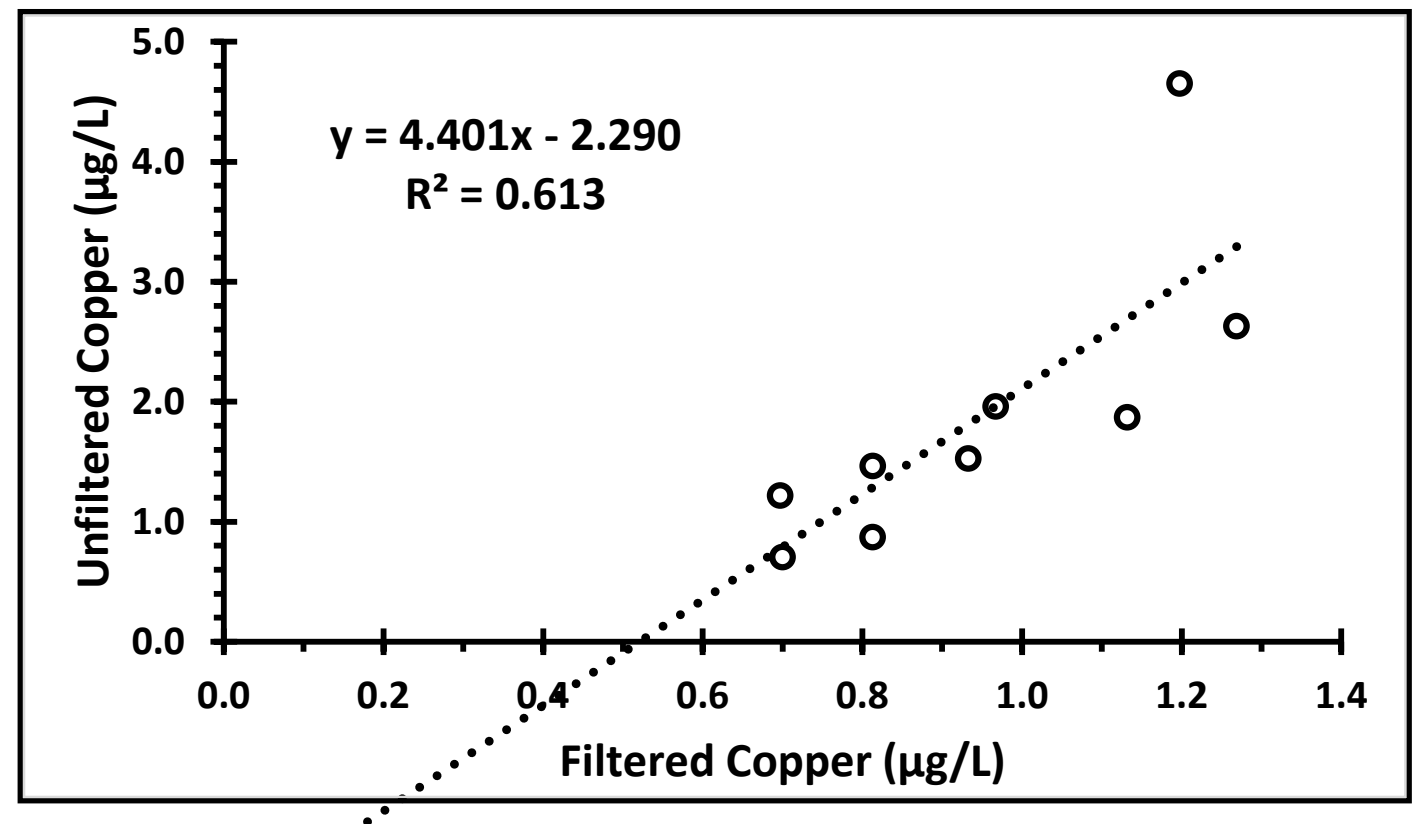

Figure 7-4. Plot of unfiltered vs. filtered copper $(\mu \mathrm{g} / \mathrm{L})$ for the mixture of Apra Harbor Wastewater Treatment Plant with seawater from Reference Site TB5 in a 2.6 mixing ratio.

\subsection{CONCLUSION}

This study investigated the relationship between total and dissolved nickel and copper resulting from the mixing of treated wastewater effluent from Apra Harbor WWTP with ambient seawater from reference Site TB5 in Tipalao Bay of the Philippine Sea. The study was designed to estimate the fraction of total recoverable metal in the effluent that will be in the dissolved fraction in the ambient seawater, which is defined as a chemical translator (USEPA, 1996a). Estimation of the 
dissolved fraction supports the use of ambient water quality criteria for regulation of point-source effluents, as it better represents the bioavailable (i.e., toxic) fraction of the metal in ambient waters. Eleven mixtures were prepared from samples collected on a monthly basis from 25 April 2013 to 7 May 2014. Unfiltered and filtered nickel and copper were quantified in these mixtures following clean-techniques (USEPA, 1996b), by flow injection analysis with ICP-MS. In accordance with USEPA (1996a) guidance, one data point associated with the nickel chemical translator (( $\left.\mathrm{f}_{\mathrm{D}} \mathrm{Nickel}\right)$ was adjusted down from 1.02 to 1.00 , and the geometric mean of the accepted individual $f_{D}$ Nickel was 0.771 . Two samples were omitted from the calculation of the copper chemical translator $\left(\mathrm{f}_{\mathrm{D}}\right.$ Copper) as measured concentrations were below the limit of detection in accordance with USEPA (1996a). The geometric mean of the accepted individual $f_{D}$ copper measurements was 0.573. These geometric means can be used for determination of the expected dissolved fraction of either Copper or Nickel in the effluent of Apra Harbor WWTP as it enters Tipalao Bay. 


\section{COPPER BIOAVAILABILITY AND TOXICITY STUDIES TOWARDS IMPROVED REGULATORY DISCHARGE LIMITS FOR GUAM, USA}

This section describes results from EPA-approved test methods for derivation of site-specific water quality criteria for copper using side-by-side standard laboratory toxicity tests comparing toxicity of added metal in laboratory water with that of water collected from the study site, commonly referred to as a Water Effect Ratio study. Additional lines of evidence are also provided, including use of the marine Biotic Ligand Model. Observed toxicity to aquatic organisms is related to bioavailability, which is insufficiently predicted by total or dissolved copper (Anderson and Morel, 1978; Kim, Ma, Allen, and Cha., 1999). Overwhelming evidence shows that site-specific physical and chemical characteristics (e.g., dissolved organic carbon, suspended solids, natural ligands, etc.) of seawater have the potential to bind with metals, rendering them less bioavailable to marine organisms (e.g., Knezovich, Harrison, and Tucker, 1981; Stauber et al., 2000; Eriksen, Mackey, van Dam, and Nowak, 2001; Lorenzo, Nieto, and Beiras, 2002; Rosen, Rivera-Duarte, Kear Padilla, and Chadwick, 2005; Arnold, Cotsifas, and Corneillie, 2006; Bosse et al., 2014). Therefore, individual water bodies differ in their potential to buffer against metal toxicity due to site-specific water quality characteristics (e.g., pH, temperature, alkalinity, hardness, suspended solids, and dissolved organic carbon).

\subsection{RELEVANCE TO GUAM}

This study examined direct toxicological effects and bioavailability of copper in 16 near-shore locations around the island of Guam to assess the potential for surface waters from Guam to buffer against copper-associated toxicity. Locations near and adjacent to Tipalao Bay and Apra Harbor were sampled on 29 April 2013, while several sites at less industrialized locations around the island were also assessed. Two types of toxicity tests were conducted, both of which included 48-hour embryolarval development tests using mussels (USEPA, 1995b). The first test involved direct exposure of all 16 surface seawater samples to assess potential ambient toxicity. The second test involved addition of multiple copper concentrations to five select samples to derive median effective concentrations (EC50s) and water effect ratios (WERs) for an initial assessment of bioavailability, and potential adjustment of NPDES discharge limits for copper in Guam based on relative bioavailability. The rationale for deriving site-specific WQC is to provide flexibility in establishing discharge limits under the NPDES while still providing the same level of protection intended in the USEPA's WQC derivation guidelines (USEPA, 1985).

The USEPA has long recognized that bioavailability-altering water chemistry (e.g., pH, salinity, and DOC) at marine sites differs, and various methods for the measurement and calculation of a sitespecific criterion have been developed, including the WER procedure (USEPA, 1994a) used here. Numerous studies throughout the nation have also examined the application of WERs as a means of determining the site-specific toxicity of copper (Gauthier et al., 1995; Rosen et al., 2005; Rosen, Rivera-Duarte, Johnston, and Pdegracz, 2009; Earley et al., 2007; CH2M Hill, 2000; USEPA, 1994c; ESD, 1998; Bosse et al., 2014). In many of these studies, the magnitude of the WER was linked to the concentration of dissolved organic carbon (DOC) concentrations at the sites. In particular, DOC concentration appears to reliably predict mussel embryo EC50s exposed to dissolved copper (Arnold, 2005; Arnold, Cotsifas, and Corneillie, 2006; HydroQual, 2012).

SSC Pacific also used the marine Biotic Ligand Model (BLM) for copper to predict the copper concentration that results in toxicity to bivalve embryos. The freshwater version of the BLM became USEPA approved in 2007 (USEPA, 2007), and the marine version of this model is currently under review by USEPA, as an alternative to the WER procedure for developing site-specific criteria. The 
only data required include basic water chemistry parameters (e.g., temperature, salinity, $\mathrm{pH}$, and DOC [HydroQual, 2012]). The BLM is based on the concept that toxicity occurs when the metalbiotic ligand complex reaches a critical concentration. The biotic ligand interacts with the metal ions in solution and the amount of metal that binds is determined by a competition for metal ions between the biotic ligand and other complexing ligands, particularly dissolved organic matter (DOM), and the competition for the biotic ligand between the toxic metal ion and the other metal ions in solution. The model is a generalization of the free ion activity model (FIAM), which indicates that the free metal ion is the best predictor of toxicity.

The BLM and empirical toxicity data were both used to estimate dissolved copper concentrations that would provide the level of protection intended by USEPA. These concentrations were expressed as site-specific criteria, which involved integration of nationally recommended water quality criteria with adjustments for copper bioavailability at the site.

\subsection{MATERIALS AND METHODS}

This section provides the details of the field methods and laboratory materials utilized during the study to ensure that data and information measured was accurate and precise. The information presented demonstrates that the near-shore areas around the island of Guam are not impaired for copper and establishes a site-specific copper criteria for Guam. .

\subsubsection{Study Site}

The U.S. Navy maintains a NPDES permit (NPDES Permit No. GU0110019) pursuant to U.S. USEPA regulations set forth in Title 40, Code of Federal Regulations (CFR), Part 122.21, for the discharge of treated effluent from its Apra Harbor WWTP to the Tipalao Bay of the Philippine Sea. Effluent is pumped through the Tipalao Bay ocean outfall (Discharge Point No. 001), a predominantly subsurface offshore steel pipeline that terminates approximately 1,800 feet offshore at a depth of 120 feet.

Corrosion of the drinking water distribution pipes and fixtures into the Apra Harbor sewer systems are likely sources of copper to Tipalao Bay. In addition, a number of smaller industrial sources may account for copper in Tipalao Bay, including Collect Hold and Transfer (CHT) tanks associated with ships sanitary, the three bilge oily wastewater treatment units, the Fleet Industrial Service Center (FISC) fuel reclamation unit, heat exchanger coil and cooling tower corrosion, and vehicle maintenance shops.

The definition of the 'Site' is critical towards the development of site-specific criteria, as individual results are typically pooled and are required to meet certain specifications (e.g., USEPA, 1994a). Meetings with NAVFAC Marianas and Guam EPA resulted in consensus that the 'Site' in this case should represent the island of Guam and not simply the area immediately adjacent to the outfall. We ultimately sampled 16 near-shore surface water locations (Table 8-1, Figure 8-1) based on specific comments and suggestions from the aforementioned meetings. We characterized all stations for chemical constituents and ambient toxicity, and selected a subset for conducting the WER study.

\subsubsection{Water Collection}

The team conducted one sampling event in Guam on 29 April 2013, where we collected seawater samples at 1-m depth from the 16 stations listed in Table 8-1 and shown geographically in Figure 81. Sample collection times, locations, and descriptions are summarized in Table 8-1. We sampled all stations for toxicity testing, dissolved copper, total suspended solids (TSS), dissolved organic carbon 
(DOC), salinity (ppt), $\mathrm{pH}$, dissolved oxygen $(\mathrm{mg} / \mathrm{L})$, and temperature $\left({ }^{\circ} \mathrm{C}\right)$. Additionally, sites selected for the WER study were sampled for total organic carbon (TOC).

Trace metal clean techniques (USEPA, 1996b) were used throughout preparation of sampling equipment, and during sampling, manipulation and analysis of the samples. This included acid soaking of sampling material and equipment, and collection of water using clean hands-dirty hands techniques. Samples for measuring metals were filtered in place with acid-cleaned $0.45-\mu \mathrm{m}$ PTFE membranes with polypropylene housings (Whatman ${ }^{\mathrm{TM}}$ disposable syringe filters) and collected in 125-mL HPDE bottles. We collected TOC and DOC samples in pre-cleaned 125-mL amber bottles, with the DOC samples first filtered through pre-cleaned syringes with polypropylene plungers and ashed GF/F filter capsules. All samples were placed in clean bags and placed in coolers with ice until shipment to the appropriate laboratory.

Personnel hand carried all samples to SSC Pacific bioassay laboratory for toxicity testing and metals analysis. The lab received the samples 29 April 2013 at 09:45 a.m. (note: sample and receipt times are particular to the time zones where they were recorded; sample collection was taken in the Chamorro Time Zone [UTC+10:00]; sample receipt was recorded in the Pacific Time Zone [UTC08:00]). Upon arrival, SSC Pacific personnel immediately evaluated the samples for condition and water quality parameters. Samples were stored at $4{ }^{\circ} \mathrm{C}$ upon arrival. Samples for TOC and DOC were shipped for analysis at the Pacific Northwest National Laboratory (PNNL) in Sequim, WA.

\subsubsection{Dissolved Copper Concentrations}

Metal concentrations in the spiked seawater used for the toxicity tests were quantified by dilution and direct injection into an ICP-MS. The samples were diluted to a factor of 31 with $\mathrm{pH} \leq 2$ $18-\mathrm{M} \Omega / \mathrm{cm}$ water. Each run included two duplicates (average recovery \pm standard deviation, $88 \pm 4 \%$ for copper, and $106 \pm 14 \%$ for nickel), and one spiked sample (89\% recovery for copper and 91\% recovery for nickel. The lab analyzed a blank made up of $0.45-\mu m$ filtered seawater from outside San Diego Bay. The blank was sampled on 1 September 2011, and acidified to $\mathrm{pH} \leq 2$ with quartz-still grade nitric acid every five samples to ensure cleanliness of the system and provide a reference point for the background metal concentration with an average concentration of $0.039 \pm 0.08-\mu \mathrm{g} / \mathrm{L}$ copper and $0.13 \pm 0.22-\mu \mathrm{g} / \mathrm{L}$ nickel. SSC Pacific also analyzed the standard reference material (SRM) 1643e, trace elements in water, from the National Institute of Standards \& Technology, every five samples. We did this to ensure that the instrument was measuring accurately and precisely, with a recovery of $105 \pm 9.1 \%$ of the certified concentration of $22.76 \pm 0.31 \mu \mathrm{g} / \mathrm{L}$ for copper, and $109 \pm 17.3 \%$ of the certified concentration of $62.41 \pm 0.69 \mu \mathrm{g} / \mathrm{L}$ for nickel.

Dissolved nickel and copper concentrations in ambient water samples were measured using in-line pre-concentration flow injection analysis into an ICP-MS (Ndung'u, Franks, Bruland, and Flegal, 2003). Samples are treated online with TOYOPEARL AF-Chelate-650M resin in a Perkin-Elmer Flow Injection Analysis System (FIAS) 400 to remove salt from the sample, and then transferred into the ICP-MS for metal concentration quantification. Each run included two duplicates (average recovery \pm standard deviation, $104 \pm 7.1 \%$ for copper and $127 \pm 56 \%$ for nickel), and two spiked samples (92 $\pm 24 \%$ for copper, and $93 \pm 16 \%$ for nickel). For every five samples, a blank was analyzed. The blank was the 0.45 - $\mu$ m filtered seawater from outside San Diego Bay sampled on September 1, 2011, which had an average concentration of $0.23 \pm 0.056 \mu \mathrm{g} / \mathrm{L}$ for copper, and -0.037 $\pm 0.060 \mu \mathrm{g} / \mathrm{L}$ for nickel. We also quantified the Standard Reference Material CASS 4 (coastal seawater), from the National Research Council of Canada, every five samples. We had an average recovery of $103 \pm 8.9 \%$ of the certified copper concentration of $0.592 \pm 0.055 \mu \mathrm{g} / \mathrm{L}$, and $109 \pm 16.8 \%$ of the certified nickel concentration of $0.314 \pm 0.030 \mu \mathrm{g} / \mathrm{L}$. Reported concentrations are not corrected for blank or SRM recoveries. 
Table 8-1. Sample collection times and site descriptions.

\begin{tabular}{|c|c|c|c|c|c|}
\hline \multirow{2}{*}{ Site ID } & \multirow{2}{*}{$\begin{array}{l}\text { Sample Collection } \\
\text { Date/Time }\end{array}$} & \multirow{2}{*}{ Site Description } & \multicolumn{2}{|c|}{ GPS Coordinates } & \multirow{2}{*}{ Tests / Analyses Conducted } \\
\hline & & & Latitude & Longitude & \\
\hline G1 & 4/29/2013 08:58 & Port Ops & 13.25 .002 & 144.39 .670 & $\begin{array}{l}\text { WER, AT, DCu, DOC, TOC, } \\
\text { BLM }\end{array}$ \\
\hline $\mathrm{G} 2$ & 4/29/2013 09:46 & TB-5 - Reference Station & 13.24.717 & 144.38 .946 & AT, DCu, DOC, BLM \\
\hline G3 & 4/29/2013 10:00 & TB-3 - Outfall & 13.24 .914 & 144.38 .610 & $\begin{array}{l}\text { WER, AT, DCu, DOC, TOC, } \\
\text { BLM }\end{array}$ \\
\hline G4 & 4/29/2013 10:15 & Shark's Pit & 13.25 .288 & 144.38 .360 & AT, DCu, DOC, BLM \\
\hline G5 & $4 / 29 / 201310: 28$ & Orote Dump Site & 13.25 .798 & 144.38 .301 & AT, DCu, DOC, BLM \\
\hline G6 & 4/29/2013 10:47 & Mouth of Apra Harbor & 13.27.056 & 144.37 .402 & AT, DCu, DOC, BLM \\
\hline G7 & 4/29/2013 11:15 & $\begin{array}{l}\text { Commercial Port, Piti Canal } \\
\text { (Back Bay) }\end{array}$ & 13.27.582 & 144.40 .402 & AT, DCu, DOC, BLM \\
\hline G8 & 4/29/2013 11:36 & $\begin{array}{l}\text { Sasa Bay/Dry Dock Point in } \\
\text { inner harbor }\end{array}$ & 13.26 .960 & 144.40 .223 & $\begin{array}{l}\text { WER, AT, DCu, DOC, TOC, } \\
\text { BLM }\end{array}$ \\
\hline G9 & 4/29/2013 11:45 & Dry Dock in Apra Harbor & 13.26 .631 & 144.39 .646 & AT, DCu, DOC, BLM \\
\hline G10 & 4/29/2013 13:50 & Piti Canal & 13.27.961 & 144.41 .137 & AT, DCu, DOC, BLM \\
\hline G11 & 4/29/2013 14:40 & Hagatna - Near Agana River & 13.28 .684 & 144.45 .286 & AT, DCu, DOC, BLM \\
\hline G12 & $4 / 29 / 201315: 50$ & Tumon Bay & 13.30 .696 & 144.48 .126 & AT, DCu, DOC \\
\hline G13a & 4/29/2013 16:15 & Tanguisson (within seep) & 13.32.872 & 144.48 .637 & $\begin{array}{l}\text { WER, AT, DCu, DOC, TOC, } \\
\text { BLM }\end{array}$ \\
\hline G13b & 4/29/2013 16:30 & Tanguisson (outside seep) & & & $\begin{array}{l}\text { WER, AT, DCu, DOC, TOC, } \\
\text { BLM }\end{array}$ \\
\hline G14 & 4/29/2013 17:20 & Pago Bay & 13.25 .659 & 144.47 .939 & AT, DCu, DOC, BLM \\
\hline G15 & 4/29/2013 14:18 & Hagatna Marina Boat Ramp & 13.28.655 & 144.44 .962 & AT, DCu, DOC, BLM \\
\hline
\end{tabular}

WER - Water Effect Ratio study, AT - Ambient Toxicity Testing, DCu - Dissolved Copper, DOC - Dissolved Organic Carbon, TOC - Total Organic Carbon 

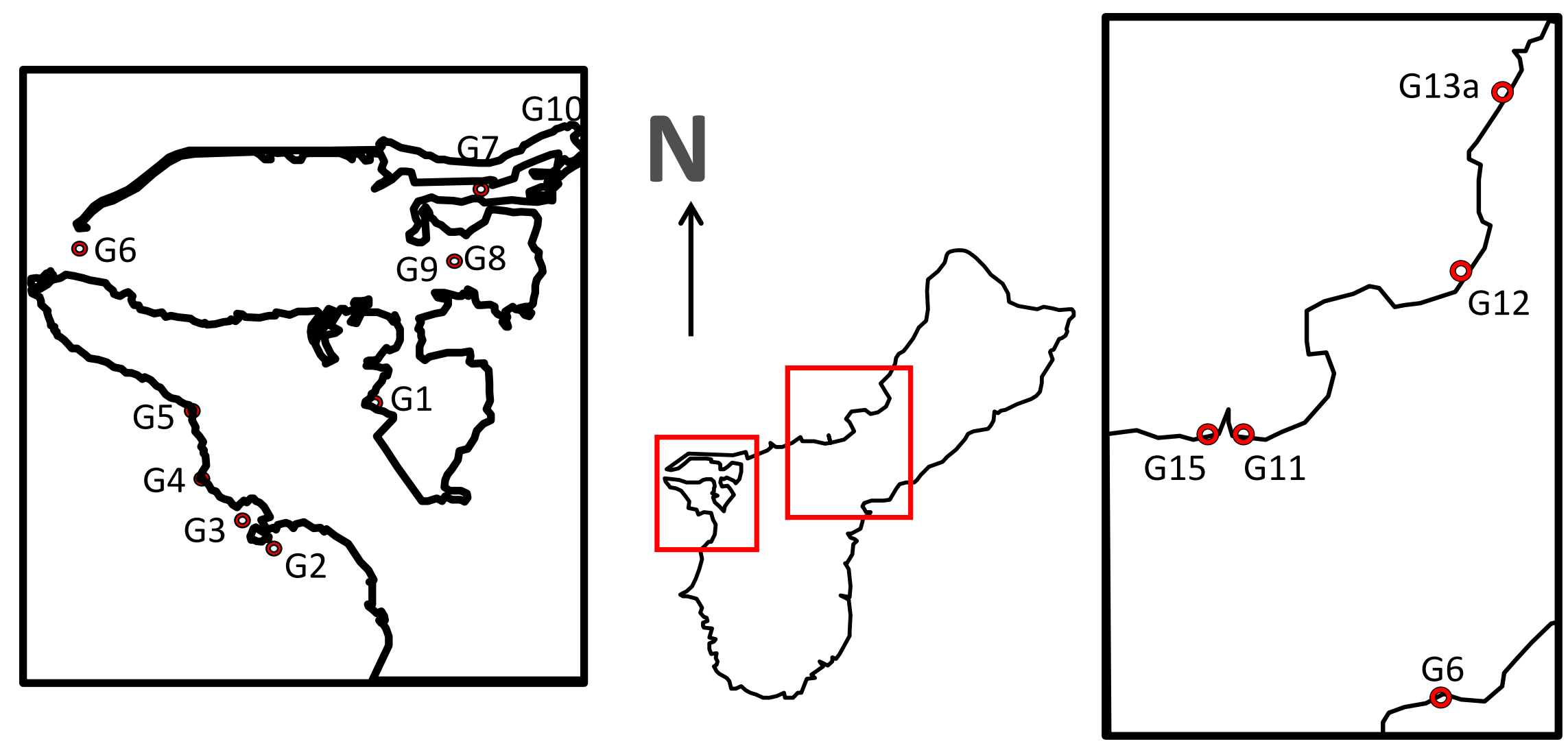

Figure 8-1 Sampling locations in near-shore areas around Guam, including overview of all 16 locations, with the focus in and around Tipalao Bay and Apra Harbor. Ambient toxicity testing and the Biotic Ligand Model were used to predict copper toxicity at all 16 stations. The Water Effect Ratio study was conducted for stations G1, G3, G8, and for two samples collected at G13. 


\subsubsection{DOC and TSS Analysis}

Dissolved organic carbon (DOC) and total suspended solids (TSS) were quantified for all ambient samples. For DOC, sub-samples were filtered through a $0.7-\mu \mathrm{m}$ nominal pore size pre-combusted glass fiber filter and immediately transferred to 125 - $\mathrm{mL}$ amber glass bottles containing $8-\mu \mathrm{L} 85 \%$ $\mathrm{H}_{3} \mathrm{PO}_{4}$. The bottles were quickly sealed and placed on ice for shipment. We conducted $18 \mathrm{M} \Omega / \mathrm{cm}$ water blanks and method blanks (rinsed through syringe and filter unit) at the beginning, middle, and end of each survey. Method blanks were all less than the reporting limit, with values ranging from 3.3 to $6.7 \mu \mathrm{M}$. Method detection limits and reporting limits for the laboratory were 0.030 and 0.095 mg/L, respectively. SSC Pacific used a High Temperature Catalytic Oxidation (HTCO) method to analyze the DOC samples. The instrument is specially equipped with a high-salt sample combustion tube kit and halogen scrubber for seawater analysis. Seawater samples were acidified to $\mathrm{pH}<2$ by concentrated hydrochloric acid (trace metal grade, Fisher Chemical) prior to analysis, then charged for 2 minutes to remove inorganic carbon (IC). The non-purgeable organic carbons (NPOC) in samples were further converted to $\mathrm{CO}_{2}$ by oxidation at $680^{\circ} \mathrm{C}$ with a platinum catalyst. A nondispersive infrared detector (NDIR) was used to detect the converted $\mathrm{CO}_{2}$ for quantification of NPOC.

Sub-samples of all ambient sites were quantified for TSS by filtering an average of $853 \pm 193 \mathrm{~mL}$ of sample through pre-dried and pre-weighed glass-fiber filters (1.2- $\mu \mathrm{m}$ nominal pore size). The filters were rinsed with deionized water to remove dissolved salts, then dried and weighed to determine the mass of the filtered solids. The limit of detection, based on the lowest detected TSS concentration, was $0.866 \mathrm{mg} \mathrm{L}^{-1}$.

\subsubsection{Toxicity Testing}

Environmental parameters were monitored in the laboratory during the toxicity testing for quality control and test acceptability. Parameters included temperature, $\mathrm{pH}$, salinity, and dissolved oxygen (DO). These measurements were also required for calculation of chemical speciation and toxicity with the marine BLM (HDR | HydroQual, 2012).

SSC Pacific used two approaches to assess toxicity, including (1) exposures with site (ambient) water samples, and (2) site water samples spiked with multiple concentrations of copper for WER determinations. We investigated ambient toxicity by exposing $M$. galloprovincialis embryos to seawater collected from the water surface (top 1 meter) from each site (Figure 8-1). We added copper to unfiltered surface seawater from the five WER sites (Sites G1, G3, G8, G13a and G13b) and a laboratory control seawater sample at 10 nominal copper concentrations $(0,2.9,4.2,5.8,8.4,12$, 17.2, 24, 35, and $50 \mu \mathrm{g} / \mathrm{L}$ ). We did this to derive median effective concentrations (EC50) for calculating a site-specific criterion for copper (USEPA, 1994a). Filtered $(0.45-\mu \mathrm{m})$ seawater from the Marine Pollution Studies Laboratory at Granite Canyon (GC), Monterey, California, served as a laboratory control due to its previously reported acceptability for embryo-larval development tests and relatively low DOC concentration (Rosen et al., 2008).

The team conducted both ambient and WER toxicity testing at the SSC Pacific Bioassay Laboratory, San Diego, California, following the methods published in USEPA (1995b) and summarized in Table 8-2. We stored water samples at $4{ }^{\circ} \mathrm{C}$ and initiated the bioassays on 2 May 2013, within 96 hours of collection (USEPA, 2001). Exposures were conducted in 20-mL glass scintillation vials that were pre-conditioned in uncontaminated filtered seawater (FSW) for 24 hours, rinsed with deionized (DI) water, and dried prior to use. We replicated each water sample and laboratory control four times, with each vial consisting of a 10-mL sample. Spiked copper solutions were prepared in 125-mL Erlenmeyer flasks, which were acid cleaned and pre-conditioned in FSW

for 24 hours, then rinsed with DI water. We allowed all spiked and unspiked samples associated with 
the WER exposures to equilibrate in an incubator for 1 to 3 hours at $18^{\circ} \mathrm{C}$ before addition of embryos.

Adult gravid M. galloprovincialis were purchased from Carlsbad Aquafarm (Carlsbad, California) and induced to spawn by thermal shock (raising the temperature by about $10^{\circ} \mathrm{C}$ from ambient). Within 4 hours of fertilization, approximately 150 embryos, at or beyond the two-cell stage, were transferred to each test vial. We incubated vials at $18^{\circ} \mathrm{C}$ for 48 hours under a 16-hour light:8-hour dark photoperiod. At 0,24 , and 48 hours, water quality measurements including $\mathrm{pH}$, temperature, $\mathrm{DO}$, and salinity were recorded. Once the successful development of embryos in the control treatments was established (within 46 to 50 hours of initiation), the tests were terminated by adding $10 \%$ buffered formalin to each vial. Larval development in the laboratory and ambient site water samples was evaluated using two endpoints: proportion normal and normal survival. The proportion normal endpoint is defined as the number of normal straight-hinged, D-shaped larvae relative to the total number of larvae (normal and abnormal) counted in a vial at the conclusion of the test. In comparison, the normal survival endpoint measures the percentage of normally developed D-shaped larvae observed at the end of the test relative to the initial number of embryos added to the test vial, as determined from initial density vials preserved shortly after test initiation. Normal survival is generally considered a more comprehensive endpoint, as it considers both survival and normal larval development success.

Ambient toxicity was evaluated by comparing larval development success from Guam samples with laboratory controls using two-sample t-tests $(\alpha=0.05)$. The $\%$ normal alive larvae from the multi-concentration tests were used to calculate EC50 values using measured dissolved copper (DCu)

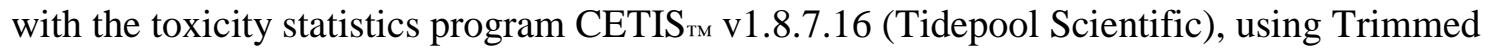
Spearman Karber (TSK) methods. The site-specific criterion for each station was calculated using the EC50s, WERs and current national WQC (3.1 $\mu \mathrm{g} \mathrm{L}^{-1}$; USEPA, 2006b). The WER served as a multiplier to adjust the national WQC to a more relevant site-specific criterion, and was used as shown in the following equation (Equation 8-1), (USEPA, 1994a):

$$
W E R=E C 50_{\text {site }} E C 50_{\text {lab }}
$$

and

$$
S S C=3.1 \mu g L^{-1} 1 W E .
$$

Equation 8-1. $\mathrm{EC} 50_{\text {site }}$ is the site water $\mathrm{EC} 50$ and $\mathrm{EC} 50_{\mathrm{lab}}$ is the laboratory water $\mathrm{EC} 50$ (GC seawater).

The team used quality assurance (QA) procedures in accordance with the SSC Pacific QA Manual to conduct and evaluate toxicity testing, which is based on applicable protocols and guidance documents. These procedures include all aspects of testing, including the source, handling, condition, receipt, and proper storage of samples and test organisms, as well as the appropriate calibration and maintenance of instruments and equipment. All data generated by the laboratory were evaluated for completeness and accuracy. Appropriate laboratory controls were conducted with each test, and were required to meet specific test acceptability criteria. For the mussel test, $\geq 70 \%$ normally developed larvae relative to the number of embryos initially added (\% normal alive) in the controls is required for the test to be acceptable. In addition, reference toxicant tests were conducted with each test, as a measure of the laboratory's performance and test batch sensitivity. Reference toxicant EC50 values were required to be within two standard deviations of the laboratory's running mean. 


\subsubsection{Biotic Ligand Model}

The BLM is a chemical speciation model that can be used to predict the equivalent of a sitespecific criterion for a given body of water, defined here as the estimated chronic limit (ECL). For this study, the draft BLM for copper in saltwater (HDR | HydroQual, 2012), currently under review for publication by the USEPA, was used to calculate a site-specific criterion for Guam. Application of the marine BLM required only water chemistry data (i.e., salinity, temperature, $\mathrm{pH}$ and DOC) from the site. Using chemical speciation data of the different components in seawater, the BLM predicts the dissolved copper that would provide enough binding at the biotic ligand to reach the

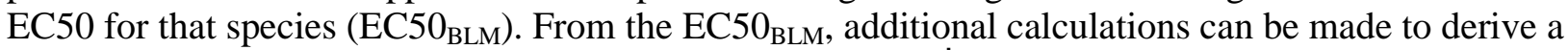
site-specific criterion, currently expressed as the ECL (HDR | Hydroqual, 2012).

Table 8-2. Bivalve embryo development test specifications.

\begin{tabular}{|c|c|}
\hline Test period & 2 to 5 May 2013 \\
\hline Test endpoints & $\begin{array}{l}\text { Embryo Development Rate (Proportion Normal) } \\
\text { Embryo Combined Development Rate (\% Normal Alive) }\end{array}$ \\
\hline Test organism & Mytilus galloprovincialis (Mediterranean mussel) \\
\hline Test organism source & Carlsbad Aquafarms; Carlsbad, California \\
\hline Test solution renewal & None \\
\hline Feeding & None \\
\hline Test chamber & 20-ml scintillation vial \\
\hline Test solution volume & $10 \mathrm{ml}$ \\
\hline Test temperature & $18 \pm 1^{\circ} \mathrm{C}$ \\
\hline Control/Dilution water & $\begin{array}{l}\text { Natural seawater (Source: Marine Pollution Studies } \\
\text { Laboratory at Granite Canyon (GC), Monterey, California) }\end{array}$ \\
\hline Additional control & Salt Control \\
\hline Sample manipulation & $\begin{array}{l}\text { Artificial sea salt was used to increase the salinity of } \\
\text { sample G11 to } 34 \pm 2 \text { ppt. No other samples were altered. }\end{array}$ \\
\hline Number of organisms/chamber & $\begin{array}{l}200 \text { eggs, appropriate sperm density to provide }>95 \% \\
\text { fertilization success (determined in a pre-test trial) }\end{array}$ \\
\hline Minimum number of replicates & 4 \\
\hline Photoperiod & 16 hours light:8 hours dark \\
\hline Test protocol & ASTM 1999 and USEPA 1995b (600/R-95/136) \\
\hline $\begin{array}{l}\text { Test acceptability criteria for } \\
\text { controls }\end{array}$ & $\begin{array}{l}\geq 70 \% \text { normal development of embryos added to a given } \\
\text { vial, }<25 \% \text { Minimum Significant Difference (MSD) }\end{array}$ \\
\hline Reference toxicant & Copper sulfate \\
\hline
\end{tabular}




\subsection{RESULTS}

\subsubsection{Water Quality Characteristics}

Table 8-3 lists water quality parameters measured during sample collection with portable meters. Water quality parameters measured for the ambient samples upon receipt at the SSC Pacific laboratory are listed in Table 8-4. Table 8-5 lists the copper measurements and other water quality characteristics for input into the BLM, DOC (mg/L), TOC (mg/L), and TSS (mg/L) of ambient site waters and the Granite Canyon Laboratory water.

Arrival temperature of water samples in San Diego minimally exceeded recommended guidelines $\left(0\right.$ to $\left.6{ }^{\circ} \mathrm{C}\right)$; however, samples had undergone substantial cooling during transport $(<24 \mathrm{~h})$, and were immediately stored at $4{ }^{\circ} \mathrm{C}$ upon arrival in San Diego, which is acceptable per the laboratory's QA Manual.

Table 8-3. Water quality parameters as measured during sample collection.

\begin{tabular}{|c|c|c|c|c|}
\hline \hline Site ID & $\begin{array}{c}\text { Temperature } \\
\left({ }^{\circ} \mathrm{C}\right)\end{array}$ & $\begin{array}{c}\text { Salinity } \\
(\mathrm{ppt})\end{array}$ & $\begin{array}{c}\mathrm{pH} \\
(\mathrm{pH})\end{array}$ & $\begin{array}{c}\mathrm{DO} \\
(\mathrm{mg} / \mathrm{L})\end{array}$ \\
\hline \hline $\mathrm{G} 1$ & 29.2 & 34.8 & 8.12 & 6.2 \\
\hline $\mathrm{G} 2$ & 28.8 & 34.7 & 8.19 & 6.4 \\
\hline $\mathrm{G} 3$ & 28.8 & 34.6 & 8.20 & 6.5 \\
\hline $\mathrm{G} 4$ & 28.8 & 34.7 & 8.20 & 6.4 \\
\hline $\mathrm{G} 5$ & 28.8 & 34.6 & 8.21 & 6.5 \\
\hline $\mathrm{G} 6$ & 29.0 & 37.3 & 8.19 & 6.4 \\
\hline $\mathrm{G} 7$ & 30.2 & 34.6 & 8.15 & 6.2 \\
\hline $\mathrm{G} 8$ & 29.3 & 34.4 & 8.15 & 6.8 \\
\hline G9 & 29.1 & 34.6 & 8.17 & 6.2 \\
\hline G10 & 29.5 & 33.7 & 8.08 & 7.0 \\
\hline G11 & 32.8 & 25.7 & 8.21 & 10.9 \\
\hline G12 & 30.8 & 30.7 & 8.28 & 10.3 \\
\hline G13a & NM & 20.1 & 8.38 & 13.5 \\
\hline G13b & 31.7 & 26.0 & 8.34 & 12.3 \\
\hline G14 & 29.7 & 33.4 & 8.28 & 9.4 \\
\hline G15 & 29.7 & 34.4 & 8.09 & 6.3 \\
\hline
\end{tabular}

$\mathrm{NM}=$ not measured 
Table 8-4. Water quality parameters as measured upon receipt at the SSC Pacific Bioassay Laboratory.

\begin{tabular}{|c|c|c|c|c|}
\hline Site ID & $\begin{array}{c}\text { Temperature } \\
\left({ }^{\circ} \mathrm{C}\right)\end{array}$ & $\begin{array}{c}\text { Salinity } \\
(\mathrm{ppt})\end{array}$ & $\begin{array}{c}\mathrm{pH} \\
(\mathrm{pH})\end{array}$ & $\begin{array}{c}\mathrm{DO} \\
(\mathrm{mg} / \mathrm{L})\end{array}$ \\
\hline \hline $\mathrm{GC}$ & 18.9 & 34 & 7.70 & 8.5 \\
\hline $\mathrm{G} 1$ & 7.0 & 35 & 7.85 & 8.8 \\
\hline $\mathrm{G} 2$ & 7.0 & 35 & 8.07 & 8.9 \\
\hline $\mathrm{G} 3$ & 7.0 & 35 & 7.96 & 8.6 \\
\hline $\mathrm{G} 4$ & 7.0 & 36 & 8.09 & 8.6 \\
\hline $\mathrm{G} 5$ & 7.0 & 36 & 8.08 & 8.6 \\
\hline $\mathrm{G} 6$ & 7.0 & 36 & 8.06 & 8.7 \\
\hline $\mathrm{G} 7$ & 7.0 & 36 & 8.06 & 9.0 \\
\hline $\mathrm{G} 8$ & 7.0 & 36 & 7.93 & 8.8 \\
\hline $\mathrm{G} 9$ & 7.0 & 36 & 8.03 & 9.0 \\
\hline G10 & 7.0 & 34 & 7.97 & 9.0 \\
\hline G11 & 7.0 & 21 & 8.15 & 8.9 \\
\hline G12 & 7.0 & 33 & 8.18 & 8.9 \\
\hline G13a & 7.0 & 30 & 8.09 & 8.9 \\
\hline G13b & 7.0 & 30 & 8.05 & 8.9 \\
\hline G14 & 7.0 & 33 & 7.16 & 9.0 \\
\hline G15 & 7.0 & 35 & 8.06 & 9.6 \\
\hline
\end{tabular}


Table 8-5. Water quality characteristics for Granite Canyon Laboratory water (GC) and the 16 site waters from Guam.

\begin{tabular}{|c|c|c|c|}
\hline Site ID & $\begin{array}{c}\mathrm{DCu} \\
(\mu \mathrm{g} / \mathrm{L}) \\
\end{array}$ & $\begin{array}{c}\text { TSS } \\
(\mathrm{mg} / \mathrm{L}) \\
\end{array}$ & $\begin{array}{c}\mathrm{DOC} \\
(\mathrm{mg} / \mathrm{L}) \\
\end{array}$ \\
\hline GC & $1.90^{\star}$ & NM & 0.659 \\
\hline G1 & 0.661 & ND & 0.832 \\
\hline G2 & 0.257 & ND & 0.949 \\
\hline G3 & 0.174 & ND & 0.899 \\
\hline G4 & 0.199 & ND & 0.909 \\
\hline G5 & 0.224 & ND & 0.899 \\
\hline G6 & 0.277 & ND & 0.820 \\
\hline G7 & 0.469 & 2.1 & 0.870 \\
\hline G8 & 0.474 & ND & 0.819 \\
\hline G9 & 0.518 & ND & 0.842 \\
\hline G10 & 0.271 & ND & 0.662 \\
\hline G11 & 0.621 & 10.7 & 2.09 \\
\hline G12 & 0.294 & 1.0 & 0.974 \\
\hline G13a & 0.190 & ND & 0.950 \\
\hline G13b & 0.214 & ND & 0.935 \\
\hline G14 & 0.123 & ND & 0.806 \\
\hline G15 & 2.09 & ND & 1.12 \\
\hline
\end{tabular}

*From WER study, not measured as ambient sample. $\mathrm{NM}=$ not measured. $\mathrm{ND}=$ not detected.

TSS values were generally low for all sites and ranged from $<1$ to $10.7 \mathrm{mg} / \mathrm{L}$ (Table 8-5), but an average was not calculated due to the large number of samples that were undetected for TSS. DOC concentrations were also generally relatively low for all sites, ranging from 0.66 to $2.09 \mathrm{mg} / \mathrm{L}$, and averaging $0.97 \pm 0.32 \mathrm{mg} / \mathrm{L}$ ( $\pm 1 \mathrm{SD}$ ).

\subsubsection{Ambient Dissolved Copper Concentrations}

Dissolved copper $(\mathrm{DCu})$ concentrations in ambient samples were approximately one order of magnitude below the current national marine chronic WQC (3.1 $\mu \mathrm{g} / \mathrm{L}$; USEPA 1995a), averaging $0.44 \pm 0.47 \mu \mathrm{g} / \mathrm{L}$ ( $\pm 1 \mathrm{SD}$ ) (Table 8-5).

\subsubsection{Toxicity Testing}

Toxicity tests were initiated within the 96-h holding time requirement for WER studies (USEPA, 2001). Salinity, $\mathrm{pH}$, dissolved oxygen, and temperature did not vary substantially among any of the toxicity exposures and were within acceptable ranges for the bioassay (USEPA, 1995b). Mean \pm 1 SD values during the toxicity exposures were as follows: salinity, $34.9 \pm 1.2 \mathrm{ppt}$; $\mathrm{pH}, 8.13 \pm 0.4$; dissolved oxygen, $8.6 \pm 0.2 \mathrm{mg} / \mathrm{L}$; and temperature, $18.2 \pm 0.2{ }^{\circ} \mathrm{C}$. 


\subsubsection{Ambient Toxicity Tests}

Larval development in the unspiked (ambient) laboratory and site water samples was evaluated using two endpoints: proportion normal and \% normal alive. The proportion normal endpoint is defined as the number of normal straight-hinged, D-shaped, larvae relative to the total number of larvae (normal and abnormal) counted in a vial at the conclusion of the test. Of the surviving larvae, at least $70 \%$ must achieve normal shell development in the controls to meet test acceptability criteria, according to the ASTM (1999).

The mean proportion normal for the GC laboratory control water was $88 \%$. Proportion normal for site waters ranged from 77 to $86 \%$. Significant differences were observed when compared to the laboratory control for stations G2, G7 and G11, with mean proportion normal at 77, 77 and 78\%, respectively (t-tests, $p<0.05$ ). All other sites showed no significant differences when compared to the laboratory control (t-tests, $p>0.05$ ).

In comparison, the \% normal alive endpoint measures the percentage of normally developed Dshaped larvae observed at the end of the test relative to the initial number of embryos added to the test vial, as determined from initial density vials preserved shortly after test initiation. Percent normal alive is generally considered a more comprehensive endpoint, as it considers both survival and normal larval development success. The control test acceptability criterion used in this study for \% normal alive is $\geq 70 \%$ (ASTM, 1999). The unspiked laboratory water sample met the minimum criterion, with normal survival of 70\% (ASTM, 1999). Ambient site waters resulted in mean \% normal alive ranging from 61 to $75 \%$, all of which were statistically indistinguishable from the laboratory water controls, suggesting no adverse effects observed with this endpoint (t-tests, $p>0.05$ ) Figure 8-2, Table 8-6)

\subsubsection{Water Effect Ratio}

When the team added copper to laboratory and site waters, it observed a dose response for all samples (Figure 8-3). We calculated the dissolved EC50, WER, and site-specific criterion for the laboratory control water (Granite Canyon [GC]) and five WER stations: G1, G3, G8, G13a and G13b using measured dissolved copper concentrations for each multi-concentration test (Table 8-7 and Table 8-8). The EC50 value for the laboratory control water, which also served as the reference toxicant, was $9.44 \mu \mathrm{g} / \mathrm{L}$. EC50 values for the site samples were all higher than that of the GC EC50 and ranged from 10.6 to $17.3 \mu \mathrm{g} / \mathrm{L}$, while WERs ranged from 1.12 to 1.83 (table 8-7). WER values greater than 1 suggest protection at the site is greater than that provided by the laboratory water, such as that used in development of the USEPA (1995a) national criterion.

Using the EC50s, WERs, and the current national criterion for DCu (USEPA, 1995a), we calculated a site-specific criterion for each of the five WER sampling locations on Guam (USEPA, 1994b). The site-specific criterion, based on the WER study, ranged from 3.48 to $5.68 \mu \mathrm{g} / \mathrm{L}$. These values average 71\% higher than the USEPA (1995a) national criterion for DCu (3.1 $\mu \mathrm{g} / \mathrm{L})$. A final dissolved WER of 1.40 resulted in a site-specific criterion of $4.34 \mu \mathrm{g} / \mathrm{L}$ for the entire island of Guam (Table 8-7). When combined with the recalculation method used in Section 3, the WER provides an site-specific criterion of $5.75 \mu \mathrm{g} / \mathrm{L}$. 
Table 8-6. Results of two different endpoints from toxicity tests performed with mussel (Mytilus galloprovincialis) embryos collected from 16 stations around Guam.

\begin{tabular}{|l|c|c|c|c|c|c|}
\hline \multirow{2}{*}{ Site ID } & \multicolumn{2}{|c|}{ Proportion Normal } & \multicolumn{4}{c|}{ \% Normal Alive } \\
\cline { 2 - 7 } & Mean & S.D. & Mean & S.D. & $p$ - value & \% of LC \\
\hline \hline LC & 88.4 & 6.4 & 70.0 & 17.7 & - & 100 \\
\hline G1 & 85.7 & 2.0 & 75.7 & 1.0 & 0.562 & 108 \\
\hline G2 & 77.0 & 2.5 & 74.7 & 0.6 & 0.630 & 107 \\
\hline G3 & 78.9 & 4.2 & 71.2 & 4.2 & 0.897 & 102 \\
\hline G4 & 82.7 & 4.8 & 64.1 & 7.4 & 0.571 & 92 \\
\hline G5 & 79.5 & 7.4 & 71.2 & 8.3 & 0.909 & 102 \\
\hline G6 & 82.8 & 5.3 & 69.7 & 4.6 & 0.976 & 100 \\
\hline G7 & 77.5 & 1.9 & 69.4 & 6.7 & 0.953 & 99 \\
\hline G8 & 83.8 & 3.7 & 71.0 & 10.1 & 0.922 & 101 \\
\hline G9 & 79.3 & 4.9 & 67.3 & 6.6 & 0.793 & 96 \\
\hline G10 & 82.3 & 4.4 & 68.3 & 6.5 & 0.872 & 98 \\
\hline G11 & 78.7 & 3.2 & 61.1 & 4.9 & 0.397 & 87 \\
\hline G12 & 81.6 & 4.5 & 68.0 & 4.7 & 0.846 & 97 \\
\hline G13a & 86.3 & 3.2 & 73.6 & 8.0 & 0.723 & 105 \\
\hline G13b & 84.8 & 4.3 & 69.1 & 5.9 & 0.929 & 99 \\
\hline G14 & 83.2 & 1.7 & 69.1 & 7.7 & 0.931 & 99 \\
\hline G15 & 85.7 & 3.3 & 65.7 & 10.7 & 0.696 & 94 \\
\hline Mean & 81.9 & & 69.3 & & & 99.1 \\
\hline Std. Dev. & 3.0 & & 3.8 & & & 5.4 \\
\hline LC Labo & Contro & & & & & \\
\hline
\end{tabular}

LC = Laboratory Control 


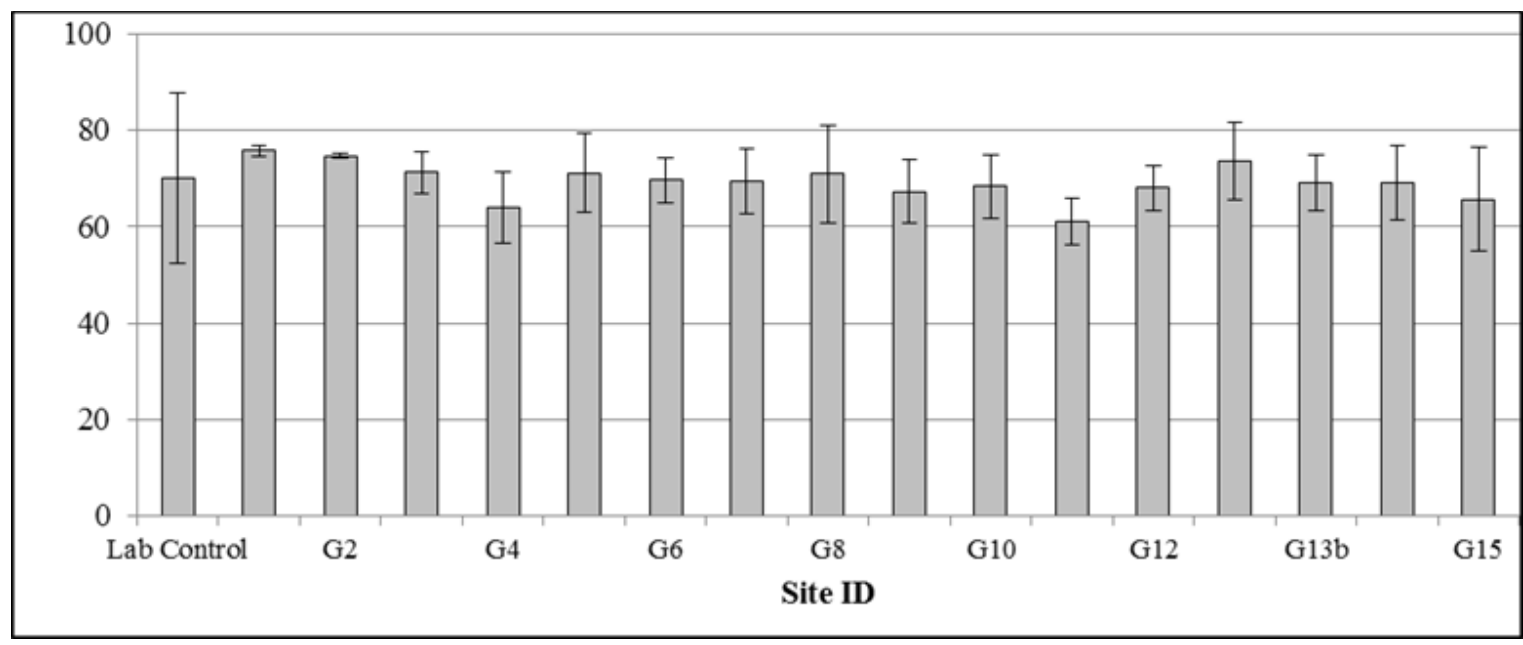

Figure 8-2. Results from embryo-larval development toxicity tests performed with mussel (Mytilus galloprovincialis) on laboratory control (LC) waters and the ambient site samples collected from Guam. Test acceptability in the laboratory control for this endpoint is $70 \%$ normal alive larvae (ASTM 1999), which was met.

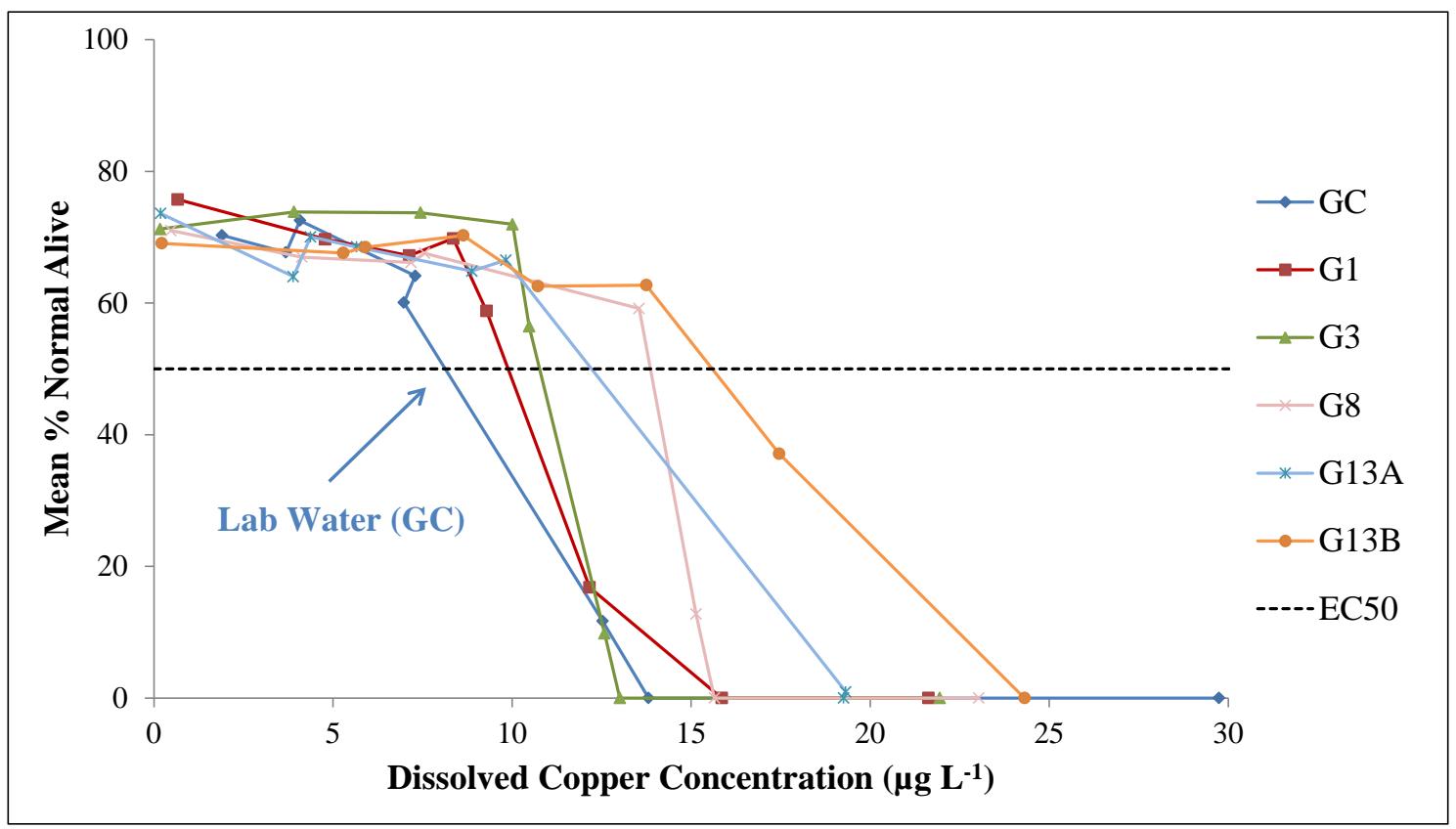

Figure 8-3. Dose response curves for the laboratory water (Granite Canyon [GC]) and each of the five study site water samples collected around Guam for the WER study. 
Table 8-7. Median effective concentrations (EC50), site-specific criteria based on WER

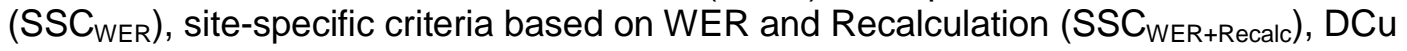
concentrations, and water effect ratios (WER) for the five WER stations and laboratory control.

\begin{tabular}{|l|l|c|c|c|c|c|}
\hline \hline Site ID & Water Type & $\begin{array}{c}\text { DCu } \\
(\mu \mathrm{g} / \mathrm{L})\end{array}$ & $\begin{array}{c}\text { EC50 } \\
(\mu \mathrm{g} / \mathrm{L})\end{array}$ & WER & $\begin{array}{c}\mathrm{SSC}_{\text {WER }} \\
(\mu \mathrm{g} / \mathrm{L})\end{array}$ & $\begin{array}{c}\text { SSC } \\
(\mu \mathrm{g} / \mathrm{L})\end{array}$ \\
\hline \hline GC & Laboratory & $1.90^{*}$ & 9.44 & - & - & - \\
\hline G1 & Site & 0.661 & 10.61 & 1.12 & 3.48 & 4.59 \\
\hline G3 & Site & 0.174 & 11.32 & 1.20 & 3.72 & 4.92 \\
\hline G8 & Site & 0.474 & 13.83 & 1.47 & 4.54 & 6.03 \\
\hline G13a & Site & 0.190 & 13.11 & 1.39 & 4.31 & 5.70 \\
\hline G13b & Site & 0.214 & 17.29 & 1.83 & 5.68 & 7.50 \\
\hline Mean & All Sites & 0.343 & 13.20 & 1.40 & 4.34 & 5.75 \\
\hline
\end{tabular}

Table 8-8. Measured dissolved copper concentrations for each of the test concentrations used in the WER study for the five site water stations and the GC laboratory water station used for calculating EC50 values.

\begin{tabular}{|c|c|c|c|c|c|c|}
\hline \hline \multirow{2}{*}{$\begin{array}{c}\text { WER Nominal } \\
\begin{array}{c}\text { copper } \\
\text { concentration } \\
(\mu \mathrm{g} / \mathrm{L})\end{array}\end{array}$} & \multicolumn{6}{|c|}{ WER Dissolved Cu Concentration $(\mu \mathrm{g} / \mathrm{L})$} \\
\cline { 2 - 7 } & 1.90 & 0.66 & 0.17 & 0.47 & 0.19 & 0.21 \\
\hline \hline 0.0 & 3.69 & 4.78 & 3.91 & 4.13 & 3.89 & 5.29 \\
\hline 2.9 & 4.08 & 7.13 & 7.44 & 7.18 & 4.37 & 5.90 \\
\hline 4.1 & 7.30 & 8.36 & 10.01 & 7.56 & 5.66 & 8.64 \\
\hline 5.8 & 6.98 & 9.29 & 10.48 & 13.55 & 8.88 & 10.72 \\
\hline 8.4 & 12.53 & 12.17 & 12.58 & 15.14 & 9.83 & 13.75 \\
\hline 12.0 & 13.81 & 15.86 & 13.01 & 15.65 & 19.32 & 17.46 \\
\hline 17.2 & 29.74 & 21.63 & 21.94 & 23.03 & 19.26 & 24.31 \\
\hline 24.0 & $\mathrm{NM}$ & $\mathrm{NM}$ & $\mathrm{NM}$ & $\mathrm{NM}$ & $\mathrm{NM}$ & $\mathrm{NM}$ \\
\hline 35.0 & $\mathrm{NM}$ & $\mathrm{NM}$ & $\mathrm{NM}$ & $\mathrm{NM}$ & $\mathrm{NM}$ & $\mathrm{NM}$ \\
\hline 50.0 & & & & & \\
\hline
\end{tabular}

$\mathrm{NM}=$ not measured 


\subsubsection{Toxicity and DOC}

The bioavailability and potential for toxicity of copper depends on various water quality characteristics, largely the DOC concentration. For the five WER stations, DOC concentration averaged $1.17 \pm 0.50 \mathrm{mg} \mathrm{L}^{-1}$ in site waters, and was $0.659 \mathrm{mg} \mathrm{L}^{-1}$ in the laboratory control water from Granite Canyon. A significant positive relationship between the EC50 values and DOC concentration among the five WER stations was observed (Least Square Regression, $\mathrm{r}^{2}=0.758, \mathrm{p}<0.024$ (Figure 8-4).

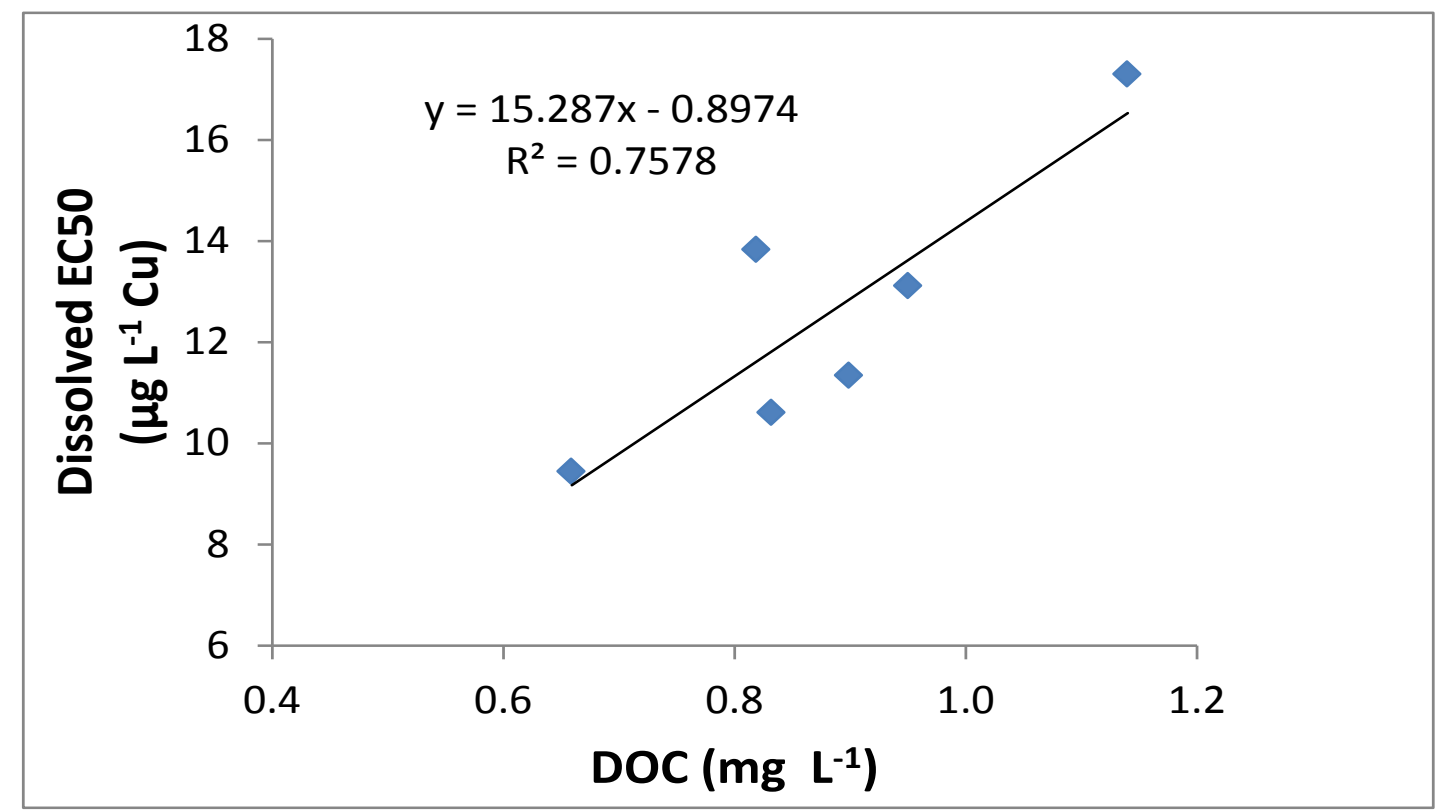

Figure 8-4. Relationship between dissolved EC50 and dissolved organic carbon (DOC) from the WER testing $(\mathrm{N}=6)$.

\subsubsection{Biotic Ligand Model}

The BLM was used to predict EC50 values (EC50 $\mathrm{BLM}$ ) using water chemistry data for each station as an alternative to WER testing. We also used the BLM (Table 8-8. ) to calculate an estimated chronic limit (ECL BLM $_{\text {), a value analogous to the SSC }}$ WER. For comparison, BLM calculations used both water quality parameters collected from the field and those from the laboratory toxicity tests

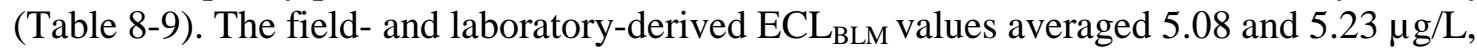
respectively. The ECL $L_{\mathrm{BL}}$ for each station and event are shown in comparison to measured $\mathrm{DCu}$ (Figure 8-5). Arithmetic means for the site samples were calculated for the EC50 ${ }_{\mathrm{BLM}}$ and $\mathrm{EC} 50_{\mathrm{WER}}$ values, the ECL $\mathrm{BLM}_{\mathrm{B}}$, the $\mathrm{SSC}_{\mathrm{WER}}$ and the DCu (Figure 8-6). The $\mathrm{SSC}_{\mathrm{WER}}$ combined with the adjusted criterion based on the Recalculation Procedure (SSC $\left.{ }_{W E R+R e c a l c}\right)$ (see Section 3) is also shown for comparison. 
Table 8-9. Biotic Ligand Model (BLM) calculated ECL and EC50 values for copper $(\mu \mathrm{g} / \mathrm{L})$ from all Guam sampling stations, using water chemistry data collected from the field and under laboratory toxicity testing conditions. Ambient dissolved copper data shown for reference. All values other than DOC are expressed as dissolved copper $(\mu \mathrm{g} / \mathrm{L})$.

\begin{tabular}{|c|c|c|c|c|c|c|}
\hline \multirow{2}{*}{ Station } & \multirow{2}{*}{$\begin{array}{c}\mathrm{DOC} \\
(\mathrm{mg} / \mathrm{L})\end{array}$} & \multirow{2}{*}{$\begin{array}{c}\text { Ambient } \\
\text { Dissolved } \\
\mathrm{Cu} \\
(\mu \mathrm{g} / \mathrm{L})\end{array}$} & \multicolumn{2}{|c|}{ Field-Derived } & \multicolumn{2}{|c|}{ Laboratory-Derived } \\
\hline & & & ECL & $\mathrm{EC} 50_{\mathrm{BLM}}$ & ECL & $\mathrm{EC} 50_{\mathrm{BLM}}$ \\
\hline G1 & 2.04 & 0.661 & 4.49 & 5.39 & 4.53 & 5.44 \\
\hline G2 & 0.949 & 0.257 & 5.07 & 6.08 & 5.14 & 6.17 \\
\hline G3 & 0.899 & 0.174 & 4.79 & 5.75 & 4.88 & 5.86 \\
\hline G4 & 0.909 & 0.199 & 4.85 & 5.82 & 4.93 & 5.92 \\
\hline G5 & 0.899 & 0.224 & 4.78 & 5.74 & 4.87 & 5.85 \\
\hline G6 & 0.820 & 0.277 & 4.45 & 5.34 & 4.45 & 5.34 \\
\hline G7 & 0.870 & 0.469 & 4.67 & 5.61 & 4.73 & 5.68 \\
\hline G8 & 0.819 & 0.474 & 4.39 & 5.27 & 4.48 & 5.37 \\
\hline G9 & 0.842 & 0.518 & 4.51 & 5.41 & 4.59 & 5.50 \\
\hline G10 & 0.662 & 0.271 & 3.57 & 4.28 & 3.57 & 4.28 \\
\hline G11 & 2.09 & 0.621 & 10.4 & 12.6 & 11.0 & 13.1 \\
\hline G12 & 0.974 & 0.294 & 4.99 & 5.99 & 5.19 & 6.23 \\
\hline G13a & 0.950 & 0.190 & 4.44 & 5.33 & 5.01 & 6.01 \\
\hline G13b & 0.935 & 0.214 & 5.59 & 6.70 & 6.02 & 7.22 \\
\hline G14 & 0.806 & 0.123 & 4.21 & 5.05 & 4.31 & 5.17 \\
\hline G15 & 1.12 & 2.090 & 6.04 & 7.25 & 6.04 & 7.25 \\
\hline Mean & 0.974 & 0.441 & 5.08 & 6.10 & 5.23 & 6.28 \\
\hline Std. Dev. & 0.320 & 0.470 & 1.54 & 1.85 & 1.64 & 1.97 \\
\hline
\end{tabular}




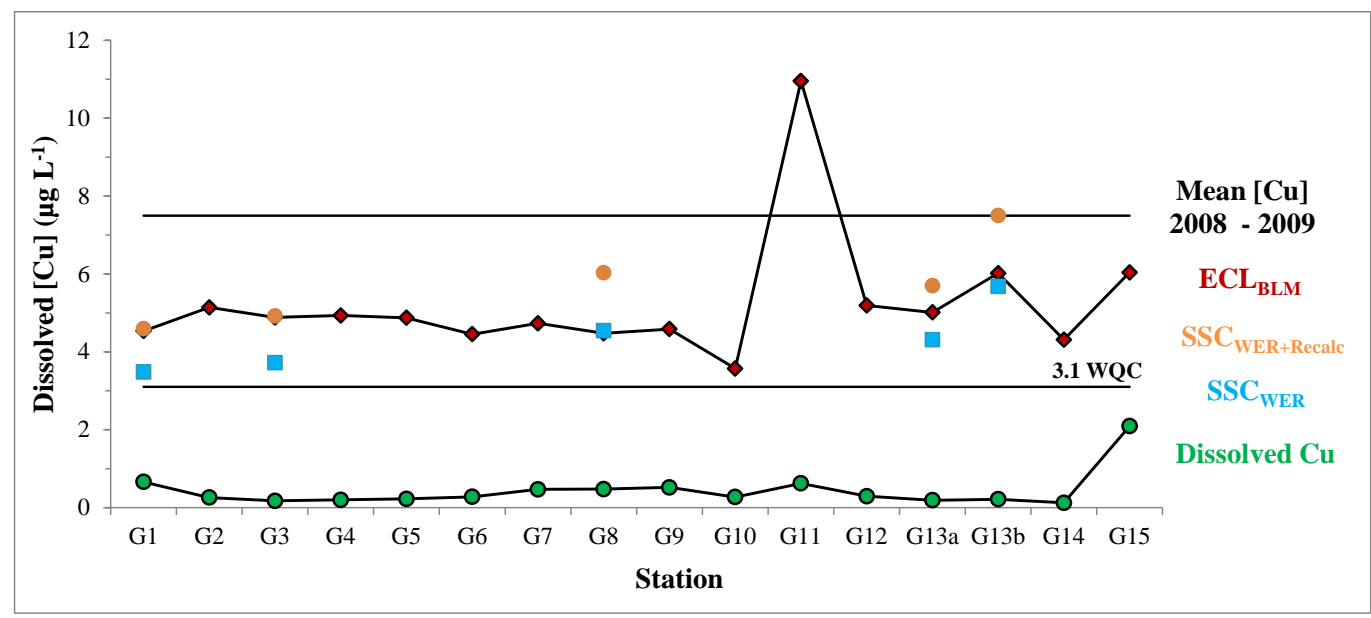

Figure 8-5. WER- and BLM-based criteria derived for Guam by station. The national water quality criterion (WQC) of 3.1-g/L DCu, measured $\mathrm{DCu}$, and mean discharge monitoring data from Tipalao Bay from 2008 and 2009 are shown for reference.

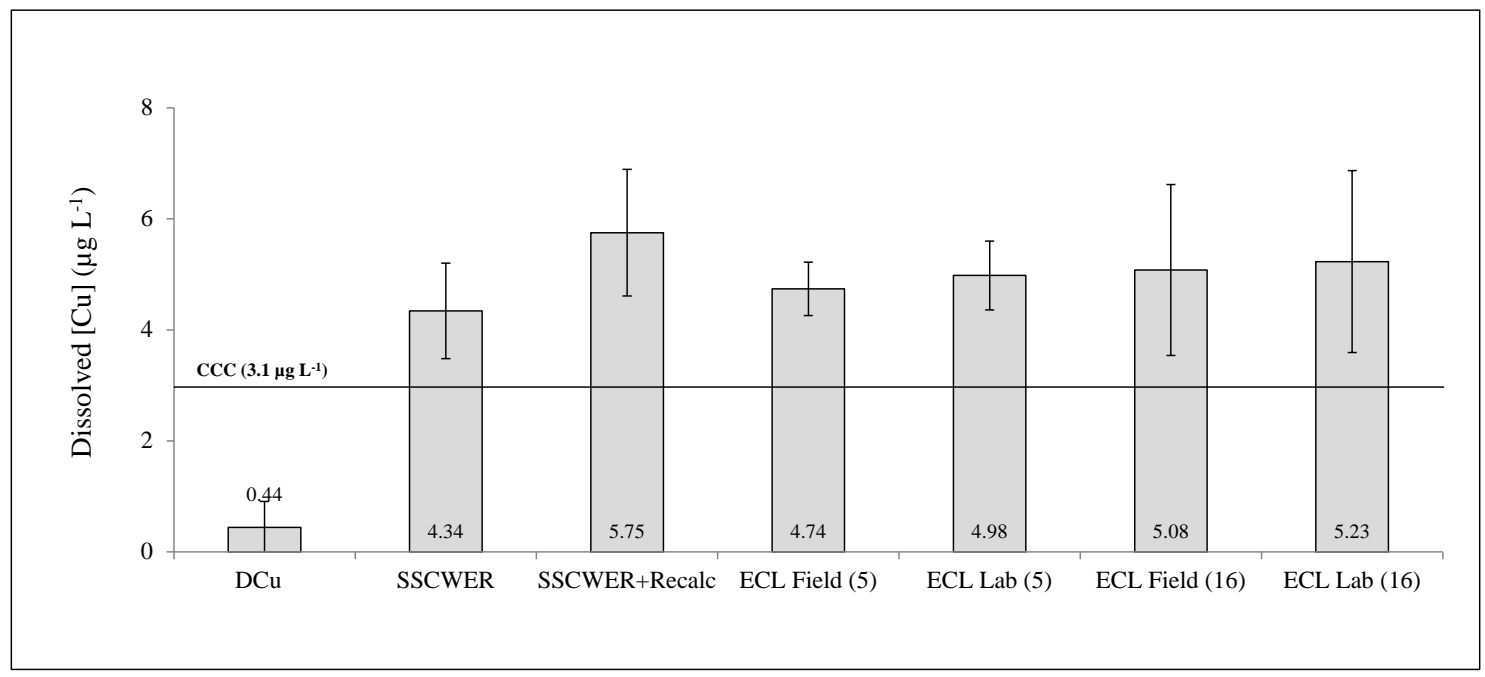

Figure 8-6. Arithmetic means and standard deviations for Guam site-specific criterion (SSC) and equivalent estimated chronic limits (ECL) generated from WER and BLM procedures, respectively. BLM calculations were conducted using both field and laboratory water chemistry data, and for the five WER stations and all 16 stations sampled at Guam. The average ambient DCu from the 16 stations and the national WQC of $3.1 \mu \mathrm{g} / \mathrm{L}$ are shown for comparison.

\subsubsection{QA/QC}

As noted previously, toxicity tests met the $70 \%$ normal alive test acceptability criterion. The results for the reference toxicant test for copper was 9.44- $\mu \mathrm{g} \mathrm{DCu} / \mathrm{L}$, which is within two standard deviations of the SSC Pacific Bioassay laboratory’s running mean with this test (7.14 $\pm 4.4 \mu \mathrm{g} / \mathrm{L})$.

On our raw data sheets, we noted a few minor QA/QC deviations from USEPA and internal protocols that occurred during testing. A thorough review of the data and test procedures did not find any evidence that these deviations affected the test results; therefore, all presented data were acceptable for reporting.. 
The team conducted all tests within the 96-h holding time allotted for conducting WER studies (USEPA, 2001). Samples were outside the USEPA recommended range of 0 to $6{ }^{\circ} \mathrm{C}$ upon receipt at the SSC Pacific Laboratory due to the long travel time between Guam and San Diego (approximately 24 hours). As noted previously, however, samples were at $7{ }^{\circ} \mathrm{C}$, which indicates they were substantially cooled from their ambient collection temperatures, which is acceptable under SSC Pacific’s Environmental Laboratory Accreditation Program (ELAP) laboratory QA manual.

The team observed some minor deviations in test protocols during testing, but these deviations did not affect test validity. For sample G15, the dissolved oxygen levels at initiation exceeded the recommended range of $9 \mathrm{mg} / \mathrm{L}$. However, the samples remained within $10 \%$ of $100 \%$ saturation, and because there were no observable effects on the test organisms, we were unconcerned about this relatively minor deviation.

\subsection{DISCUSSION}

In comparison to the current national WQC for copper (3.1 $\mu \mathrm{g} \mathrm{DCu} / \mathrm{L}$; USEPA, 1995a), all 16 of the samples collected from near-shore stations around Guam were well below, averaging one order of magnitude lower (0.44- $\mu \mathrm{g} \mathrm{DCu/L;} \mathrm{Table} \mathrm{8-7and} \mathrm{and} \mathrm{Table} \mathrm{8-9).} \mathrm{In} \mathrm{addition,} \mathrm{no} \mathrm{significant} \mathrm{toxicity}$ was observed from any of these stations using the USEPA's most sensitive accepted endpoint for copper in saltwater, embryo-larval development success of the mussel Mytilus galloprovincialis (USEPA, 1995b).

The USEPA's Water Effect Ratio (WER) procedure and the marine Biotic Ligand Model (BLM) for copper (USEPA approval pending; HydroQual, 2012), both of which are used to quantify bioavailability and potential for toxicity of copper in surface waters, showed similar results. For the five WER stations, both WER and BLM derived criteria ranged from 47 to 69\% (depending on specific comparisons; Figure 8-6) greater than the current national criterion. After incorporation of the adjusted criterion based on the Recalculation Procedure (see Section 3), the WER becomes 85\% higher than the current national criterion. Despite relatively low DOC (concentrations among the WER sites averaged $~ 1 \mathrm{mg} / \mathrm{L}$; Table 8-9), both the WER and BLM approaches indicate that a Guam-specific criterion for copper could allow for scientifically relevant permit limits and remain environmentally protective of the receiving environment. A WER- or BLM-based modification of the NPDES permit for copper, which is now based on the national criterion, would provide the same level of protection intended by USEPA (1985).

The WER study results were derived empirically and therefore may be considered more desirable in some respects. The WER study from five stations provided a multiplier of 1.40, which adjusts the chronic criterion from 3.1- to 4.34- $\mu \mathrm{g} \mathrm{DCu} / \mathrm{L}$ (and the site-specific recalculated criterion from 4.1- to $5.75-\mu \mathrm{g} \mathrm{DCu} / \mathrm{L}$ ). The positive correlation between EC50 and DOC was expected, as DOC has been repeatedly shown to buffer against copper toxicity (Arnold, 2005; Arnold, Cotsifas, and Corneillie, 2006; Chadwick et al., 2008; Rosen et al., 2009), and is the basis of the marine BLM (HDR | HydroQual, 2012). Note, however, that this study provided a 'preliminary' WER based on one sampling event. Although the results were minimally variable among sampling locations, full-scale WER studies typically involve at least three sampling events to provide a more robust data set and account for temporal variability at the site (USEPA, 1994a).

The BLM has established itself as a viable alternative to conducting much more costly and resource intensive WER studies. It is routinely employed in freshwater (USEPA, 2007), has been validated for saltwater (Chadwick et al., 2008; Bosse et al., 2014), and is currently under final review by USEPA (Robert Santore, personal communication) for incorporation into an update of the saltwater criterion document. 
The team used the marine BLM here to estimate site-specific criteria at 16 sampling locations. BLM-derived, site-specific criteria, expressed as ECLs, were very similar to criteria derived using the WER procedure, ranging from 4 to $15 \%$ higher, depending on the number and source of the water chemistry data used (Figure 8-6). The site ECL was most similar to the WER-derived criterion when only the chemistry data from the five WER stations were calculated ( $4.98 \mu \mathrm{g} \mathrm{DCu} / \mathrm{L})$. The 16 station ECL (5.23- $\mu \mathrm{g} \mathrm{DCu} / \mathrm{L}$ ), however, is much more robust and representative of the island as a whole. Although model inputs for DOC were the same for both field- and laboratory-based data sets, $\mathrm{pH}$, temperature, and salinity differences explain minor differences in ECL values generated from the same sampling locations Table 8-9). Although it is probably more relevant to report the field-based ECLs for WQC generation purposes in general, the laboratory-based ECLs are more directly comparable to the laboratory WER data. In both cases (field and lab ECLs), no detectable differences were observed (t-tests, $\alpha=0.05$ ) when comparing mean ECLs generated with the BLM with sitespecific criterion generated using the WER data.

Although the WER and BLM resulted in similar site-specific criteria, note that direct comparison of a site-specific criterion for copper using the two approaches is actually somewhat limited because the BLM methodology incorporates significant updates (HDR | HydroQual, 2012) to the 1995 USEPA draft copper criterion on which the WER-derived criterion was based. Briefly, the BLM draft criterion document includes (1) a substantially more robust toxicity data set, (2) normalization of toxicity data to DOC concentration, and (3) an adjustment of the calculation and magnitude of the final acute value (FAV) and the acute-chronic ratio (ACR) used in deriving acute and chronic criteria, respectively. Another limiting factor is that the BLM uses a nationally represented toxicity data set, while this study resulted in derivation of a recalculated (site-specific) toxicity data set (Section 3), which makes direct comparisons additionally difficult. It may be conceivable that the BLM output resultscould be applied to a multiplier to account for the difference between the national criterion for copper and the site-specific recalculated value.

\subsection{CONCLUSION}

The results of this study suggest that the near-shore areas around the island of Guam are not impaired for copper, with dissolved copper concentrations close to an order of magnitude lower than nationally recognized criteria for copper. The findings are supported by an absence of significant toxicity at any of 16 stations in laboratory tests with the Mytilus embryos, the most sensitive in USEPA's species sensitivity distribution. Further, the study developed site-specific copper criteria for Guam that range from 4.3- $\mu \mathrm{g}$ (WER-based) to 5.23- $\mu \mathrm{g}$ (BLM-based) DCu/L, indicating that the national criterion (3.1- $\mu \mathrm{g} \mathrm{DCu} / \mathrm{L}$; USEPA, 1995a) could be updated while still providing the same level of protection. We discussed the advantages of WER and BLM approaches, with the latter a more up to date, streamlined, and cost-effective means of developing protective criteria. Finally, incorporating concurrent efforts, including a national toxicity data set for copper and translator study results, could be combined with this result to update the discharge limit for Tipalao Bay. 


\section{CLEAN CHEMISTRY}

One of the most common issues with quantifying heavy metals in environmental samples is related to using appropriate sampling, manipulation (i.e., acidification and dilution under laboratory conditions) and analysis of water samples. In support of the sampling and analytical facilities at the Apra Harbor WWTP, the SSC Pacific team gave a presentation on proper Clean Sampling, Manipulation and Analysis Techniques for Seawater (Figure 9-1) at the chemical laboratory facility in the Apra Harbor Waste Water Treatment Plant on 25 April 2012.

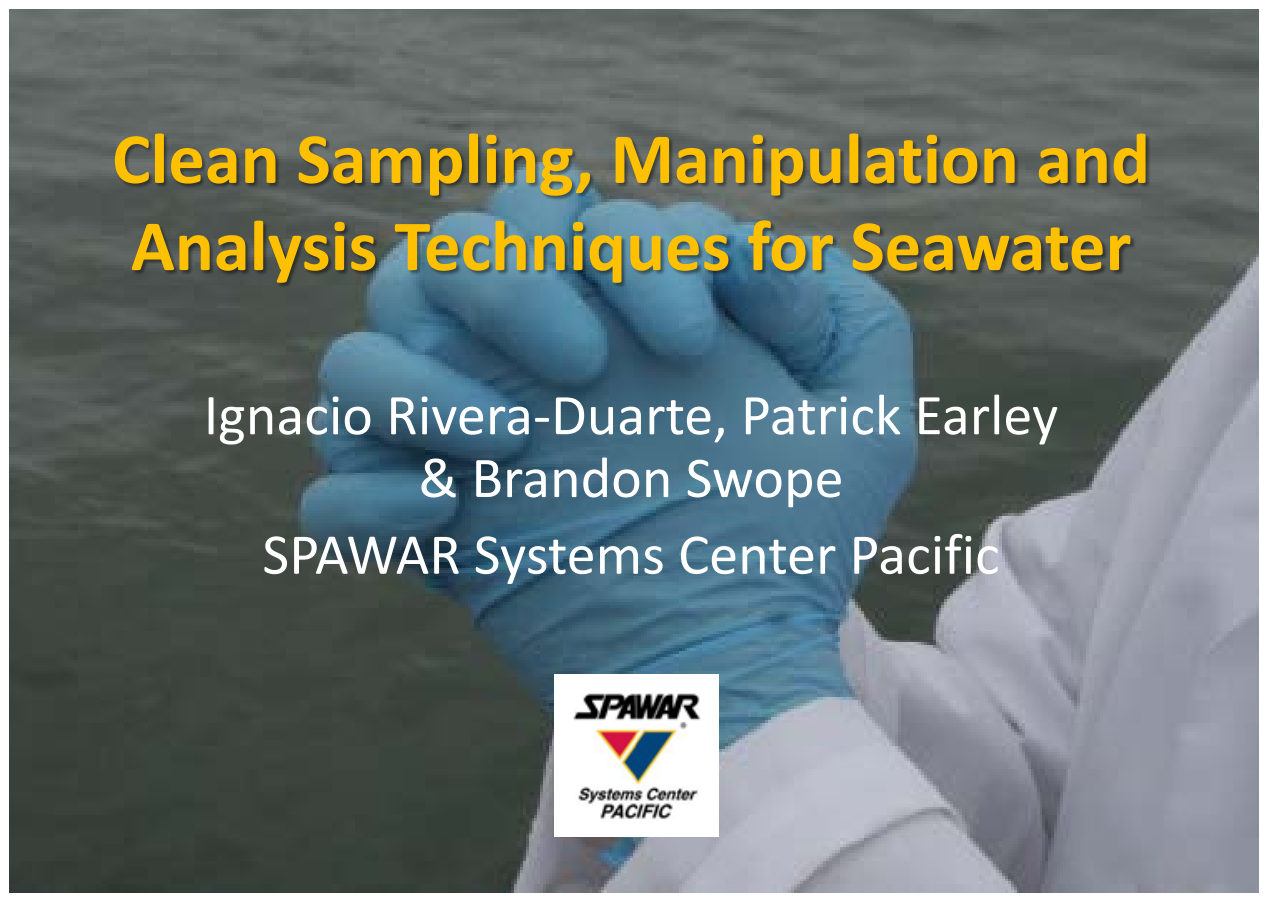

Figure 9-1. Title slide for the presentation on trace-metal clean techniques for quantification of heavy metals in water samples at environmentally relevant concentrations.

Trace-metal clean techniques were developed in the 1970s (Patterson and Settle, 1976) for analysis of metals in open-ocean waters. Metal concentrations in open- ocean are extremely low, and the simple action of opening a sample bottle in a laboratory can result in contamination, resulting in associated excessive concentrations that are not representative of environmental conditions. Contamination is mainly derived from particles in the air, and the objective of clean techniques is to control particle presence throughout the whole process from sampling to analysis. USEPA's Method 1669, Sampling Ambient Water for Trace Metals at USEPA Water Quality Criteria Levels (USEPA, 1996b) emphasizes the importance of applying these techniques.

The above-mentioned presentation covers the basic information on clean techniques. This information included types of acids and detergents to be used in cleaning of sampling and laboratory equipment, sampling considerations regarding wind and particle sources, a detailed explanation of “clean-hands dirty-hands" sampling technique, sample manipulation in the laboratory under High Efficiency Particulate Air (HEPA) working areas, and procedures for acidification and dilution of samples. The presentation also included a general review of most common analytical techniques for metal quantification, and the issues with the use of some of them. Most importantly, the presentation 
also alludes to the matrix effects derived from salts in the water samples, and provides an example of a commercial off-the-shelf (COTS) technology that addresses this issue.

The presentation ends with a brief explanation of the results from applying clean techniques in three separate wastewater treatment plants by an independent user. Mrs. Stephanie Scheringer from the City of Gastonia, North Carolina, Wastewater Treatment Division, has a presentation titled "Clean Techniques for Metals Collection and Analysis," dated July 17, 2002. Mrs. Scheringer's presentation is available at http://www.teledynelee-manlabs.com/company/seminars/EPA1631/Clean\%20Techniques\%20for\%20Metals\%20Colle ction\%20and\%20Analysis\%20\%20Steph.pdf. Inclusion of Mrs. Scheringer's insight is important, as it provides an independent assessment of the use of clean techniques by an end-user. In her presentation, Mrs. Scheringer described the approach followed for implementing clean techniques in their facilities (i.e., three separate wastewater treatment plants, and a single analytical laboratory), and the resulted decrease or elimination of notices of violation (NOVs) resulting from this implementation. 


\section{PROPOSED PERMIT LIMIT}

NAVFAC Marianas initiated a study to develop site-specific discharge limitations using appropriate methods and guidance documents from the USEPA. This study incorporates the results from multiple lines of evidence to examine copper, nickel, and aluminum criteria as they are applied in the permit and seeks to establish new regulatory discharge limits based on the current state of the science, including the use and application of a mixing zone analysis, a recalculation procedure, a chemical translator study, a WER procedure, and the Biotic Ligand Model.

Based on the data generated from these studies (Table 10-1), our recommended new NPDES discharge limits for copper and nickel are outlined below, whereas a separate rationale exists for justifying the removal of aluminum from further regulatory limits.

Table 10-1. NPDES permit limit calculations for copper and nickel $(\mu \mathrm{g} / \mathrm{L})$.

\begin{tabular}{|l|c|c|c|c|c|}
\hline \multicolumn{1}{|c|}{ Parameter } & $\begin{array}{c}\text { Copper } \\
\text { (acute) }\end{array}$ & $\begin{array}{c}\text { Copper } \\
\text { (chronic) }\end{array}$ & $\begin{array}{c}\text { Copper } \\
\text { BLM (acute } \\
\text { and chronic) }\end{array}$ & $\begin{array}{c}\text { Nickel } \\
\text { (acute) }\end{array}$ & $\begin{array}{c}\text { Nickel } \\
\text { (chronic) }\end{array}$ \\
\hline \hline Recalc WQC $_{\mathrm{DM}}$ & 8.2 & 4.1 & 5.2 & 68.1 & 22.8 \\
\hline WER $_{\mathrm{DM}}$ & 1.40 & 1.40 & $\mathrm{~N} / \mathrm{A}$ & $\mathrm{N} / \mathrm{A}$ & $\mathrm{N} / \mathrm{A}$ \\
\hline $\mathrm{MZ}$ & 39.2 & 39.2 & 39.2 & 39.2 & 39.2 \\
\hline $\mathrm{CT}$ & 0.57 & 0.57 & 0.57 & 0.77 & 0.77 \\
\hline Final Permit Limit & 790 & 395 & 358 & 3467 & 1161 \\
\hline
\end{tabular}

The copper limit is calculated as follows for the Apra Harbor WWTP:

$(8.2 \mu \mathrm{g} / \mathrm{L}) \times(1.40) \times(39.2) /(0.57)=790 \mu \mathrm{g} / \mathrm{L}$ total recoverable copper (acute)

$(4.1 \mu \mathrm{g} / \mathrm{L}) \times(1.40) \times(39.2) /(0.57)=395 \mu \mathrm{g} / \mathrm{L}$ total recoverable copper (chronic)

The BLM copper limit is calculated as follows for the Apra Harbor WWTP:

$(5.2 \mu \mathrm{g} / \mathrm{L}) \times(39.2) /(0.57)=358 \mu \mathrm{g} / \mathrm{L}$ total recoverable copper (acute and chronic)

The nickel limit is calculated as follows for the Apra Harbor WWTP:

$(68.1 \mu \mathrm{g} / \mathrm{L}) \times(39.2) /(0.77)=3467 \mu \mathrm{g} / \mathrm{L}$ total recoverable nickel (acute)

$(22.8 \mu \mathrm{g} / \mathrm{L}) \times(39.2) /(0.77)=1611 \mu \mathrm{g} / \mathrm{L}$ total recoverable nickel (chronic)

If aluminum were considered critical to maintain within the current permit, the new proposed limit would be calculated by multiplying the current permit limit by the mixing zone consideration as follows:

$(200 \mu \mathrm{g} / \mathrm{L}) \times(39.2)=7840 \mu \mathrm{g} / \mathrm{L}$ total recoverable aluminum (acute and chronic)

These new site-specific limits will enable the Navy to continue business and industrial operations in Guam while providing environmental protection and maintaining water quality in Tipalao Bay and the surrounding waters. 
The Guam Waterworks Authority (GWA) and the U.S. Navy have a combined discharge out of the same outfall in Tipalao Bay, Guam. GWA submitted a mixing zone application on April 27, 1995; the mixing zone request specifically requested discharge limits for copper (300 $\mu \mathrm{g} / \mathrm{L}$ ) and nickel 870 $(\mu \mathrm{g} / \mathrm{L})$. The U.S. Navy submitted a mixing zone application on June 4, 2010 requesting a mixing zone allowance for copper $(300 \mu \mathrm{g} / \mathrm{L})$ and nickel $870(\mu \mathrm{g} / \mathrm{L})$. Currently, the Navy has not been granted a mixing zone. Both of these mixing zone applications were based on engineering calculations associated with the outfall design and a diffuser installation (CH2M HILL.1992) that are all in place.

The current proposed limits in Table 10-1 have environmentally conservative modeling assumptions built into the calculated dilution factor at the edge of the mixing zone using the EPAapproved CORMIX model. In addition, we adhered to EPA-recommended approaches (Water Effect Ratio, Recalculation, Translator, and the Biotic Ligand Model) to provide a comprehensive assessment of site-specific environmental conditions. These assessments (detailed in the previous sections) include considerations of locally important species, relevant environmental conditions, and a realistic understanding of environmental fate and effects associated with the Apra Harbor Wastewater Treatment Plant discharge in Tipalao Bay. 


\section{REFERENCES}

Ahsanullah, M. and G. H. Arnott. 1978. “Acute Toxicity of Copper, Cadmium, and Zinc to Larvae of the Crab Paragrapsus quadridentatus (H. Milne Edwards), and Implications for Water Quality Criteria,” Australian Journal of Marine and Freshwater Research 29(1):1-8.

Amesbury, J. R. 1999. “Changes in Species Composition of Archaeological Marine Shell Assemblages in Guam,” Micronesica 1(2):347-366.

Amesbury, J. R. and R. L. Hunter-Anderson. 2003. "Review of Archaeological and Historical Data Concerning Reef Fishing in the U.S. Flag Islands of Micronesia: Guam and the Northern Mariana Islands.” Western Pacific Regional Fishery Management Council, Honolulu, HI.

Amesbury, J. R. and R. L. Hunter-Anderson. 2008. "An Analysis of Archaeological and Historical Data on Fisheries for Pelagic Species in Guam and the Northern Mariana Islands.” Pelagic Fisheries Research Program, University of Hawaii at Manoa, Honolulu, HI.

Anderson, D. M. and F. M. M. Morel. 1978. “Cu Sensitivity of Gonyaulax tamarensis,” Limnology \& Oceanography 23:283-295.

Arnold W. R. 2005. "Effects of Dissolved Organic Carbon on Copper Toxicity: Implications for Saltwater Copper Criteria,” Integrated Environmental Assessment and Management 1:34-39.

Arnold, W. R., J. S. Cotsifas, and K. M. Corneillie. 2006. "Validation and Update of a Model used to Predict Copper Toxicity to the Marine bivalve Mytilus sp.,” Environmental Toxicology 21:6570.

Arnold, W. R., J. S. Cotsifas, D. S. Smith, S. Le Page, and K. M. Gruenthal. 2009. “A Comparison of the Copper Sensitivity of Two Economically Important Saltwater Mussel Species and a Review of Previously Reported Copper Toxicity Data for Mussels: Important Implications for Determining Future Ambient Copper Saltwater Criteria in the USA,” Environmental Toxicology 24(6):618-628.

ASTM. 1999. "Standard Guide for Conducting Static Acute Toxicity Tests Starting with Embryos of Four Species of Saltwater Bivalve Mollusks.” In American Society for Testing and Materials Annual Book of Standards. E724-98. American Society of Testing and Materials, Philadelphia, PA.

Bailey-Brock, J. H. 2003. “Coral Reef Polychaetes of Guam and Saipan, Mariana Islands. Micronesica 35-36:200-217.

Bielmyer, G. K., K. V. Brix, T. R. Capo, and M. Grosell. 2005. “The Effects of Metals on EmbryoLarval and Adult Life Stages of the Sea Urchin Diadema antillarum,” Aquatic Toxicology 74(3):254-263.

Bosse, C., G. Rosen, M. Colvin, P. Earley, R. Santore, and I. Rivera-Duarte. 2014. “Copper Bioavailability and Toxicity to Mytilus galloprovincialis in Shelter Island Yacht Basin, San Diego, CA,” Marine Pollution Bulletin 85:225-234.

Brainard, R. E., C. Birkeland, C. M. Eakin, P. McElhany, M. W. Miller, M. Patterson, and G. A. Piniak. 2011.” Status Review Report of 82 Candidate Coral Species Petitioned Under the U.S. Endangered Species Act.” NOAA Technical Memorandum NMFS-PIFSC-27. Pacific Islands Fisheries Science Center, Honolulu, HI. 
Braley, R. D. 1984. "Mariculture Potential of Introduced Oysters Saccostrea cucullata tuberculata and Crassostrea echinata, and a Histological Study of Reproduction of C. echinata," Australian Journal of Marine and Freshwater Research 35(2):129-141.

Calabrese, A., R. S. Collier, D. A. Nelson, and J. R. MacInnes. 1973. "The Toxicity of Heavy Metals to Embryos of the American Oyster Crassostrea virginica,” Marine Biology 18(3):162-166.

Carpenter, K. E., V. H. Niem, Eds. 1998a. The Living Marine Resources of the Western Central Pacific. Volume 1. Seaweeds, Corals, Bivalves and Gastropods. Food and Agricultural Organization of the United Nations (FAO) Species Identification Guide for Fishery Purposes. FAO, Rome, Italy.

Carpenter, K. E. and V.H. Niem, Eds. 1998b. The Living Marine Resources of the Western Central Pacific. Volume 2. Cephalopods, Crustaceans, Holothurians and Sharks. FAO Species Identification Guide for Fishery Purposes. FAO, Rome, Italy.

Carpenter, K. E. and V. H. Niem, Eds. 1999. The Living Marine Resources of the Western Central Pacific. Volume 4. Bony Fishes Part 2 (Mugilidae to Carangidae). FAO Species Identification Guide for Fishery Purposes. FAO, Rome, Italy.

Chadwick, D. B., I. Rivera-Duarte, G. Rosen, P.-F. Wang, R. C. Santore, A. C. Ryan, P. R. Paquin, S. D. Hafner, and W.H. Choi. 2008. "Demonstration of an Integrated Compliance Model for Predicting Copper Fate and Effects in DoD Harbors. Environmental Security Technology Certification Program, Project ER-0523.” Technical Report 1973, Space and Naval Warfare Systems Center Pacific (SSC Pacific), San Diego, CA. Available online at http://www.serdp.org/content/download/5030/71864/file/ER-0523-FR.pdf. Accessed July 11, 2016.

Chen, J. C. and C. H. Lin. 2001. "Toxicity of Copper Sulfate for Survival, Growth, Molting and Feeding of Juveniles of the Tiger Shrimp Penaeus monodon,” Aquaculture 192(1):55-65.

CH2M Hill. 1992. "Feasibility Study Tipalao Bay Outfall, Agat/Santa Rita (Area IV) Wastewater System Guam.” Prepared for the Public Utility Agency of Guam.

CH2M Hill. 2000. "Site-specific Saltwater Quality Criteria for Copper Determined by the Calculation Procedure for the Hampton Roads/Elizabeth River Estuary.” Final Report. Project 105020.A0, Contract N6247093D4014. Englewood, CO.

Clark, A. H. 1954. “Records of Indo-Pacific Echinoderms,” Pacific Science 8(3):243-263.

Clark, A. M. and F. W. E. Rowe. 1971. "Monograph of Shallow-water Indo-West Pacific Echinoderms,” Trustees of the British Museum (Natural History), London, England.

Clark, H. L. 1925. “A Catalogue of the Recent Sea-Urchins (Echinoidea) in the Collection of the British Museum (Natural History). British Museum (Natural History), London, England.

DAWR. 2000. “FY00 Inshore Fisheries Survey.” Progress Report F-1R-8. Guam Department of Agriculture, Division of Aquatic and Wildlife Resources, Mangilao, Guam.

DeForest, D. and C. Schlekat. 2013. "Species Sensitivity Distribution Evaluation for Nickel Toxicity to Marine Organisms,” Integrated Environmental Assessment and Management 9(4):580-589.

Denton, G. R. W. and C. Burdon-Jones. 1982. "The Influence of Temperature and Salinity upon the Acute Toxicity of Heavy Metals to the Banana Prawn (Panaeus menguiensis de Man),” Journal of Chemical Ecology 1:131-143. 
Denton, G. R. W. and C. Burdon-Jones. 1986. "Environmental Effects on Toxicity of Heavy Metals to Two Species of Tropical Marine Fish from Northern Australia,” Journal of Chemical Ecology 2(3):233-249.

Denton, G. R. W., L. P. Concepcion, H. R. Wood, V. S. Eflin, and G.T. Pangelinan. 1999. Heavy Metals, PCBs and PAHs in Marine Organisms from Four Harbor Locations on Guam: A Pilot Study.” Technical Report 87. Water and Environmental Research Institute of the Western Pacific, University of Guam, Mangilao, Guam.

Doneker, R. L. 2013. Personal communication between Patrick Earley from SSC Pacific and Robert Doneker, CORMIX inventor, regarding the proper use and application of model parameters.

Doneker, R. L. and G. H. Jirka. 2007. “CORMIX User Manual: A Hydrodynamic Mixing Zone Model and Decision Support System for Pollutant Discharges into Surface Waters.” USEPA823-K-07-001. Washington, DC.

Duenas Camacho \& Associates. 2015 (March 3). “30\% Basis of Design Report: Agat-Santa Rita Wastewater Treatment Plant.” for Guam Waterworks Authority. pVI-1. Hagatña, Guam

Earley, P. J., G. Rosen, I. Rivera-Duarte, R. Gauthier, Y. M. Arias-Thode, J. Thompson, and B. Swope. 2007. “A Comprehensive Copper Compliance Strategy: Implementing Regulatory Guidance at Pearl Harbor Naval Shipyard \& Intermediate Maintenance Facility.” Technical Report 1952. Space and Naval Warfare Systems Center Pacific San Diego (now SSC Pacific), San Diego, CA.

Earley, P. J., R. L. Dwyer, J. W. Gorsuch, R. K. Johnston, I. Rivera-Duarte, and D. B. Chadwick. 2010. "Development of Compliance Tools for Metals in Marine and Estuarine Environment." SETAC North America 31st Annual Meeting. November 7-11, Portland, OR.

Environmental Services Department (ESD). 1998. “Development of a Site-Specific Water Quality Criterion for Copper in South San Francisco Bay. San Jose/Santa Clara Water Pollution Control Plant, San Jose, CA.

Eriksen R. S., D. J. Mackey, R. van Dam, and B. Nowak. 2001. "Copper Speciation and Toxicity in Macquarie Harbour, Tasmania: An Investigation using a Copper Ion Selective Electrode.” Marine Chemistry 74:99-113.

Esquivel, I. F. 1986. "Short Term Copper Bioassay on the Planula of the Reef Coral Pocillopora damicornis.” In Coral Reef Population Biology, pp. 465-472, P. L. Jokiel, R. H. Richmond, and R. A. Rogers, Eds. Technical Report No. 37-472. NIHI-SEAGRANT-CR-86-01. Hawaii Institute of Marine Biology, Kaneohe, HI.

Flammang, P., M. Warnau, A. Temara, D. J. W. Lane, and M. Jangoux. 1997. "Heavy Metals in Diadema setosum (Echinodermata, Echinoidea) from Singapore Coral Reefs,” Journal of Sea Research 38:35-45.

Florida DEP. 1997. “Correspondence dated 13 June 1997 from Nancy Turner, Florida Department of Environmental Protection, to Mr. Gilbert Peralta, Dade County Environmental Resources Management.”

FWS. 2012. "Species by County Report. Environmental Conservation Online System.” Available at http://ecos.fws.gov/tess_public/countySearch!speciesByCountyReport.action?fips=66010, updated. Accessed 14 August 2012. 
Gauthier, R. D., S. Harrel, R. Johnston, G. Key, P. Earley, M. Caballero, T. Snipes, D. Kopack, and R. Benze. 1995. “An Integrated Marine Environment Compliance Program for Naval Shipyards: Final Phase I Report.” Technical Document 3114. Space and Naval Warfare Systems Center San Diego (now SSC Pacific), San Diego, CA.

Goh, B .P. L. 1991. "Mortality and Settlement Success of Pocillopora damicornis Planula Larvae during Recovery from Low Levels of Nickel,” Pacific Science 45(3):276-286.

Guam EPA. 2001. “Guam Water Quality Standards 2001 Revision. Appendix A, Table IV.” Guam Environmental Protection Agency, Tiyan, Barrigada, Guam

Guam EPA 2009. "National Pollutant Discharge Elimination System Fact Sheet to Accompany Permit No. GU0110019.” Guam Environmental Protection Agency, Tiyan, Barrigada, Guam

HDR | HydroQual, 2012. "Draft Update of Aquatic Life Ambient Saltwater Quality Criteria for Copper.” Prepared for the U.S. Environmental Protection Agency.

Hensley R. A. and T.S. Sherwood. 1993. “An Overview of Guam's Inshore Fisheries,” Marine Fisheries Review 55(2):129-138.

Hunt, J. W., B. S. Anderson, B. M. Phillips, R. S. Tjeerdema, H. M. Puckett, M. Stephenson, D. W. Tucker, and D. Watson. 2002. “Acute and Chronic Toxicity of Nickel to Marine Organisms: Implications for Water Quality Criteria,” Environmental Toxicology and Chemistry 21(11):2423-2430.

Keenan, C. P., P. J. F. Davie, and D. L. Mann. 1966. “A Revision of the genus Scylla De Haan, 1833 (Crustacea: Decapoda: Brachyura: Portunidae),” Raffles Bulletin of Zoology 46(1):217-245.

Kim, S. D., H. Ma, H. E. Allen, and D. K. Cha. 1999. "Influence of Dissolved Organic Matter on the Toxicity of Copper to Ceriodaphnia dubia: Effect of Complexation Kinetics,” Environmental Toxicology and Chemistry 18:2433-2437.

Knezovich, J. P., F. L. Harrison, and J. S. Tucker. 1981. "The Influence of Organic Chelators on the Toxicity of Copper to Embryos of the Pacific Oyster, Crassostrea gigas,” Archives of Environmental Contamination and Toxicology 10:241-249.

Lessios, H. A., B. D. Kessing, and J. S. Pearse. 2001. "Population Structure and Speciation in Tropical Seas: Global Phylogeography of the Sea Urchin Diadema,” Evolution 55(5):955975.

Lorenzo, J. I., O. Nieto, and R. Beiras. 2002. "Effect of Humic Acids on Speciation and Toxicity of Copper to Paracentrotus Lividus Larvae in Seawater,” Aquatic Toxicology 58:27-41.

Muthiga, N. A. 2003. "Coexistence and Reproductive Isolation of the Sympatric Echinoids Diadema savignyi Michelin and Diadema setosum (Leske) on Kenyan Coral Reefs,” Marine Biology 143:669-677.

Myers, R. F. and T. J. Donaldson. 2003. “The Fishes of the Mariana Islands,” Micronesica 35-36: 594-648.

National Oceanographic and Atmospheric Administration (NOAA). 2006. “Map 81048: Mariana Islands Island of Guam, Territory of Guam; Cocos Lagoon.” 10th ed. Washington, DC.

National Oceanographic and Atmospheric Administration. 2012. "Proactive Conservation Program: Species of Concern. Office of Protected Resources.” Available at http://www.nmfs.noaa.gov/pr/species/concern/, updated 18 May 2012. Accessed 14 August 2012. 
Ndung'u, K., R. P. Franks, K. W. Bruland, and A. R. Flegal. 2003. “Organic Complexation and Total Dissolved Trace Metal Analysis in Estuarine Waters: Comparison of Solvent-Extraction Graphite Furnace Atomic Absorption Spectrometric and Chelating Resin Flow Injection Inductively Coupled Plasma-Mass Spectrometric Analysis,” Analytica Chimica Acta 481:127138.

Nelson, D. A., J. E. Miller, and A. Calabrese. 1988. "Effect of Heavy Metals on Bay Scallops, Surf Clams, and Blue Mussels in Acute and Long-term Exposures,” Archives of Environmental Contamination and Toxicology 17(5):595-600.

Nelson, J. S. 2006. Fishes of the World. 4th ed. John Wiley \& Sons, New York, NY.

Ng, P. K. L., D. Guinot, P. J. F. Davie. 2008. “Systema Brachyurorum: Part I. An Annotated Checklist of Extant Brachyuran Crabs of the World,” Raffles Bulletin Zoology 17:1-286.

Novelli, A. A., C. Losso, P. F. Ghetti, A. V. Ghirardini. 2003. “Toxicity of Heavy Metals using Sperm Cell and Embryo Toxicity Bioassays with Paracentrotus lividus (Echinodermata: Echinoidea): Comparisons with Exposure Concentrations in the Lagoon of Venice, Italy,” Environmental Toxicology and Chemistry 22(6):1295-1301.

Patterson, C. C. and D. M. Settle. 1976. “Accuracy in Trace Analysis.” National Bureau of Standards Special Publication 422. P. D. LaFleur, Ed. U.S. Government Printing Office, Washington, DC.

Paulay, G. 2003a. "The Asteroidea, Echinoidea, and Holothuroidea (Echinodermata) of the Mariana Islands,” Micronesica 35-36:563-583.

Paulay, G. 2003b. “Marine Bivalvia (Mollusca) of Guam,” Micronesica 35-36:218-243.

Paulay, G., R. Kropp, P. K. L. Ng, and L. G. Eldredge. 2003. "The Crustaceans and Pycnogonids of the Mariana Islands,” Micronesica 35-36:456-513.

Phillips, B. M., P. A. Nicely, J. W. Hunt, B. S. Anderson, R. S. Tjeerdema, S. E. Palmer, F. H. Palmer, and H. M. Pucket. 2003. "Toxicity of Cadmium-Copper-Nickel-Zinc Mixtures to Larval Purple Sea Urchins (Strongylocentrotus purpuratus),” Bulletin of Environmental Contamination and Toxicology 70:592-599.

Ramachandran, S., T. R. Patel, and M. H. Colbo. 1997. "Effect of Copper and Cadmium on Three Malaysian Tropical Estuarine Invertebrate Larvae,” Ecotoxicology and . Environmental Safety 36(2):183-188.

Randall, R. H. 2003. "An Annotated Checklist of Hydrozoan and Scleractinian Corals Collected from Guam and other Mariana Islands,” Micronesica 35-36:121-137.

Rathbun, M. J. 1918. “The Grapsoid Crabs of America,” Bulletin of the United States National Museum 97. Smithsonian Institution, Washington, DC.

Rayburn, J. R. and R. K. Aladdin. 2003. "Developmental Toxicity of Copper, Chromium, and Aluminum using the Shrimp Embryo Teratogenesis Assay: Palaemonid with Artificial Seawater,” Bulletin of Environmental Contamination and Toxicology 71(3):0481-0488.

Reichelt-Brushett, A. J. and P. L. Harrison. 1999. "The Effect of Copper, Zinc and Cadmium on Fertilization Success of Gametes from Scleractinian Reef Corals,” Marine Pollution Bulletin 38(3):182-187. 
Reichelt-Brushett, A.J. and P.L. Harrison. 2005. "The Effect of Selected Trace Metals on the Fertilization Success of Several Scleractinian Coral Species,” Coral Reefs 24(4):524-534.

Reichelt-Brushett, A. J. and K. Michalek-Wagner. 2005. "Effects of Copper on the Fertilization Success of the Soft Coral Lobophytum compactum.” Aquatic Toxicology 74(3):280-284.

Ringwood, A. H. 1992. "Comparative Sensitivity of Gametes and Early Developmental Stages of a Sea Urchin Species (Echinometra Mathaei) and a Bivalve Species (Isognomon Californicum) during Metal Exposures,” Archives of Environmental Contamination and Toxicology 22(3): 288-295.

Rivera-Duarte, I., G. Rosen, D. Lapota, D. Chadwick, L. Kear-Padilla, and A. Zirino. 2005. “Copper Toxicity to Larval Stages of Three Marine Invertebrates and Copper Complexation Capacity in San Diego Bay, California,” Environmental Science and Technology 39:1542-1546.

Rosen, G., I. Rivera-Duarte, R. Dolecal, L. Raymundo, M. Colvin, and P. Earley. In review. Nickel and Copper Toxicity to Embryos of the Long-spined Sea Urchin, Diadema savignyi," Archive of Environmental Contamination and Toxicology.

Rosen, G., I. Rivera-Duarte, L. Kear-Padilla, and D. B. Chadwick. 2005. "Use of Laboratory Toxicity Tests with Bivalve and Echinoderm Embryos to Evaluate the Bioavailability of Copper in San Diego Bay, California, USA,” Environmental Toxicology and. Chemistry 24:415-422.

Rosen, G., I. Rivera-Duarte, D.B. Chadwick, A. Ryan, R. C. Santore, and P.R. Paquin. 2008. "Critical Tissue Copper Residues for Marine Bivalve (Mytilus galloprovincialis) and Echinoderm (Strongylocentrotus purpuratus) Embryonic Development: Conceptual, Regulatory and Environmental implications,” Marine Environmental Research 66:327-336.

Rosen G, I. Rivera-Duarte, R. K. Johnston, and J. Podegracz. 2009. “An Assessment of Copper Bioavailability and Toxicity in Surface Waters of Sinclair and Dyes Inlets, Puget Sound, Washington.” Technical Report 1985. Space and Naval Warfare Systems Center Pacific (SSC Pacific), San Diego, CA.

Smith, B. D. 2003. “Prosobranch Gastropods of Guam,” Micronesica 35-36:244-270.

Smith, B. D., T. J. Donaldson, T. Schils, A. Reyes, K. Chop, and K. Dugger. 1999. “Marine Biological Survey of Inner Apra Harbor, Guam.” Technical Report 126. University of Guam Marine Laboratory, Mangilao, Guam,

Stauber, J. L., R. J. Benning, L. T. Hales, R. Eriksen, and B. Nowak. 2000. “Copper Bioavailability and Amelioration of Toxicity in Macquarie Harbour, Tasmania, Australia,” Marine and Freshwater Research 51:1-10.

U.S. Environmental Protection Agency. 1973. “Water Quality Handbook - Chapter 3: Water Quality Criteria (40 CFR 131.11).” Washington, DC.

U.S. Environmental Protection Agency. 1985. "Guidelines for Deriving Numerical National Water Quality Criteria for the Protection of Aquatic Organisms and their Uses.” USEPA/822/R85/100. Washington, DC.

U.S. Environmental Protection Agency. 1986. “Ambient Aquatic Life Water Quality Criteria for Nickel.” USEPA 440/5-86-004. Washington, D.C..

U.S. Environmental Protection Agency. 1988. "Water Quality Criteria for Aluminum.” USEPA 440/5-86-008. Washington, D.C. 
U.S. Environmental Protection Agency. 1991. “Technical Support Document for Water Qualitybased Toxics Control.” USEPA-505-2-90-001. Washington, DC.

U.S. Environmental Protection Agency. 1994a. "Interim Guidance on Determination and Use of Water-Effect Ratios for Metals.” USEPA-823-B-94-001. Washington, DC.

U.S. Environmental Protection Agency. 1994b. "Development of Site-specific Copper Criteria for the NY/NJ Harbor Complex Using the Indicator Species Procedure.” USEPA, Surface Water Quality Branch, Region II, June 3, 1994. Washington, DC.

U.S. Environmental Protection Agency. 1994c. "Water Quality Standards Handbook: Second Edition.” USEPA-823-B-94-005a. Washington, D.C.

U.S. Environmental Protection Agency. 1995a. “Ambient Water Quality Criteria-Saltwater Copper Addendum (Draft), April 14.” Office of Water, Office of Science and Technology, Washington, DC.

U.S. Environmental Protection Agency. 1995b.” Short-Term Methods for Estimating the Chronic Toxicity of Effluents and Receiving Waters to West Coast Marine and Estuarine Organisms.” USEPA-600-R-95-136. Washington, D.C.

U.S. Environmental Protection Agency. 1996a. "The Metals Translator: Guidance for Calculating a Total Recoverable Permit Limit from a Dissolved Criterion.” USEPA 823-B-96-007. Washington, DC.

U.S. Environmental Protection Agency 1996b. "Method 1669, Sampling Ambient Water for Determination of Trace Metals in Environmental Samples.” USEPA/600-R-94-111. Washington, DC.

U.S. Environmental Protection Agency. 1997b. "Modifications to Guidance Site Specific Criteria. Memorandum from Jeanette Wiltse, Director, Health and Ecological Criteria Division, to Water Quality Branch Chiefs, November 19, 1997.” U.S. Environmental Protection Agency, Office of Water, Washington, DC.

U.S. Environmental Protection Agency. 2001. “Streamlined Water Effect Ratio Procedure for Discharges of Copper.” United States Environmental Protection Agency, Office of Water, USEPA-822-R-01-005 (March). p. 34. Washington, DC.

U.S. Environmental Protection Agency. 2006a. "Compilation of EPA Mixing Zone Documents. United States Environmental Protection Agency.” USEPA-823-R-06-003. Office of Water, Washington, DC.

U.S. Environmental Protection Agency. 2006b. "National Recommended Water Quality Criteria. Office of Water, Office of Science and Technology (4304T). http://www.epa.gov/waterscience/criteria/nrwqc-2006.pdf

U.S. Environmental Protection Agency. 2007. “Aquatic Life Ambient Freshwater Quality CriteriaCopper.” February 2007 Revision. USEPA-822-R-07-001. U.S. Environmental Protection Agency, Office of Water. Washington, DC.

U.S. Environmental Protection Agency. 2009. "Nationally Recommended Water Quality Criteria.” Office of Water. http://water.epa.gov/scitech/swguidance/standards/criteria/current/upload/nrwqc-2009.pdf 
U.S. Environmental Protection Agency. 2012. "Tropical Collector Urchin, Tripneustes gratilla, Fertilization Test Method EPA/600/R-12/022. U.S. EPA, Region 9 Laboratory, Richmond, CA, and U.S. EPA, Office of Research and Development, Narragansett, RI.” April 2012. Washington, DC.

U.S. Environmental Protection Agency. 2013. "Revised Deletion Process for the Site-Specific Recalculation Procedure for Aquatic Life Criteria.” USEPA-823-R-13-001 (April). U.S. Environmental Protection Agency, Office of Water. Washington, DC.

U.S. Navy. “Apra Harbor WWTP NPDES Permit No. GU0110019 Fact Sheet, ” p. 10. Naval Base Guam, Agat, Guam.

Vazquez, L. C. 2003. "Effect of Sperm Cell Density on Measured Toxicity from the Sea Urchin Tripneustes gratilla Fertilization Bioassay,” Environmental Toxicology and Chemistry 22(9): 2191-2194.

Wagner, A. and D. Nacci. 2012. "Tropical Collector Urchin, Tripneustes gratilla, Fertilization Test Method.” USEPA/600/R-12/022. U.S. Environmental Protection Agency, Washington, DC.

Wilson, S. P. and R. V. Hyne. 1997. "Toxicity of Acid-sulfate Soil Leachate and Aluminum to Embryos of the Sydney Rock Oyster,” Ecotoxicology and Environmental Safety 37:30-36. 

suggestions for reducing the burden to Department of Defense, Washington Headquarters Services Directorate for Information Operations and Reports (0704-0188), 1215 Jefferson Davis Highway, Suite 1204, Arlington VA 22202-4302. Respondents should be aware that notwithstanding any other provision of law, no person shall be subject to any penalty for failing to comply with a collection of

PLEASE DO NOT RETURN YOUR FORM TO THE ABOVE ADDRESS.

\begin{tabular}{|l|l|}
\hline $\begin{array}{l}\text { 1. REPORT DATE (DD-MM-YYYY) } \\
\text { July } 2016\end{array}$ & $\begin{array}{l}\text { 2. REPORT TYPE } \\
\text { Final }\end{array}$ \\
\hline
\end{tabular}

\section{TITLE AND SUBTITLE}

\section{DATES COVERED (From - To)}

Development of Site-Specific Water Quality Criteria for the Arpa Harbor

Wastewater Treatment Plant in Tipalao Bay, Guam

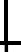

5a. CONTRACT NUMBER

5b. GRANT NUMBER

5c. PROGRAM ELEMENT NUMBER

5d. PROJECT NUMBER

6. AUTHORS

P. J. Earley

G, H, Risen

R. Dolecal

I. D. Rivera-Duarte

SDSU Research Foundation

M. A. Colvin

SSC Pacific

7. PERFORMING ORGANIZATION NAME(S) AND ADDRESS(ES)

SSC Pacific

53560 Hull Street

San Diego, CA 92152-5001

9. SPONSORING/MONITORING AGENCY NAME(S) AND ADDRESS(ES)

Commander, Naval Facilities Engineering Command Pacific

258 Makalapa Drive, Suite 100

Joint Base Pearl Harbor-Hickam, HI 96860-3134

\section{DISTRIBUTION/AVAILABILITY STATEMENT}

Approved for public release.

\section{SUPPLEMENTARY NOTES}

This is work of the United States Government and therefore is not copyrighted. This work may be copied and disseminated without restriction.

\section{ABSTRACT}

Space and Naval Warfare Systems Center Pacific (SSC Pacific) performed the studies described in this report to develop a new National Pollutant Discharge Elimination Systems (NPDES) Permit for the discharge of effluents from the Apra Harbor Wastewater Treatment Plant (WWTP) in Agat, Guam, into Tipalao Bay of the Philippine Sea. The technical approach adhered to proposed U.S. Environmental Protection Agency (USEPA) guidelines to develop and apply mixing zone analysis, recalculation procedure, water effect ratio (WER), and translator.

Naval Facilities Engineering Command (NAVFAC) Marianas recognized the requirements and conditions within the National Pollutant Discharge Elimination System Permit No. GU0110019 and initiated a study to develop site-specific discharge limitations using appropriate methods and guidance documents from the USEPA. This study incorporates the results from multiple lines of evidence to examine copper, nickel, and aluminum criteria applied in the permit. The objective is to establish new regulatory discharge limits based on the current state of the science, including the use and application of a mixing zone analysis, a recalculation procedure, a chemical translator study, a WER procedure, and the Biotic Ligand Model.

Based on the data generated from these studies, we recommend new NPDES discharge limits for copper and nickel as outlined below, while a separate rationale exists to justify the removal of aluminum from further regulatory limits.

\section{SUBJECT TERMS}

mixing zone analysis; recalculation procedure; water effect ratio; translator; regulatory dischage limits copper; nickel; aluminum; Biotic Ligand Model; metal analysis; toxicity testing

16. SECURITY CLASSIFICATION OF:

\begin{tabular}{|c|c|c|}
\hline a. REPORT & b. ABSTRACT & c. THIS PAGE \\
$\mathrm{U}$ & $\mathrm{U}$ & $\mathrm{U}$ \\
\hline
\end{tabular}

17. LIMITATION OF ABSTRACT

18. NUMBER
OF
PAGES
108

19a. NAME OF RESPONSIBLE PERSON Patrick Earley 19B. TELEPHONE NUMBER (Include area code) 



\section{INITIAL DISTRIBUTION}

84300

85300

71750

71750

71760

71760
Library

Archive/Stock

P. J. Earley

I. D. Rivera-Duarte

G. H. Rosen

M. Colvin

Defense Technical Information Center

Fort Belvoir, VA 22060-6218
(1)

SDSU Research Foundation

Attn: R. Dolecal

5250 Campanile Drive

San Diego, California 92182 



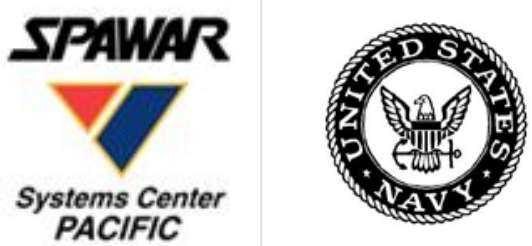

SSC Pacific

San Diego, CA 92152-5001 